\title{
Atmosphere-ocean-aerosol-chemistry-climate model SOCOLv4.0: description and evaluation
}

\author{
Timofei Sukhodolov ${ }^{1,2,3,4}$, Tatiana Egorova ${ }^{1,2}$, Andrea Stenke ${ }^{2}$, William T. Ball ${ }^{5}$, Christina Brodowsky ${ }^{2}$, \\ Gabriel Chiodo $^{2,6}$, Aryeh Feinberg ${ }^{2,7,8}$, Marina Friedel ${ }^{2}$, Arseniy Karagodin-Doyennel ${ }^{1,2}$, Thomas Peter $^{2}$, \\ Jan Sedlacek $^{1}$, Sandro Vattioni ${ }^{2}$, and Eugene Rozanov ${ }^{1,2,3}$ \\ ${ }^{1}$ Physikalisch-Meteorologisches Observatorium Davos and World Radiation Center, Davos, Switzerland \\ ${ }^{2}$ Institute for Atmospheric and Climate Science, ETH Zurich, Zurich, Switzerland \\ ${ }^{3}$ St. Petersburg State University, St. Petersburg, Russia \\ ${ }^{4}$ Institute of Meteorology and Climatology, University of Natural Resources and Life Sciences, Vienna, Austria \\ ${ }^{5}$ Department of Geoscience and Remote Sensing, Faculty of Civil Engineering and Geosciences, \\ TU Delft, Delft, the Netherlands \\ ${ }^{6}$ Department of Applied Physics and Applied Mathematics, Columbia University, New York, NY, USA \\ ${ }^{7}$ Institute of Biogeochemistry and Pollutant Dynamics, ETH Zurich, Zurich, Switzerland \\ ${ }^{8}$ Eawag, Swiss Federal Institute of Aquatic Science and Technology, Dübendorf, Switzerland
}

Correspondence: Timofei Sukhodolov (timofei.sukhodolov@pmodwrc.ch)

Received: 6 February 2021 - Discussion started: 11 March 2021

Revised: 13 July 2021 - Accepted: 27 July 2021 - Published: 8 September 2021

\begin{abstract}
This paper features the new atmosphere-oceanaerosol-chemistry-climate model, SOlar Climate Ozone Links (SOCOL) v4.0, and its validation. The new model was built by interactively coupling the Max Planck Institute Earth System Model version 1.2 (MPI-ESM1.2) (T63, L47) with the chemistry (99 species) and size-resolving (40 bins) sulfate aerosol microphysics modules from the aerosolchemistry-climate model, SOCOL-AERv2. We evaluate its performance against reanalysis products and observations of atmospheric circulation, temperature, and trace gas distribution, with a focus on stratospheric processes. We show that SOCOLv4.0 captures the low- and midlatitude stratospheric ozone well in terms of the climatological state, variability and evolution. The model provides an accurate representation of climate change, showing a global surface warming trend consistent with observations as well as realistic cooling in the stratosphere caused by greenhouse gas emissions, although, as in previous model versions, a too-fast residual circulation and exaggerated mixing in the surf zone are still present. The stratospheric sulfur budget for moderate volcanic activity is well represented by the model, albeit with slightly underestimated aerosol lifetime after major eruptions. The presence of the interactive ocean and a successful representation of re-
\end{abstract}

cent climate and ozone layer trends make SOCOLv4.0 ideal for studies devoted to future ozone evolution and effects of greenhouse gases and ozone-destroying substances, as well as the evaluation of potential solar geoengineering measures through sulfur injections. Potential further model improvements could be to increase the vertical resolution, which is expected to allow better meridional transport in the stratosphere, as well as to update the photolysis calculation module and budget of mesospheric odd nitrogen. In summary, this paper demonstrates that SOCOLv4.0 is well suited for applications related to the stratospheric ozone and sulfate aerosol evolution, including its participation in ongoing and future model intercomparison projects.

\section{Introduction}

Global modeling of the atmosphere and its interaction with oceans, cryosphere, biosphere, and land surface dates back several decades (e.g., Manabe and Bryan, 1969). The numerical approximation of each of these Earth system components is a complex task by itself, and therefore their development often began and continued independently from 
each other, with simplified descriptions of missing, but important, processes included in the form of boundary conditions. With the rapid development of computational facilities and methods, the models grew in their complexity in terms of the number of processes described and the quality of their description. Motivated primarily through the context of climate change research, scientific advances in global numerical modeling have shown that, even though stand-alone approximations are still sufficient for some specific modeling tasks, the interaction of Earth system components is required for reasonable model performance in many cases. These advances can be tracked in the history of the Climate Model Intercomparison Project (CMIP) requirements for models in its different phases (https://www.wcrp-climate. org/wgcm-cmip, last access: 2 September 2021). Due to the importance of the dynamical links between the troposphere and the stratosphere (Kidston et al., 2015), many climate groups have also extended their state-of-the-art models vertically into the mesosphere (e.g., Manzini et al., 2006) or even the thermosphere (e.g., Whole Atmosphere Community Climate Model (WACCM), Marsh et al., 2013; and the Hamburg Model of the Neutral and Ionized Atmosphere (HAMMONIA), Schmidt et al., 2006). For example, variations in the stratospheric polar night jet can induce significant changes in surface weather on timescales ranging from daily to longterm climate effects (e.g., Gerber et al., 2012, and references therein). Variability of this dynamical coupling can be induced by the Earth system itself, i.e., responding to ocean temperature changes and vertically propagating waveforcing from the troposphere, or by external factors such as volcanic eruptions, variations in the solar UV irradiance, and greenhouse gas changes (Kidston et al., 2015).

Middle atmosphere studies are closely linked to the representation of atmospheric chemistry since the ozone layer primarily determines the temperature structure of the stratosphere through the absorption of solar ultraviolet (UV) irradiance. This has an influence on the general circulation of the stratosphere and subsequently also on the tropospheric climate. Stratospheric ozone itself is influenced by many factors, such as the heterogeneous chemistry intensification after volcanic eruptions (e.g., Revell et al., 2016) or the acceleration of ozone destruction cycles after energetic particle precipitation events (Rozanov et al., 2012; Mironova et al., 2015). Moreover, it is also largely affected by climate change, via radiatively induced changes in upper stratospheric chemistry, as well as changes in the Brewer-Dobson circulation (BDC, Chiodo et al., 2018). Changes in ozone can also in turn affect the BDC (e.g., Polvani et al., 2019). Therefore, changes in stratospheric ozone and dynamics feed back on each other. Ozone-circulation feedbacks have been assessed in several studies, showing their importance for stratosphere-troposphere coupling in mid-winter (Haase and Matthes, 2019; Oehrlein et al., 2020) and polar stratospheric temperature variability in springtime (Rieder et al., 2019). Long-term stratospheric ozone variations (e.g., depletion and recovery) are able to significantly affect the tropospheric climate (Previdi and Polvani, 2014; Brönnimann et al., 2017), and even the climate response to global warming might be biased if ozone feedbacks are not taken into account (Nowack et al., 2015).

The main driving issue in middle atmosphere chemistry research was the discovery of the ozone hole in the 1980s (Farman et al., 1985). The ozone layer plays an important role in shielding the biosphere from dangerous solar ultraviolet radiation and the risk of related increasing cases of skin cancer and other diseases induced progress in atmospheric ozone science that led to strong limitations on the production of halogen-containing ozone-depleting substances (hODS) in 1987 through the Montreal Protocol and its Amendments (MPA). Since then, observations and models have demonstrated the positive role of these restrictive measures (e.g., Velders et al., 2007; Egorova et al., 2013) and some signs of the ozone recovery have already been observed (Chipperfield et al., 2017). However, the expected recovery in the lower stratosphere has been questioned, based on the updated observations (Ball et al., 2018, 2019). This issue is one of many requiring further investigation and deeper understanding. Other issues and research fields include the appearance of an unprecedentedly large ozone hole over the Northern Hemisphere in spring 2020 (Witze, 2020; Manney et al., 2020); the formation of a large and deep Antarctic ozone hole in autumn 2020 (NASA Ozone Watch, https: //ozonewatch.gsfc.nasa.gov/, last access: 2 September 2021); continuous unexpected chlorofluorocarbon (CFC)-11 emissions (Fleming et al., 2020); a potential decline of the solar activity (Arsenovic et al., 2018); the potential stratospheric injection of sulfur-containing species for solar geoengineering purposes (Tilmes et al., 2009; Vattioni et al., 2019); and a potential impact of increasing trends of iodine in the stratosphere (Koenig et al., 2020). These examples underline that our understanding of atmospheric ozone specifically, and atmospheric chemistry in general, is far from being fully resolved and inspires further model developments and studies of the ozone layer evolution, in the present and future.

The need to represent the large number of processes involved in the state evolution of the ozone layer led to the development of atmospheric chemistry models ranging from simple box models to chemistry-transport models and finally to chemistry-climate models that include at least interactive chemistry and atmospheric dynamics but may include ocean dynamics, aerosol microphysics, and other components (https://www.sparc-climate.org/activities/ccm-initiative, last access: 2 September 2021). The chemistry-climate model SOCOL (SOlar Climate Ozone Links) was initially developed for studies related to the ozone layer (Egorova et al., 2005). Through its versions (from v1 to v3), it was used with prescribed sea surface temperature and sea ice coverage fields, advancing over time in terms of model numerics, stratospheric chemistry, and transport representation. Since the publication of the base version SOCOLv3 (Stenke et al., 
2013), the atmospheric-chemistry part has undergone many further improvements, such as an addition of the volatile organic compound (VOC) chemistry, an interactive lightning $\mathrm{NO}_{x}$ parameterization, corrections in schemes for solar heating rates and photolysis rates, parameterization of energetic particles, and interactive deposition schemes. The base version of Stenke et al. (2013), however, further branched into two significant subversions: SOCOL-MPIOM with interactive ocean (Muthers et al., 2014) and SOCOL-AER with interactive aerosol microphysics (Sheng et al., 2015), each of them receiving further, independent, upgrades (Arsenovic et al., 2018; Feinberg et al., 2019), and several smaller variants, such as an improved tropospheric ozone budget (Revell et al., 2015, Revell et al., 2018), detailed methane sources and sinks (Feinberg et al., 2018), and atmospheric selenium cycling (Feinberg et al., 2020).

The natural next step was to combine the multiple improvements and model versions into a single fourth version of the SOCOL model by coupling these updated modules onto an upgraded atmospheric model, since it also underwent many improvements in recent years. As a basis for this, we used the Max Planck Institute Earth System Model (MPI-ESM1.2), so that the chemistry (MEZON) and aerosol (AER) models are attached to the atmosphere (ECHAM6.3), ocean (MPIOM1.6.3), land surface (JSBACH3.2), ocean biogeochemistry (HAMOCC6) model coupled through the OASIS3-MCT coupler. In this paper, we describe the new atmosphere-ocean-aerosol-chemistry-climate SOCOLv4.0 model and its components in detail (Sect. 2) and validate its performance against available observations and reanalysis products. The main motivation is to provide a solid reference of model performance for future improvements and applications, including model intercomparison projects (MIPs). The validation is split into two main parts: atmospheric dynamics (Sect. 3.2) and atmospheric chemistry with the primary focus on stratospheric ozone (Sect. 3.3).

\section{Model description}

SOCOLv4.0 (SOCOLv4 hereafter) consists of the Earth system model MPI-ESM1.2 (Mauritsen et al., 2019), the chemistry model MEZON (Egorova et al., 2003), and the sulfate aerosol microphysical model AER (Weisenstein et al., 1997), with all these parts being interactively coupled to each other, as schematically presented in Fig. 1. In simple terms, chemistry and aerosol microphysics rely on atmospheric temperature, winds, and relative humidity and in turn influence the atmosphere and ocean through the short- and longwave radiation schemes, while aerosol microphysics depend on sulfur chemistry and provide the aerosol surface area density and number density necessary for heterogeneous chemistry calculations. Transport of individual gases and aerosols is performed by the flux-form semi-Lagrangian scheme of Lin and Rood (1996) in the dynamical core of ECHAM6 that has re-

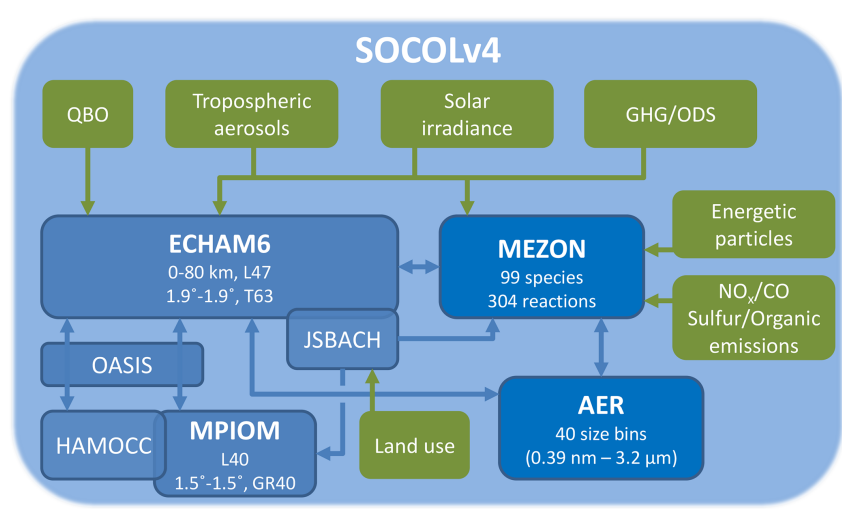

Figure 1. Components and information flow in the atmosphereocean-aerosol-chemistry-climate model SOCOLv4. Green boxes symbolize prescribed boundary conditions.

mained unchanged from its predecessor, ECHAM5. Transport is calculated every dynamical time step (15 min). The dry and wet deposition of gases and aerosols is also based on the ECHAM6 parameters such as near-surface turbulence and precipitation. In the following, we discuss each of these main components separately and describe the latest changes.

SOCOLv4 is based on the low-resolution (LR) configuration of the MPI-ESM model. This configuration corresponds to a spectral truncation at $\mathrm{T} 63$ providing an approximate horizontal grid spacing of $1.9^{\circ} \times 1.9^{\circ}$. The vertical resolution of the atmosphere is set to 47 levels from the surface to $0.01 \mathrm{hPa}$, using a hybrid sigma-pressure coordinate system. Although other higher horizontal and vertical resolutions of MPI-ESM are also tuned and available for use, we chose the LR configuration since it is the most used, better tuned (Mauritsen et al., 2019), and better suited for long-term climate simulations in terms of required computational resources and storage. It must be noted that we did not change anything in the tuning of the MPI-ESM1.2 LR model version described in Mauritsen et al. (2019). All our changes refer to the coupled chemistry and sulfate aerosols modules. Mostly due to the large number of new tracers introduced, SOCOLv4 is about 2.6 times slower than MPI-ESM, $30 \%$ of which is from AER.

\subsection{MPI-ESM1.2 Earth system model}

The Earth system model MPI-ESM1.2 (Mauritsen et al., 2019) is a further development of its predecessor, MPIESM (Giorgetta et al., 2013). The main components of MPIESM are highlighted by the blue boxes in Fig. 1. The ocean dynamical model, MPIOM1.6.3, transports tracers of the ocean biogeochemistry model, HAMOCC6. The atmosphere model, ECHAM6.3, is directly coupled to the land model, JSBACH3.2, through surface exchange of mass, momentum, and heat. These two major model blocks are then coupled via the OASIS3-MCT coupler (Craig et al., 2017). The coupler 
aggregates, interpolates, and exchanges fluxes and state variables once a day between ECHAM6-JSBACH and MPIOMHAMOCC. Here, we only describe the latest states of the MPI-ESM components that are used in SOCOLv4 and do not focus on the differences between MPI-ESM versions, as this is already discussed in greater detail by Mauritsen et al. (2019). Hereafter we refer to MPI-ESM1.2 as MPIESM, and ignore version numberings for other components, unless otherwise stated. In terms of differences to the earlier versions, we only focus on those between the atmospheric part of the latest version, ECHAM6, and the atmospheric part used in SOCOLv3, ECHAM5.4, as changes between versions contribute the differences between the chemical response of SOCOLv4 and all subversions of SOCOLv3.

\subsubsection{Ocean model MPIOM}

The oceanic part, MPIOM, is formulated on an Arakawa$\mathrm{C}$ grid in the horizontal and on $z$ levels in the vertical direction and solves the primitive equations with the hydrostatic and Boussinesq approximations (Jungclaus et al., 2006,, 2013). Subgrid-scale parameterizations include lateral mixing on isopycnals and tracer transports by unresolved eddies. Vertical mixing is represented as a combination of the Richardson-number-dependent scheme and the wind-driven turbulent mixing in the mixed layer (for details, see Jungclaus et al., 2013). The horizontal grid is consistent with the MPI-ESM LR configuration, which implies a bipolar grid (GR1.5) featuring one grid pole under Greenland and one under Antarctica. The resolutions are then regionally enhanced in the deep water formation regions and the overflows across the Greenland-Scotland Ridge so that the grid varies between 22 and $350 \mathrm{~km}$. In the vertical, 40 levels are unevenly placed in the water column, with the first 20 levels distributed over the top $700 \mathrm{~m}$. The bottom topography is represented by a partial-step formulation (Wolff et al., 1997).

The sea ice model combines the codes of MPIOM and ECHAM. In ECHAM, a simplified thermodynamic sea ice model is incorporated to provide at each atmospheric time step a physically consistent surface temperature in icecovered regions. This part also contains a melt-pond scheme, which divides the surface of the sea ice into snow, bare ice, and melt pond with individual albedos (Pedersen et al., 2009). The atmospheric part of the sea ice model then integrates all surface fluxes into ice and provides this information to the oceanic part of the code, which uses it to calculate the sea ice surface energy balance and related changes in ice thickness. The calculations of sea ice concentration and thickness are based on the Semtner (1976) formulation and tuned in MPI-ESM to produce the annual average pre-industrial Arctic sea ice volume of roughly 20000 $25000 \mathrm{~km}^{3}$ (see Mauritsen et al., 2019). Sea ice dynamics is calculated following a viscoplastic approach of Hibler (1979).

\subsubsection{Marine biogeochemistry model HAMMOC}

Ocean biogeochemistry in MPI-ESM is represented by the Hamburg Ocean Carbon Cycle (HAMOCC) model (Ilyina et al., 2013; Paulsen et al., 2017). It simulates the oceanic cycles of carbon and other biogeochemical elements such as nutrients (phosphate, nitrate, and iron), oxygen, silicate, phytoplankton, zooplankton, and detritus. HAMOCC includes biogeochemical processes in the water column, the sediment, and at the air-sea interface. Biogeochemical tracers in the water column are fully advected, mixed, and diffused by the flow field of MPIOM. In total, the model has 17 state variables calculated prognostically in the water column and 12 state variables in the sediment. Nitrogen-fixing cyanobacteria was added to the model as an additional prognostic phytoplankton class by Paulsen et al. (2017).

\subsubsection{Land surface model JSBACH}

The Jena Scheme for Biosphere-Atmosphere Coupling in Hamburg (JSBACH) is the land component of MPI-ESM1.2. It provides the lower boundary conditions for the atmosphere over land and describes the dynamics of the land biogeochemistry in interaction with global climate. JSBACH treats processes like soil hydrology (five-layer scheme of Hagemann and Stacke, 2015), soil and litter decomposition, land use change (tiling approach with 12 plant functional types and two types of bare surface), fires, and a nitrogen cycle (Goll et al., 2017). Note that soil and marine chemical schemes are not yet combined with the atmospheric chemistry scheme in the current model version.

\subsubsection{ECHAM6}

ECHAM6 is an atmospheric general circulation model (GCM) that describes the large-scale circulation and its coupling to diabatic processes, both of which are ultimately driven by radiative forcing. It consists of a dry spectraltransform dynamical core, a transport model, and a suite of physical parameterizations for the representation of diabatic processes. The prognostic variables are temperature, vorticity, divergence, logarithm of surface pressure, and humidity, as well as cloud ice and water. Tracer transport and diabatic processes (also referred to as "model physics") are calculated on a Gaussian transform grid. The adiabatic core of ECHAM6 consists of a mixed finite-difference/spectral discretization of the primitive equation that is identical to that employed in ECHAM5 (Stevens et al., 2013). All major changes relative to ECHAM5 are therefore related to the model physics. These changes include an improved representation of radiative transfer in the shortwave (or solar) part of the spectrum; a completely new description of tropospheric aerosol; an improved representation of surface albedo, including the treatment of melt ponds on sea ice (see Sect. 2.1.1); and an improved representation of the middle at- 
mosphere through the gravity wave forcing. In addition, minor changes have been made in the representation of convective processes. Several coding errors in model physics were also corrected in the latest version (see details in Mauritsen et al., 2019).

Transport of species is performed with the flux-form semiLagrangian scheme of Lin and Rood (1996). Though this scheme is mass conservative by design, its application on the sigma-pressure coordinate system can cause a violation of the mass conservation especially in the case of large spatial gradients (Jöckel et al., 2001; Stenke et al., 2013). Turbulent mixing adopts an eddy diffusivity and viscosity approach following Brinkop and Roeckner (1995). Moist convection is parameterized according to Tiedtke (1989), with extensions by Nordeng (1994) and Möbis and Stevens (2012). Stratiform clouds are computed diagnostically based on a relative humidity threshold (Sundqvist et al., 1989). As in ECHAM5, gravity wave drag (GWD) is calculated using a subgrid orography scheme (Lott, 1999). The propagation and dissipation of the waves follow the formulation of Palmer et al. (1986) and Miller et al. (1989). Non-orographic GWD parameterizations are based on a wave-spectrum approach (Hines, 1997a, b). However, some parameters of both orographic and non-orographic gravity wave schemes have been adjusted for use in ECHAM6 during the tuning process of MPI-ESM (see Mauritsen et al., 2019). Both longwave and shortwave radiative-transfer calculations are now described by the PSrad scheme (Pincus and Stevens, 2013), which is based on the $k$-correlated method of the Rapid Radiative Transfer Model for GCMs (RRTM-G) (Iacono et al., 2008). Additional extra-heating parameterization in the Hartley, Huggins, and Schumann-Runge bands and the Lyman$\alpha$ line is now applied for better representation of the solar cycle in the mesosphere and stratosphere (Sukhodolov et al., 2014). The optical properties for radiation are updated every $2 \mathrm{~h}$. In contrast to the base model version, which applies climatological fields for this purpose, the radiation calculation of SOCOLv4 uses the prognostic tracer concentrations of sulfate aerosol and all radiatively active species (e.g., ozone and methane) except $\mathrm{CO}_{2}$. Concentrations for $\mathrm{CH}_{4}, \mathrm{~N}_{2} \mathrm{O}$, and CFCs are prescribed only at the lowermost model level, while $\mathrm{CO}_{2}$ is prescribed for the entire atmosphere. Note that for photolysis rates calculations, we use a separate subroutine based on the application of lookup tables (Rozanov et al., 1999). Cloud scattering is parameterized according to Mie theory using maximum-random cloud overlap and an inhomogeneity parameter to account for threedimensional effects. Surface albedo is parameterized according to Brovkin et al. (2013). The radiative properties of tropospheric aerosols are now represented by the Max Planck Institute Aerosol Climatology version 2 simple plume implementation (MACv2-SP) parameterization (Stevens et al., 2017; Fiedler et al., 2017). MACv2-SP is formulated in terms of nine spatial plumes associated with different major anthropogenic source regions. It prescribes the aerosol opti- cal depth, asymmetry factor and single scattering albedo as a function of geographical position, height above ground level, time, and wavelength. The evolution and distribution of anthropogenic aerosol is approximated with mathematical functions, while the natural aerosol is prescribed climatologically based on Kinne et al. (2013). MACv2-SP also prescribes aerosol-cloud interactions in the form of a Twomey effect (Twomey, 1977), thus allowing the increase in the cloud droplet number concentration and associated reduction in droplet size under constant liquid water path.

\subsection{Atmospheric chemistry model MEZON}

The atmospheric chemistry part of the new model is a modified version of the chemistry-transport model MEZON (Model for Evaluation of oZONe trends; Rozanov et al., 2001; Egorova et al., 2003; Schraner et al., 2008). The last base state of this code is described in detail by Stenke et al. (2013). It underwent major upgrades for participation in the Chemistry Climate Model Initiative phase 1 (CCMI) presented in Revell et al. (2015). Further upgrades were made in Revell et al. (2018) and Feinberg et al. (2019). Below, we summarize the current state of MEZON, while the history of main updates that are now included in SOCOLv4 is schematically illustrated in Fig. 2. In this paper, the direct comparison with SOCOLv4 is made only for the CCMI version (Revell et al., 2015) in Sect. 3.2.2 and 3.2.4, since it was the most widely used one in publications.

MEZON and ECHAM6 are interactively coupled by the three-dimensional fields of temperature and wind, and by the radiative forcing induced by water vapor, ozone, methane, nitrous oxide, and CFCs. The chemistry scheme is called every $2 \mathrm{~h}$. The chemical solver is based on the implicit iterative Newton-Raphson scheme (Ozolin, 1992; Stott and Harwood, 1993). The model includes 99 chemical species of the oxygen, hydrogen, nitrogen, carbon, chlorine, bromine, and sulfur groups, which are determined by 216 gas-phase reactions, 72 photolysis reactions, and 16 heterogeneous reactions in/on aqueous sulfuric acid aerosols, as well as three types of polar stratospheric clouds (PSCs): supercooled ternary solution (STS) droplets, water ice, and nitric acid trihydrate (NAT). Chemical reaction rate coefficients and absorption cross sections of all reactions follow the recommendations from NASA JPL data evaluation no. 18 (Burkholder et al., 2015). Photolysis rates are calculated at every chemical time step using a lookup-table approach (Rozanov et al., 1999), including effects of the solar irradiance variability. Based on the stand-alone photolysis codes intercomparison study (Sukhodolov et al., 2016) and additional sensitivity tests, the photodissociation rates of molecular oxygen and ozone $\left(\mathrm{O}\left({ }^{1} \mathrm{D}\right)\right.$ path) have been supplemented by the correction factors of 1.2 for oxygen in the $10-1 \mathrm{hPa}$ region and 1.5 for ozone below $100 \mathrm{hPa}$.

Dry deposition of species is based on the surface resistance approach for the estimation of dry deposition velocities 


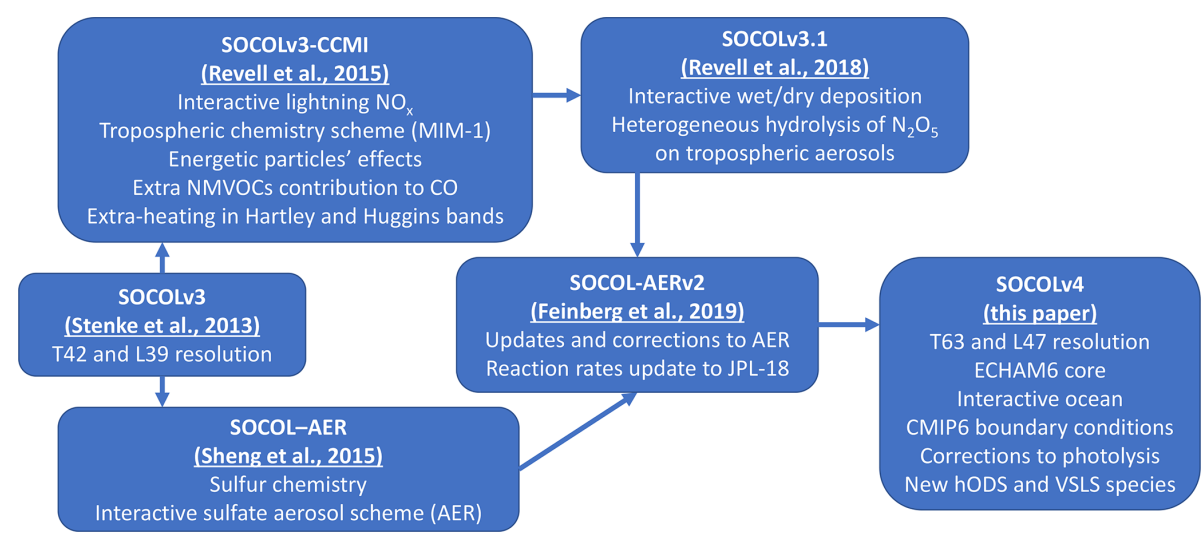

Figure 2. History of main updates through different versions of SOCOL, which contributed to the version described in this paper. Note that there were also other minor changes, adjustments, and error corrections.

proposed by Wesely (1989). This scheme takes into account actual meteorological conditions, different surface types, and trace gas properties like solubility and reactivity. Further details are given by Kerkweg et al. (2006). The wet deposition scheme is based on the scavenging scheme SCAV proposed by Tost et al. (2006). Wet deposition velocities are calculated using cloud and precipitation variables from ECHAM6, including cloud cover, liquid and ice water contents, precipitation fluxes, and the convective upward mass flux. Scavenging coefficients of gaseous species depend on their Henry's law constants. Upon evaporation of clouds and rainwater, scavenged species are transferred back into the gas phase. An additional sink for $\mathrm{HNO}_{3}$, in the form of a constant removal rate of $1 \times 10^{-6} \mathrm{~s}^{-1}$, was introduced in the upper troposphere (above $300 \mathrm{hPa}$ ), compensating the missing uptake of $\mathrm{HNO}_{3}$ by ice particles (e.g., Voigt et al., 2006).

The parameterization of heterogeneous chemistry in the stratosphere is based on Carslaw et al. (1995). It coincides with $\mathrm{HNO}_{3}$ uptake by aqueous sulfuric acid aerosols resulting in the formation of STS. The parameterization of the liquid-phase reactive uptake coefficients follows Hanson and Ravishankara (1994) and Hansen et al. (1996). The PSC scheme for water ice uses a prescribed particle number density of $0.01 \mathrm{~cm}^{-3}$ and assumes that the cloud particles are in thermodynamic equilibrium with their gaseous environment. NAT is formed if the partial pressure of $\mathrm{HNO}_{3}$ exceeds its saturation pressure, assuming a mean particle radius of $5 \mu \mathrm{m}$ for NAT. The particle number densities are limited by an upper boundary of $5 \times 10^{-4} \mathrm{~cm}^{-3}$ to account for the fact that observed NAT clouds are often strongly supersaturated. The sedimentation of NAT and water ice is based on the Stokes theory as described in Pruppacher and Klett (1997). Water ice and NAT are not explicitly transported but are evaporated back to water vapor and gaseous $\mathrm{HNO}_{3}$ after each chemical time step, transported in the vapor phase, and then depending on the saturation conditions regenerated in the next time step with the thermodynamic approximation described above. In the troposphere, the heterogeneous hydrolysis of $\mathrm{N}_{2} \mathrm{O}_{5}$ on tropospheric aerosols contributes to the sink of odd nitrogen. Note that since the MACv2-SP parameterization that is used for radiation does not provide the aerosol mass, for the tropospheric chemistry we use the tropospheric aerosol climatology that considers the aerosol properties of 11 Global Aerosol Data Set (GADS, Koepke et al., 1997) types as in the previous model version. The reaction probabilities for the different aerosol types are calculated following the parametrization by Evans and Jacob (2005).

Parameterizations of the $\mathrm{N}, \mathrm{NO}$, and $\mathrm{OH}$ production by galactic cosmic rays, solar protons, and energetic electrons with energies of $<300 \mathrm{keV}$ are introduced as $0.55,0.7$, and up to 2 molecules of $\mathrm{N}, \mathrm{NO}$, and $\mathrm{OH}$ per ion pair, respectively (Matthes et al., 2017). The contribution of thermospheric NO from downward intrusions is parameterized as a flux-form upper boundary condition (Funke et al., 2016). The lightning source of $\mathrm{NO}_{x}$ is parameterized based on the cloud top approach by Price and Rind (1992). The tropospheric budget of CO is supplemented by the Mainz Isoprene Mechanism (MIM-1, Pöschl et al., 2000) that describes the degradation of isoprene, formaldehyde, and acetic acid. Contributions of all other non-methane volatile organic compounds (NMVOCs) to $\mathrm{CO}$ is accounted for via the addition of a certain fraction of NMVOC emissions to CO. For anthropogenic, biomass burning, and biogenic NMVOC emissions the conversion factors to $\mathrm{CO}$ are 1.0, 0.31, and 0.83 , respectively (Ehhalt et al., 2001).

Several newly discovered hODS (CFC-112, CFC-112a, CFC-113a, CFC114a, and HCFC-133a) have been added to the model chemistry scheme together with some additional chlorine containing very-short-lived substances (VSLSs: $\mathrm{CHCl}_{3}, \mathrm{CH}_{2} \mathrm{Cl}_{2}, \mathrm{C}_{2} \mathrm{Cl}_{4}, \mathrm{C}_{2} \mathrm{HCl}_{3}, \mathrm{C}_{2} \mathrm{H}_{4} \mathrm{Cl}_{2}$ ) that are not controlled by the MPA. The bromine-containing VSLS forcing is now also transient compared to the previous model versions and includes $\mathrm{CH}_{3} \mathrm{Br}, \mathrm{CHBr}_{3}$, and $\mathrm{CH}_{2} \mathrm{Br}_{2}$ species. The sulfur family is represented by eight gas-phase species: carbonyl 
sulfide (OCS), $\mathrm{CS}_{2}, \mathrm{H}_{2} \mathrm{~S}$, dimethyl sulfide (DMS), methanesulfonic acid (MSA), $\mathrm{SO}_{2}, \mathrm{SO}_{3}$, and $\mathrm{H}_{2} \mathrm{SO}_{4}$ (Sheng et al., 2015).

\subsection{Sulfate aerosol microphysics model AER}

The sulfate aerosol microphysical scheme AER is based on the two-dimensional sulfate aerosol model of Weisenstein et al. (1997). It was upgraded and combined with SOCOLv3 by Sheng et al. (2015) and later further improved by Feinberg et al. (2019). Sulfate aerosol particles are resolved in 40 size bins, ranging in dry radius from $0.39 \mathrm{~nm}$ to $3.2 \mu \mathrm{m}$, corresponding to a range of 2.8-1.6 $\times 10^{12}$ molecules of $\mathrm{H}_{2} \mathrm{SO}_{4}$ per particle (assuming an $\mathrm{H}_{2} \mathrm{SO}_{4}$ density of $1.8 \mathrm{~g} \mathrm{~cm}^{-3}$ ). $\mathrm{H}_{2} \mathrm{SO}_{4}$ molecule number doubles between bins, while the corresponding wet sulfate aerosol radii can be much larger depending on local conditions. $\mathrm{H}_{2} \mathrm{SO}_{4}$ weight percent is calculated online based on actual temperature and relative humidity. The AER scheme includes submodules for the nucleation (Vehkamäki et al., 2002), composition (Tabazadeh et al., 1997), growth, evaporation (Ayers et al., 1980; Kulmala and Laaksonen, 1990), coagulation (Fuchs, 1964; Jacobson and Seinfeld, 2004), and sedimentation of sulfate aerosol (Kasten, 1968; Walcek, 2000). In addition to gasphase $\mathrm{H}_{2} \mathrm{SO}_{4}$ production, the model calculates aqueous oxidation of $\mathrm{S}(\mathrm{IV})$ by ozone $\left(\mathrm{O}_{3}\right)$ and hydrogen peroxide $\left(\mathrm{H}_{2} \mathrm{O}_{2}\right)$ (Jacob, 1986). The spatial distribution of cloud $\mathrm{pH}$ in the aqueous-phase chemistry routine is approximated based on Tost et al. (2007). The aqueous production flux of S(VI) is added directly to the scavenged aerosol flux in cloud water. Dry and wet deposition of sulfate aerosol are calculated by the similar schemes as for gas-phase species (Tost et al., 2006; Kerkweg et al., 2006). Dry and wet deposition as well as gravitational velocities of sulfate aerosol are calculated through radius-dependent parameterizations. During cloud evaporation, evaporating scavenged sulfate aerosol mass is transferred to the largest aerosol size bin. Transport of aerosols in each bin is also performed in the same way as transport of gases with a time step of $15 \mathrm{~min}$. The microphysical module is called every $2 \mathrm{~h}$ with 20 subtime steps yielding an aerosol microphysical time step of $6 \mathrm{~min}$.

The influence of the aerosol on radiation fluxes at all wavelengths (14-band shortwave and 16-band longwave) is taken into account. Extinction coefficients, single-scattering albedo, and asymmetry factors required by the radiation codes are treated following a lookup-table approach with precalculated aerosol physical properties using Mie theory for actual $\mathrm{H}_{2} \mathrm{SO}_{4}$ weight percent and temperature using refraction indices from Biermann et al. (2000). The aerosol surface area density and composition are used to calculate heterogeneous reaction rates in a chemical module. Note that AER aerosols in the model impact chemistry and radiation only in the stratosphere. In the troposphere, we use MACv2-SP for radiation and GADS for $\mathrm{N}_{2} \mathrm{O}_{5}$ hydrolysis (see Sect. 2.1.4 and 2.2).

\subsection{Model setup and boundary conditions}

As described above, SOCOLv4 is based on the latest version of MPI-ESM that was also used for the Climate Model Intercomparison Project phase 6 (CMIP6) runs. To test the new coupled model, we initialized all its parts from the MPI-ESM restart files (snapshots of the model's state at a specified time) from the end of the year 1949 and then continued the calculation until the end of 2018. The initialization of chemistry was based on SOCOLv3 runs from Revell et al. (2016). In 1980 , the reference run was split into an ensemble of three runs by imposing a temporary (1-month long) small perturbation in atmospheric $\mathrm{CO}_{2}$ concentrations. For the analysis performed here, we skip the first 30 years of simulations and focus on the 1980-2018 period, which is well covered by observations.

Model boundary conditions mostly follow the recommendations of CMIP6 provided by the input4MIPs database (https://esgf-node.llnl.gov/search/input4mips/, last access: 2 September 2021). All forcings are historical before 2015 and switched to the SSP2-4.5 scenario for the last 4 years until 2018. These include concentrations of greenhouse gases (Meinhausen et al., 2016), surface anthropogenic and biomass-burning emissions of $\mathrm{NO}_{x}$ (as well as aircraft emissions), $\mathrm{CO}, \mathrm{SO}_{2}$, and NMVOCs (Hoesly et al., 2018), ionization rates by galactic cosmic rays, solar protons, and energetic electrons, solar spectral irradiance variations, and the influx of thermospheric NO (Matthes et al., 2017). Biogenic emissions of all NMVOCs use a climatology for the year 2000 based on MEGAN (Model of Emissions of Gases and Aerosols from Nature; Guenther et al., 2006). For the longand short-lived halogenated source gases (ozone-depleting substances (ODSs) and VSLSs) we used the World Meteorological Organization (WMO) Ozone Assessment 2018 baseline mixing ratio scenario, which is a combined atmospheric observation record up to the year 2017 (Engel et al., 2018). For some ODSs, we also used the input4MIPs database. Agricultural land-use changes are based on the Land Use Harmonization project data (LUHv2h, Hurtt et al., 2011).

Continuous degassing emissions of $\mathrm{SO}_{2}$ are prescribed according to volcano locations (Andres and Kasgnoc, 1998; Dentener et al., 2006). To represent eruptive emissions, we applied a satellite-derived dataset from Carn et al. (2016). Since the emission profiles are unknown in this database, they are emitted into the upper third of the total plume height. Air-sea DMS fluxes are calculated online through a winddriven parametrization (Nightingale et al., 2000) and climatological gridded sea surface DMS concentrations (Lana et al., 2011). $1 \mathrm{Tg} \mathrm{Syr}^{-1}$ of $\mathrm{CS}_{2}$ is emitted between the latitudes of $52^{\circ} \mathrm{S}$ and $52^{\circ} \mathrm{N}$ based on Weisenstein et al. (1997). The surface mixing ratios of $\mathrm{H}_{2} \mathrm{~S}$ and OCS are prescribed as 30 pptv (Weisenstein et al., 1997) and 510 pptv (Timmreck et al., 2018), respectively.

Since the model vertical resolution is insufficient for a reasonable self-generation of the quasi-biennial oscillation 
(QBO), we nudge it to the observed equatorial wind profiles. The nudging is applied between $20^{\circ} \mathrm{N}$ and $20^{\circ} \mathrm{S}$ from $90 \mathrm{hPa}$ up to $3 \mathrm{hPa}$. Within the $\mathrm{QBO}$ core domain $\left(10^{\circ} \mathrm{N}-10^{\circ} \mathrm{S}, 50\right.$ $8 \mathrm{hPa}$ ), the relaxation time is uniformly set to $7 \mathrm{~d}$; outside of this region, the damping depends on latitude and altitude (Giorgetta, 1996).

Tropospheric aerosols are represented by two separate datasets for radiation and chemistry. For radiation, to be consistent with the base model and CMIP6 recommendations, we used the MACv2-SP approach (Stevens et al., 2017), which however provides only optical parameters of aerosols. Surface area densities required for the $\mathrm{N}_{2} \mathrm{O}_{5}$ hydrolysis are based on the tropospheric aerosol climatology of 11 aerosol types from GADS (Koepke et al., 1997), as in SOCOLv3.

\section{SOCOLv4 evaluation}

\subsection{Atmospheric dynamics}

\subsubsection{Reference data for evaluation}

We validate the simulated climate variables from SOCOLv4 against observations. For this purpose, we use reanalysis data because they incorporate various observations combined in one dataset using comprehensive techniques that allow gaps in space and time to be estimated. It should be noted that the combination of different data can lead to some errors in the reanalysis data, both in trends and variability, that have a purely methodological nature, like those due to changes in the observation systems or aging of instruments as well as the details of underlying models used for assimilation. Intercomparison of different reanalysis products by Long et al. (2017) showed that reanalyses agree in the lower-middle stratosphere but deviate more from each other in the upper stratosphere and lower mesosphere because of the decreased availability of direct observations and thus the increased dependence on the assimilating model details, like the model top and vertical resolution. This should be considered when making conclusions about deviations between model results and reanalysis. To validate the thermodynamical structure of the modeled atmosphere, we use the recent ERA5.1 reanalysis dataset (Simmons et al., 2020; Hersbach et al. 2020) from ECMWF (European Centre for MediumRange Weather Forecasts) and MERRA-2 (Modern-Era Retrospective Analysis for Research and Applications version 2, Gelaro et al., 2017). For surface air temperature, we additionally use the BEST data (the Berkeley Earth Surface Temperatures, Cowtan et al., 2015), which are a merged land-ocean dataset.

\subsubsection{Temperature and winds}

To assess the ability of SOCOLv4 to reproduce the climate and its response to historical forcing, we show variability in annual mean surface air temperature and its anomaly
(Fig. 3a, b), the Arctic sea ice extension anomaly (Fig. 3c), as well as the El Niño-Southern Oscillation (ENSO) Niño3.4 statistics (Fig. 4a, b) for the historical period 1980 to 2018. Anomalies were calculated as a deviation from the mean over the 1980-2018 period. Figure 5a, c also show the global mean $2 \mathrm{~m}$ temperature and its anomaly simulated with the SOCOLv4 and various reanalysis data. The model reveals a warming trend similar to observations, whereas the ensemble mean curve shows less interannual variability, as expected (Fig. 3a). As can be seen from the figure, the reanalysis data slightly disagree in terms of the absolute level and the model data are within this spread. Modeled global mean surface air temperature is somewhat warmer than the ERA5.1 and MERRA-2 data but colder than the BEST data. Temperature anomalies (Fig. 3b) agree very well with observational composites. The annual Arctic sea ice extent anomalies are also accurately reproduced by SOCOLv4 in line with observations, showing a pronounced decline with time because of global warming and fluctuations of magnitudes to observations (Fig. 3c). According to Ding et al. (2019), the spread in sea ice extent between the ensemble members can be attributed to internal variability driven by fluctuations in Arctic pressure expressed as high pressure enhancing the sea ice loss and low pressure restraining it. Based on the analysis of Fig. 3, we conclude that the model response to historical radiative forcing is sufficiently close to observations, which proves suitability of the model for studies of past and future climate changes.

ENSO is known as the largest mode of sea surface temperature anomalies with irregular period of $\sim 2-7$ years, which influences atmospheric circulation globally in the troposphere (e.g., Bulgin et al., 2020) as well as in the middle atmosphere (Domeisen et al., 2019). It is tracked as a variability of the sea surface temperature in the so-called Niño3.4 region $\left(5^{\circ} \mathrm{N}-5^{\circ} \mathrm{S}, 120-170^{\circ} \mathrm{W}\right)$. These temperature anomalies are usually in the range of $\pm 3 \mathrm{~K}$ with positive fluctuations being associated with El Niño events and negative with La Niña events. There were several El Niño events observed with positive deviations stronger than $+1.5 \mathrm{~K}$ during the considered decades, with the strongest being those in 1982/1983, $1997 / 1998$, and 2015/2016. To verify the model performance in this context, we analyzed the fast Fourier transform (FFT) and the probability density function (PDF) (Fig. 4a and b, respectively) of the modeled and ERA5.1 Niño3.4 indices. The analysis indicates that SOCOLv4 has realistic ENSO in terms of amplitude and periodicity; however, the 40-year period is rather short for a robust estimation of ENSO frequencies, which is illustrated as a pronounced variability among the ensemble members. The common bias shared by all members is that ENSO events in the model mostly last longer than in observations. This is expressed as the power spectrum shift to shorter frequencies and a flattened PDF. It must be noted that this is a known feature of our underlying model, MPIESM, and our FFT results are very similar to those shown by Müller et al. (2018) in their Fig. 13, where they analyzed a 

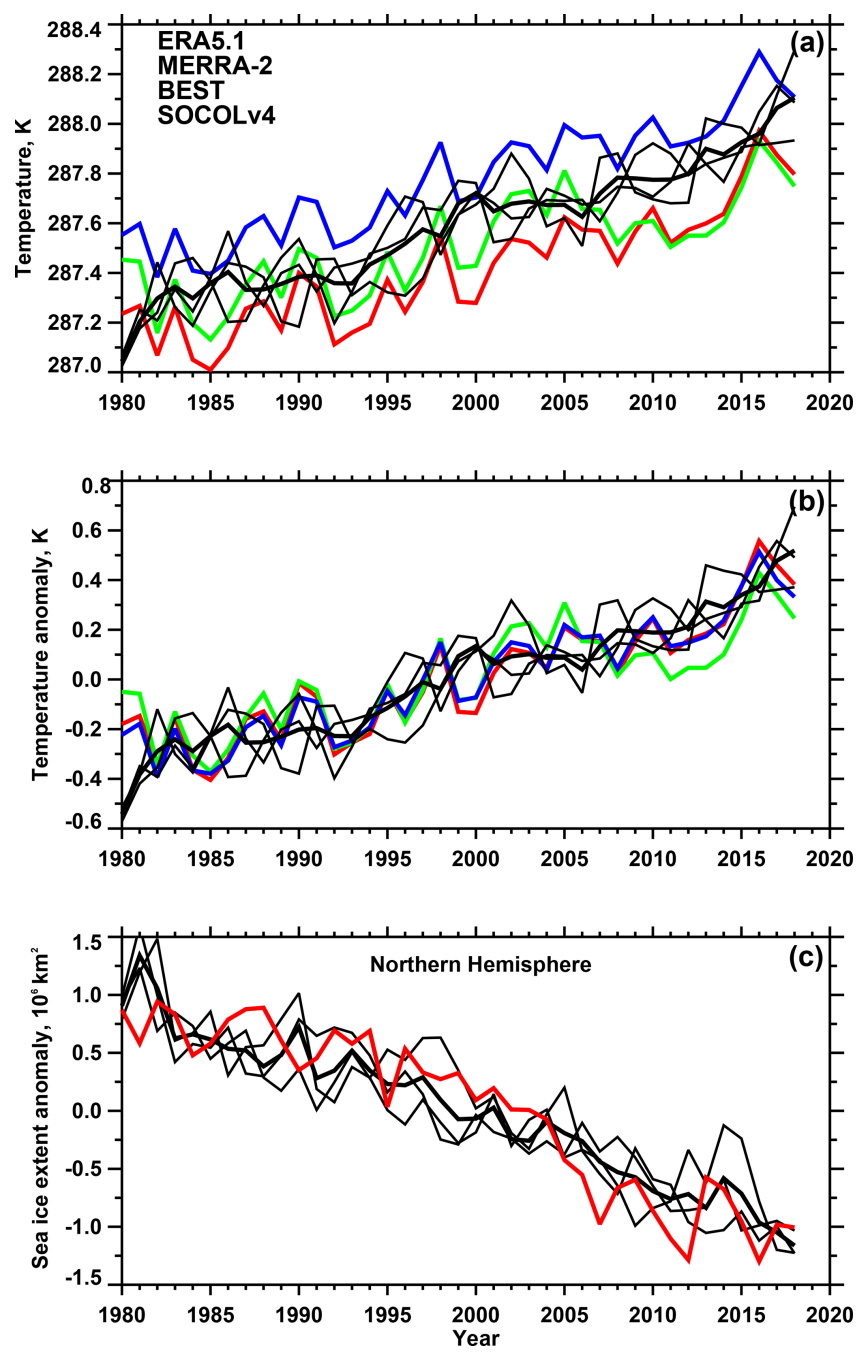

Figure 3. Global and annual mean $2 \mathrm{~m}$ temperature (a) and its anomalies relative to 1980-2018 mean (b) and Arctic sea ice extent annual anomaly (c) in comparison to reanalysis data. The thick black line represents simulated mean of the three-member SOCOLv4 ensemble, thin black lines are individual ensembles members, the red line indicates ERA5.1 reanalysis, the green line indicates MERRA-2 reanalysis, and the blue line indicates BEST reanalysis.

140-year period. The spatial pattern of ENSO in the model is reasonable but also has some biases related to the asymmetry between El Niño and La Niña events (for details see Tian et al., 2019). This drawback could be minimized by increasing coupling frequency between ocean and atmosphere from daily to hourly. However, this change also increases the computational demands to levels, which are less suitable for long-term climate calculations. Therefore, the LR version of MPI-ESM which we used for SOCOLv4 was tuned with a daily coupling (Mauritsen et al., 2019).

The left panel of Fig. 5 shows the geographical distribution of the $2 \mathrm{~m}$ air temperature climatology for 1980-2018 as sim-
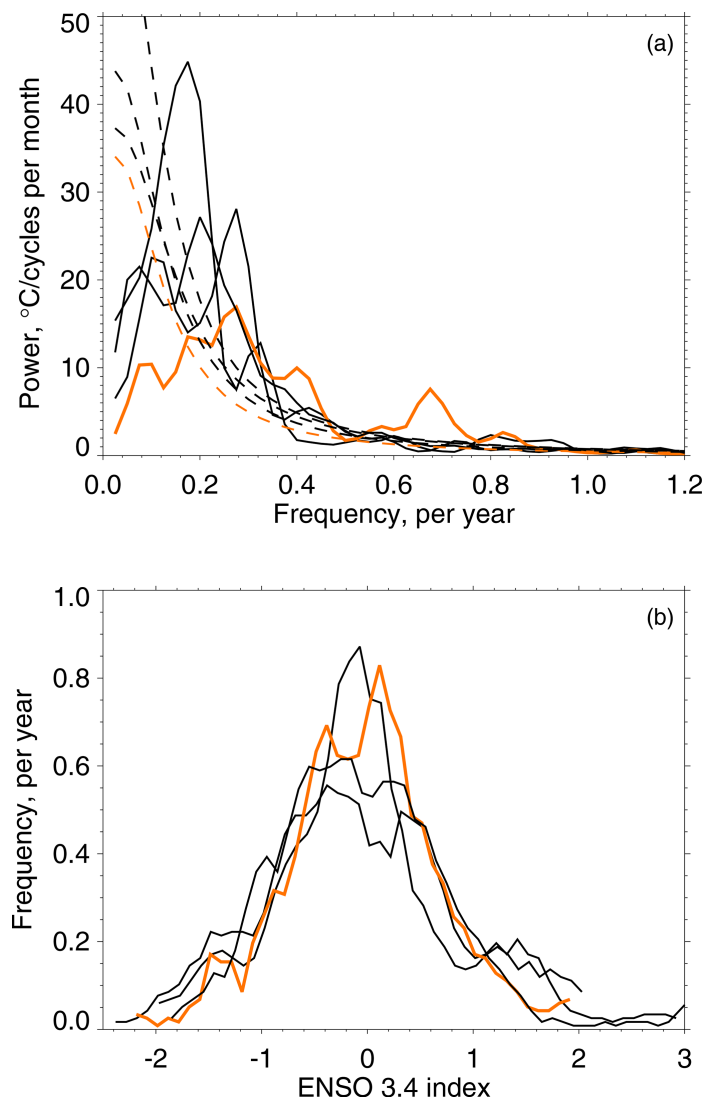

Figure 4. (a) The 1980-2018 Niño3.4 power spectra $\left({ }^{\circ} \mathrm{C} /\right.$ cycles month $\left.^{-1}\right)$ calculated from the ERA5 data (orange) as well as from the three SOCOLv4 ensemble members (black). Dashed lines are the $95 \%$ significance levels based on an autoregressive $\mathrm{AR}(1)$ process fitting. (b) Histogram of Niño3.4 temperature anomalies.

ulated with SOCOLv4 and derived from the ERA5.1 reanalysis, as well as their difference. ERA5.1 data have been interpolated to the model grid. SOCOLv4 properly reproduces the observed geographical pattern of the surface air temperature with cold high-latitude areas in both hemispheres and warm tropics and subtropics. However, there are some regional discrepancies between the model and the reanalysis data. The model surface air temperature is generally slightly $(\sim 0.2 \mathrm{~K})$ warmer than in ERA5.1, which is also seen from the global means (Fig. 3a), but there are also several spots with cold biases. In the tropical area, the discrepancies are within $\pm 1 \mathrm{~K}$, except in the eastern part of South America over the Brazilian Highlands, where negative bias reaches $-5 \mathrm{~K}$, and over the Tibetan Plateau and mainland southeast Asia, with up to $-3 \mathrm{~K}$ bias. In the northern middle latitudes, we obtain negative discrepancies of about $-5 \mathrm{~K}$ over the Rocky Mountains and the North Atlantic Ocean. The most pronounced biases of $\pm 6 \mathrm{~K}$ are located in the Southern Hemisphere over Antarctica. Most of these biases in high-altitude regions are a common feature of all coupled models, which is usually 

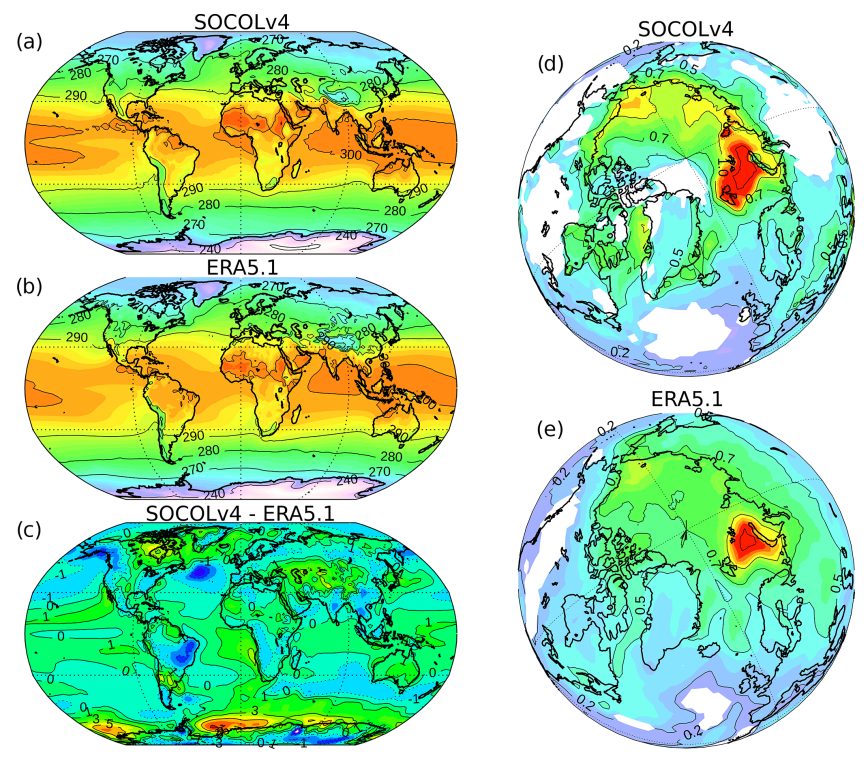

Figure 5. Left panels: global distribution of $2 \mathrm{~m}$ surface air temperature $(\mathrm{K}$, contours are $-5,-3,-1,0,1,3,5,7,9)$ averaged over the period 1980-2018 simulated by SOCOLv4 (a, ensemble mean), ERA5.1 reanalysis data (b), and their difference (c, SOCOL4ERA5.1). Right panels: $2 \mathrm{~m}$ surface air temperature trend over the Northern Hemisphere (K/10 years, contours are $-0.5,-0.2,0,0.2$, $0.5,0.7,1.0,1.5)$ simulated (d) and observed (e) over the Northern Hemisphere. White spots show where the trend is not statistically significant at the $95 \%$ level.

attributed to the simplified model's topography and uncertainties in the observational data (e.g., Guo et al., 2020). The right panel of Fig. 5 shows the $2 \mathrm{~m}$ surface air temperature trends over 1980-2018 over the Northern Hemisphere simulated by SOCOLv4 and calculated from ERA5.1 reanalysis data. The linear trend and its significance were calculated using a robust nonparametric Sen-Mann-Kendall test applying $95 \%$ confidence interval. Simulated and observed trends over the Northern Hemisphere show a good spatial agreement including the location of the warming maximum north of Siberia. The maximum simulated trend amounts to $1.69 \pm 0.16 \mathrm{~K}$, which is only about $0.25 \mathrm{~K}$ smaller than the maximum trend of $1.93 \mathrm{~K}$ derived from the reanalysis.

Zonal mean climatology of zonal winds and temperatures for boreal winter and summer as simulated by SOCOLv4 are presented in comparison to observations (mean data from reanalysis ERA5.1 and MERRA-2) in Figs. 6 and 7, respectively. Even though the model has an upper limit at $0.01 \mathrm{hPa}$, we analyze the results only up to a height of $0.1 \mathrm{hPa}$, since above ERA5.1 data are not reliable and MERRA-2 data are not available. In general, the model reproduces the observations well, but there are deviations which are, however, typical for most coupled models (Bock et al., 2020; Gettelman et al., 2019; Matthes et al., 2020). The tropospheric jets, their position, and strength are reasonably reproduced by the model with biases of $\pm 2-5 \mathrm{~m} \mathrm{~s}^{-1}$. There is a tendency of the westerlies in the midlatitudes to be insufficiently poleward, which is more pronounced in the Southern Hemisphere and represented as negative and positive deviations around 60 and $40^{\circ} \mathrm{S}$, respectively. The differences between the model and observations increase with altitude. In the stratosphere, the simulated summertime easterly jets are of similar strength to those in the observations but have some deviations in their shapes. The deviations between about 90 and $3 \mathrm{hPa}$ in the (sub)tropics are related to the hemispherically symmetric QBO nudging approach, which is applied between $20^{\circ} \mathrm{N}$ and $20^{\circ} \mathrm{S}$ (see Sect. 2.4). The wintertime polar night jets show larger deviations in both hemispheres. In the Northern Hemisphere, the modeled polar vortex is significantly weaker than in the observations and is extended equatorward in the lower mesosphere. The Southern Hemisphere vortex is of similar strength to that in reanalysis mean data in the stratosphere and the main model deviations are related to its positioning. The core of the southern polar jet is shifted to $60^{\circ}$ and located between 10 and $1 \mathrm{hPa}$, while in the reanalysis data the vortex core $\left(80 \mathrm{~m} \mathrm{~s}^{-1}\right.$ isoline) extends higher and shifts towards $40^{\circ} \mathrm{S}$. Therefore, the modeled southern polar vortex area is more isolated in the middle stratosphere. Oppositely, in the lower mesosphere, it is extended equatorwards, similar to the northern one. The latter feature might suggest that there is some overestimation in the gravity wave forcing that is dominant in this region (Plumb, 2002; Butchart, 2014).

The zonal mean temperature distribution is generally well reproduced by the model (Fig. 7), but there are also strong biases in the middle atmosphere with respect to the observations that are consistent with the biases in zonal winds. Namely, the wintertime high-latitude middle and upper stratosphere and the low mesosphere are warmer by $2-10 \mathrm{~K}$ suggesting weaker vortices and stronger meridional transport and mixing. In the rest of the stratosphere, the difference is negative (about $-2 \mathrm{~K}$ ). This is consistent with a too-fast BDC, which would cause increased adiabatic cooling in the tropics and in the summertime high latitudes. In the lowermost extratropical stratosphere, there are up to $-5 \mathrm{~K}$ temperature deviations in both hemispheres, which leads to some downward displacement of the extratropical tropopause. The modeled tropospheric temperatures agree very well with observations and only show a warm bias over Antarctica.

It has to be noted that all of the presented model deviations in thermodynamics are long-term issues of the ECHAMfamily models and global models in general (Stevens et al., 2013; Mauritsen et al., 2019). In Fig. A1, we present the same differences as in Figs. 6 and 7 but for the pure MPI-ESM CMIP6 run. As can be seen from there, SOCOLv4 and MPIESM share the same deviation patterns indicating weaker and warmer polar vortices in the stratosphere. Some differences between SOCOLv4 and MPI-ESM results are mostly related to the stratospheric ozone distribution at midlatitudes and high latitudes, as well as to the distribution of other GHGs except $\mathrm{CO}_{2}$ that are now three-dimensional, and the QBO nudging in SOCOLv4 in the tropics. Many of these problem- 

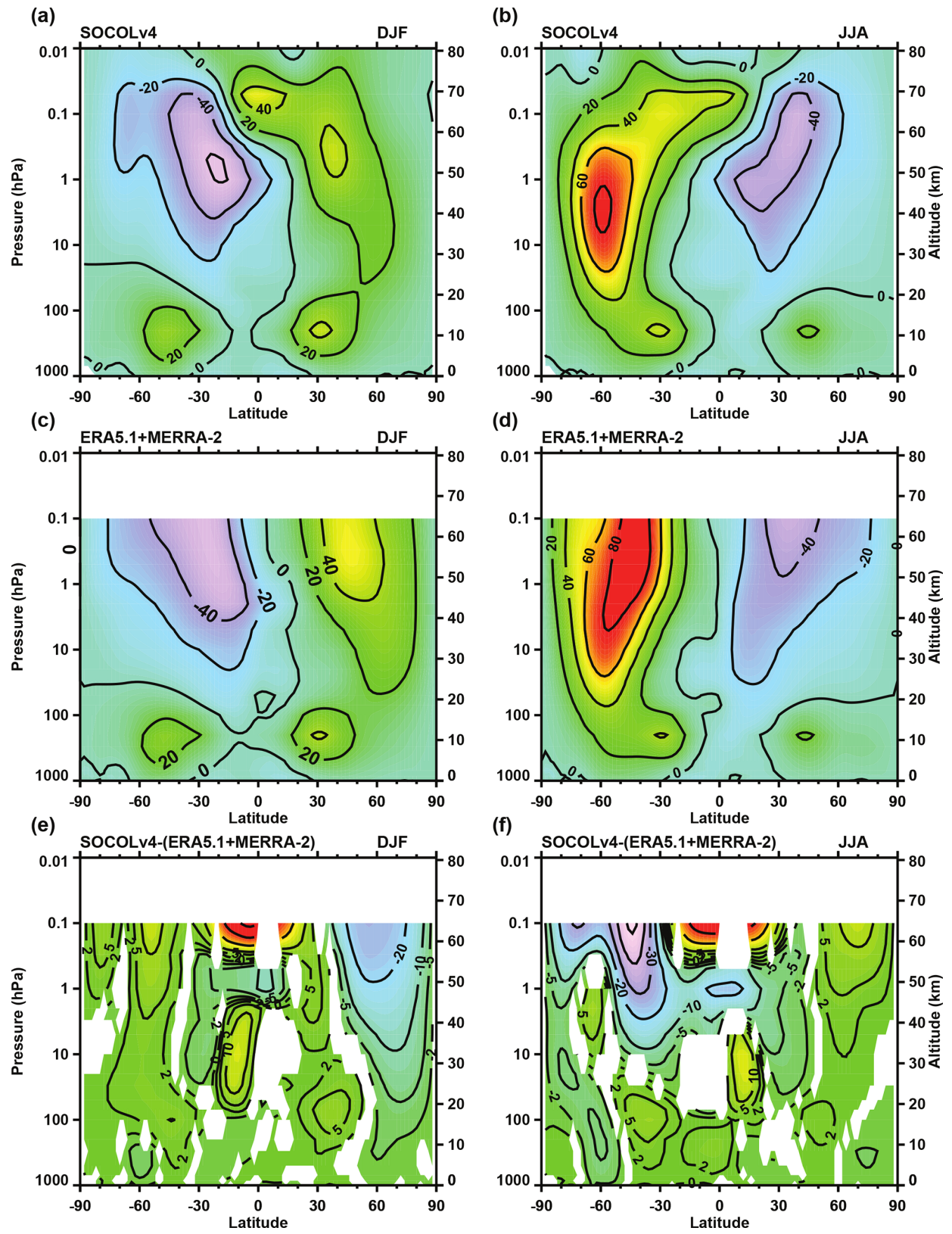

Figure 6. Zonal mean zonal wind climatology $\left(\mathrm{m} \mathrm{s}^{-1}\right)$ for DJF (a, c, e) and JJA (b, d, f) simulated with SOCOLv4 (a, b), mean of ERA5.1 and MERRA-2 reanalysis (c, $\mathbf{d})$, and differences between simulated and reanalysis data $(\mathbf{e}, \mathbf{f})$. Contour intervals for the difference are -30 , $-20,-10,-5,-2,2,5,10,20,30 \mathrm{~m} \mathrm{~s}^{-1}$. White areas denote regions where the difference between model and reanalysis data is not statistically significant at the $95 \%$ confidence level calculated with a Student's $t$ test.

atic features were shown to be greatly improved using a version of ECHAM with more detailed (95-level) vertical resolution (Schmidt et al., 2013; Stevens et al., 2013; Mauritsen et al., 2019; Matthes et al., 2020), especially the strength of the northern polar vortex and the extratropical lower stratospheric cold biases. The increase of the vertical resolution implies, however, a strong increase in computational time, because of the column physics design. It can be partly compensated by increasing the amount of processing units, but there is also a limit in model's scalability defined by horizontal resolution.

\subsection{Atmospheric chemistry and transport}

\subsubsection{Reference data for validation}

All datasets that were used for the chemistry validation are listed in Table 1. For the comparison of $\mathrm{HCl}, \mathrm{H}_{2} \mathrm{O}$, and $\mathrm{N}_{2} \mathrm{O}$, we used the Global OZone Chemistry And Re- 

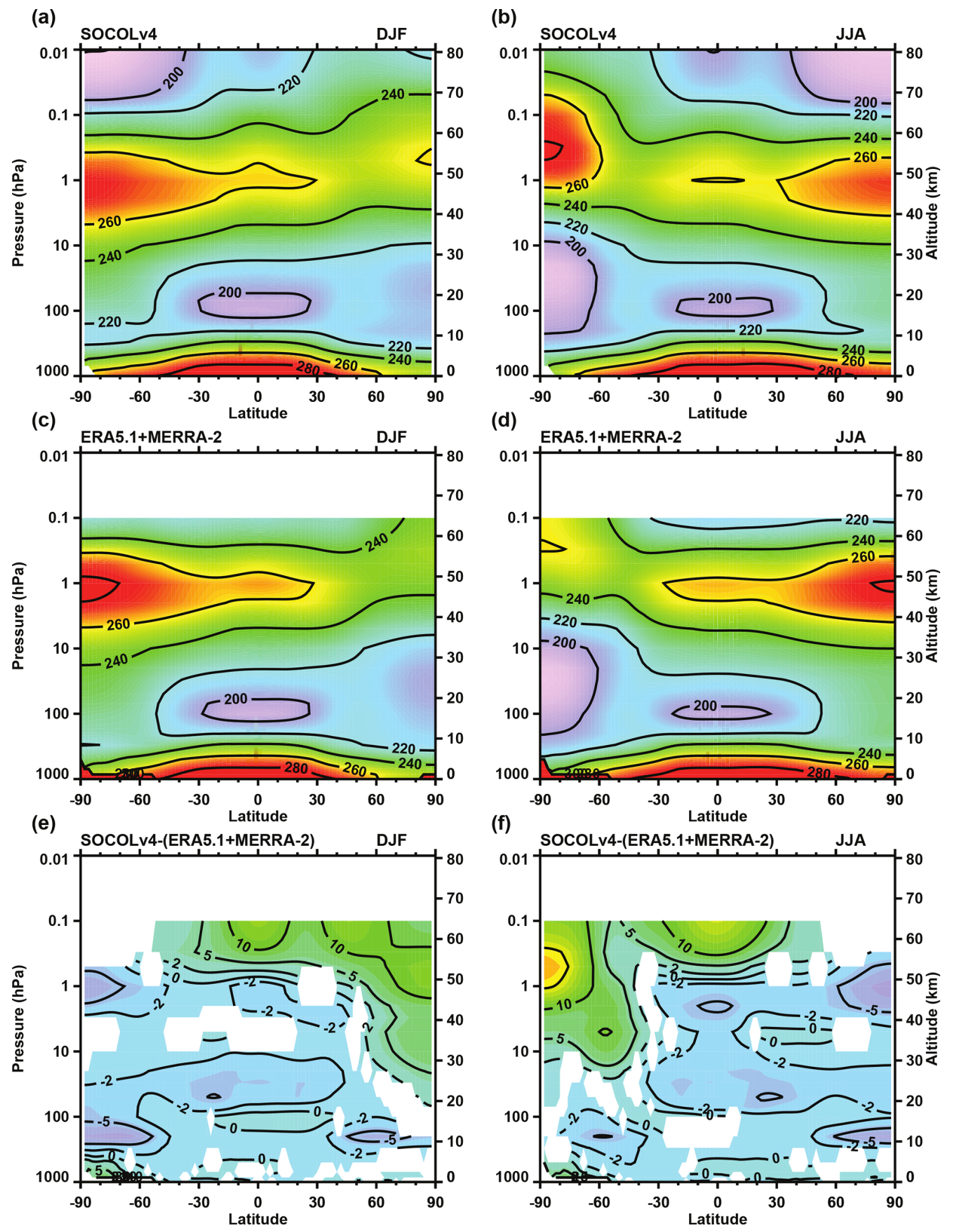

Figure 7. Zonal mean temperature climatology for DJF (a, c, e) and JJA (b, d, f) simulated with SOCOLv4 (a, b), mean of ERA5.1 and MERRA-2 reanalysis $(\mathbf{c}, \mathbf{d})$, and differences between simulated and reanalysis data $(\mathbf{e}, \mathbf{f})$. Contour intervals for the differences are $-30,-20$, $-10,-5,-2,0,2,5,10,20,30,40 \mathrm{~K}$. White areas denote regions where the difference between model and reanalysis data is not statistically significant at the $95 \%$ confidence level.

lated trace gas Data records for the Stratosphere database (GOZCARDS, Froidevaux et al., 2015), which is a composite based on the data from eight satellite instruments. The Envisat satellite Michelson Interferometer for Passive Atmospheric Sounding (MIPAS, Funke et al., 2014) instrument data were used for $\mathrm{NO}_{y}$, while the SCISAT Atmospheric Chemistry Experiment Fourier Transform Spectrometer (ACE-FTS) data climatology is used for $\mathrm{NO}_{y}$ and $\mathrm{CH}_{4}$. Besides GOZCARDS, the ozone mixing ratio is also com- pared to the BAyeSian Integrated and Consolidated composite ozone (BASIC, Alsing and Ball, 2019), and the CMIP6 ozone forcing dataset (Checa-Garcia, 2018). The latter is a compilation of CESM1-WACCM and Canadian Middle Atmosphere Model (CMAM) modeling results and is used as a standard forcing for MPI-ESM. Ozone total column is validated against Multi-Sensor Reanalysis version 2 (MSRv2, Van der A et al., 2015a) and Solar Backscatter Ultraviolet Spectral Radiometer version 2 (SBUVv8.6) (McPeters 
et al., 2013) composites. Stratospheric aerosol sulfur mass is compared to MIPAS (Günther et al., 2018) and Highresolution Infrared Radiation Sounder (HIRS) (Baran and Foot, 1994) observations and a composite recommended by CMIP6 (GloSSACv1.1, Thomason et al., 2018).

It has to be noted that observations themselves are not perfect, especially for the shorter-lived species with pronounced diurnal cycles, low concentrations, and specific regions like high latitudes and the upper troposphere/lower stratosphere (UTLS). Different satellite instruments vary in terms of measurement method, geographical coverage, spatial and temporal sampling and resolution, time period, and retrieval algorithm. All of this has also to be dealt with while constructing the observational composites, which imposes further potential uncertainties related to the homogenization methods applied. The SPARC Data Initiative (SPARC, 2017) conducted an overview of the existing trace gases and aerosol measurements and provided a set of useful recommendations concerning the related uncertainties that we used in the further sections for our validation.

\subsubsection{Trace gas climatology}

In this section, we discuss the SOCOLv4 performance in reproducing observed distributions of various trace species. Figures 8, 11, and 12 show the data from the model and observations and the relative differences between them. Figures 9 and 13 show mean seasonal cycles of several species that are also compared to observations.

\section{$\mathrm{CH}_{4}$}

Methane $\left(\mathrm{CH}_{4}\right)$ is an important source of water vapor $\left(\mathrm{H}_{2} \mathrm{O}\right)$ in the stratosphere. On average, two $\mathrm{H}_{2} \mathrm{O}$ molecules are produced per $\mathrm{CH}_{4}$ molecule oxidized. Methane mixing ratios drop very fast with height due to increasing availability of hydroxyl radical $(\mathrm{OH})$, the excited atomic oxygen $\left(\mathrm{O}\left({ }^{1} \mathrm{D}\right)\right)$, and atomic chlorine $(\mathrm{Cl})$. In the lower mesosphere, photolysis by Lyman- $\alpha$ radiation also becomes an important sink for $\mathrm{CH}_{4}$. Methane is also an important atmospheric tracer for tracking the stratospheric circulation because of its long lifetime. $\mathrm{CH}_{4}$ mixing ratio isolines in Fig. $8 \mathrm{~b}$ are lifted upward in the low latitudes by the ascending branch of the BDC and are pushed downward in the middle and high latitudes by the descending branch. Isolines in the midlatitudes are flattened as a result of rapid mixing by breaking planetary waves. The balance between horizontal mixing and the diabatic circulation produces the observed tracer slope and deviations in this distribution can hint at potential problems in transport processes (e.g., Strahan, 2015).

SOCOLv4 nicely reproduces the methane distribution in the lower stratosphere with only about $\pm 5 \%$ deviations from observations. However, above $\sim 10 \mathrm{hPa}$, the model deviation gradually increases with height to up to $50 \%$ overestimation in the lower mesosphere. The highest overestimation close to the model top in the mesosphere is likely related to the treatment of the Lyman- $\alpha$ line photolysis, while the rest is due to the problems in dynamics. Thus, a too-fast vertical transport in the tropics (Fig. 8a-c) would mean that there is less time for $\mathrm{CH}_{4}$ loss on the way upwards and therefore more $\mathrm{CH}_{4}$ arrives in the mesosphere, which can be partly enhanced by underestimation of $\mathrm{CH}_{4}$ photolysis. Dynamical lifetime got smaller with respect to chemical lifetime and the tracer became more vertically mixed. The increased concentration in the upper stratosphere is then also distributed polewards and downwards in the middle and high latitudes. Difference in skewness of the isolines suggests an overestimation of midlatitude mixing in the upper stratosphere/lower mesosphere, which is consistent with analysis of winds showing that the vortices are weaker at those altitudes (Fig. 6). Middle and lower stratospheric midlatitudes, however, show some hemispheric asymmetry with a negative bias of $5 \%$ in the $\mathrm{SH}$ and a positive bias of $5 \%-10 \%$ in the NH. Figure $9 a-b$ show the $\mathrm{CH}_{4}$ seasonal cycle at $20 \mathrm{hPa}$ and suggests that this anomaly is likely related to the deficiencies in horizontal mixing. Namely, while the model reproduces very well the tropical values (1.4 ppmv isoline), the midlatitude values ( $1 \mathrm{ppmv}$ isoline) are excessively shifted poleward in the $\mathrm{NH}$ and slightly equatorward in the SH. This is also generally consistent with Fig. 6, which shows at these altitudes a weaker $\mathrm{NH}$ polar vortex and the $\mathrm{SH}$ polar vortex that is more confined to the pole.

\section{$\mathrm{H}_{2} \mathrm{O}$}

Water vapor $\left(\mathrm{H}_{2} \mathrm{O}\right)$ provides a source for hydroxyl radicals $\left(\mathrm{HO}_{x}\right)$ in the stratosphere. Hydroxyl catalytic cycles dominate the ozone destruction above the stratopause and are also very important in the lower and middle stratosphere. The two main sources of $\mathrm{H}_{2} \mathrm{O}$ in the stratosphere are methane oxidation and the transport from the $\mathrm{H}_{2} \mathrm{O}$-rich troposphere. Transport from the troposphere is important for the lower stratosphere and is highly dependent on the cold point temperature at the tropical tropopause and vertical transport in the tropics. As seen from Fig. 8d-f, SOCOLv4 agrees very well with observations around the stratopause. In the lower stratosphere, the model is $5 \%-10 \%$ too moist, which is due to some overestimation of $\mathrm{H}_{2} \mathrm{O}$ at the entry point. In the mesosphere, the model underestimates $\mathrm{H}_{2} \mathrm{O}$ by up to $30 \%$ (or $1 \mathrm{ppmv}$ ) around the model top. This partly results from the underestimated destruction of methane (about $0.2 \mathrm{ppmv}$ ) but mostly comes from the overestimated water vapor photolysis, which was also previously reported for SOCOL in the standalone photolysis codes intercomparison study (Sukhodolov et al., 2016; Karagodin-Doyennel et al., 2021). The water vapor sink (dehydration) by PSCs in the south polar lowermost stratosphere is well captured by the model.

Water vapor is a relatively long-lived species with a highly pronounced seasonality in the lower tropical stratosphere. This seasonality is related to tropospheric wave forcing, 
Table 1. Data used in this study for chemistry validation.

\begin{tabular}{|c|c|c|}
\hline Data & Period & Source \\
\hline $\mathrm{O}_{3}$ mixing ratio & $\begin{array}{l}1985-2012 \\
1985-2012 \\
1985-2012\end{array}$ & $\begin{array}{l}\text { GOZCARDS composite (Froidevaux et al., 2015) } \\
\text { BASICv3 composite (Alsing and Ball, 2019) } \\
\text { CMIP6 composite (Checa-Garcia, 2018) }\end{array}$ \\
\hline $\begin{array}{l}\mathrm{CH}_{4}, \mathrm{NO}, \mathrm{NO}_{2}, \mathrm{~N}_{2} \mathrm{O}_{5}, \mathrm{HNO}_{3} \text {, } \\
\text { and } \mathrm{ClONO}_{2} \text { mixing ratio }\end{array}$ & 2004-2012 & ACE-FTSv3.5 (Bernath et al., 2005) \\
\hline $\mathrm{H}_{2} \mathrm{O}$ and $\mathrm{HCl}$ mixing ratio & $1991-2012$ & GOZCARDS \\
\hline $\mathrm{N}_{2} \mathrm{O}$ mixing ratio & 2004-2012 & GOZCARDS \\
\hline $\mathrm{NO}_{y}$ mixing ratio & $\begin{array}{l}2004-2012 \\
2002-2012\end{array}$ & $\begin{array}{l}\text { ACE-FTSv3.5 } \\
\text { MIPAS (Funke et al., 2014) }\end{array}$ \\
\hline $\mathrm{H}_{2} \mathrm{O}$ mixing ratio & $1991-2012$ & GOZCARDS \\
\hline Liquid $\mathrm{H}_{2} \mathrm{SO}_{4}$ mass & $\begin{array}{l}1991-1993 \\
1980-2016 \\
2002-2012\end{array}$ & $\begin{array}{l}\text { HIRS (Baran and Foot, 1994) } \\
\text { CMIP6 stratospheric aerosol composite (GloSSACv1.1, Thomason et al., 2018) } \\
\text { MIPAS (Günther et al., 2018) }\end{array}$ \\
\hline $\mathrm{O}_{3}$ total column & $\begin{array}{l}1980-2018 \\
1980-2018\end{array}$ & $\begin{array}{l}\text { MSRv2 composite (Van der A et al., 2015a) } \\
\text { SBUVv8.6 (McPeters et al., 2013) }\end{array}$ \\
\hline
\end{tabular}

which is strongest in northern winter and weakest in northern summer, leading to enhanced upwelling and colder temperatures at the tropical tropopause during boreal winter, and vice versa. In combination with the tropical pipe and the subtropical transport barrier, this makes $\mathrm{H}_{2} \mathrm{O}$ useful as a tracer of transport processes in the tropical stratosphere (Mote et al., 1998). Figure 10 shows the water vapor "tape recorder" signals obtained from GOZCARDS and SOCOLv4 to illustrate the model performance in terms of vertical transport in the tropical low and middle stratosphere. SOCOLv4 reproduces the seasonal cycle of water vapor at the tropopause level well. However, it also shows too-fast vertical propagation of the water vapor tape recorder in the observations similar to its predecessor versions (Stenke et al., 2013), which is a common peculiarity for chemistry-climate models (e.g., Dietmüller et al., 2018). This issue is related to the problems in horizontal and vertical mixing and diffusion and also to representation of the residual circulation in general, all of which are largely dependent on resolution. The overestimation of $\mathrm{H}_{2} \mathrm{O}$ of about $0.5 \mathrm{ppmv}$ throughout the middle and lower stratosphere (see also Fig. 7) is mostly due to the higher entry value during summer but can also be partly related to the overestimation of mixing with higher altitudes.

\section{HCl}

$\mathrm{HCl}$ is a chlorine reservoir that is widely used for tracking the overall chlorine abundance in the stratosphere, which also plays an important role in polar ozone chemistry. SOCOLv4 reproduces the $\mathrm{HCl}$ climatology pretty well with deviations mostly on the order of $\pm 5 \%-10 \%$ throughout the stratosphere (Fig. $8 \mathrm{~g}-\mathrm{i}$ ). The most pronounced deviation is the $\sim 5 \%$ underestimation by the model at the stratopause and the tropical mid-stratosphere. Figure $9 \mathrm{c}-\mathrm{d}$ illustrate the seasonal cycle at $70 \mathrm{hPa}$, demonstrating a rather good representation of the southern high-latitude variations with some underestimation of the PSC activation effects, the reasons for which are yet unclear. A limiting factor here can be the amount of available $\mathrm{ClONO}_{2}$ (Nakajima et al., 2016), whose observations are, however, rather sparse for these conditions. Note that $\mathrm{HCl}$ observational uncertainties are also the largest in the SH polar vortex (SPARC, 2017). In the northern polar regions, SOCOLv4 reproduces the semi-annual variability seen in observations but overestimates the wintertime decrease and underestimates the summertime one, which might be related to the weaker northern vortex that leads to higher temperature and lower frequency of PSC formation.

NO

Figure 11 shows the odd nitrogen $\left(\mathrm{NO}_{y}=\mathrm{NO}+\mathrm{NO}_{2}+2 \mathrm{~N}_{2} \mathrm{O}_{5}+\mathrm{HNO}_{3}\right)$ climatology from the model and its difference to the ACE-FTS and MIPAS instruments data. Odd nitrogen provides another important sink of ozone in the stratosphere and also negatively contributes to and is affected by other catalytic cycles of ozone destruction by deactivating odd hydrogen, chlorine, and bromine in the reservoir species $\mathrm{HNO}_{3}, \mathrm{ClONO}_{2}$, and $\mathrm{BrONO}_{2}$, respectively. The main source of $\mathrm{NO}_{y}$ in the middle atmosphere is oxidation and photolysis of nitrous oxide $\left(\mathrm{N}_{2} \mathrm{O}\right)$. The lowermost stratosphere is additionally highly affected by the mixing with the troposphere and therefore the $\mathrm{NO}_{y}$ budget also depends on the free tropospheric sources of odd nitrogen such as aircraft engines and lightning (Grewe, 

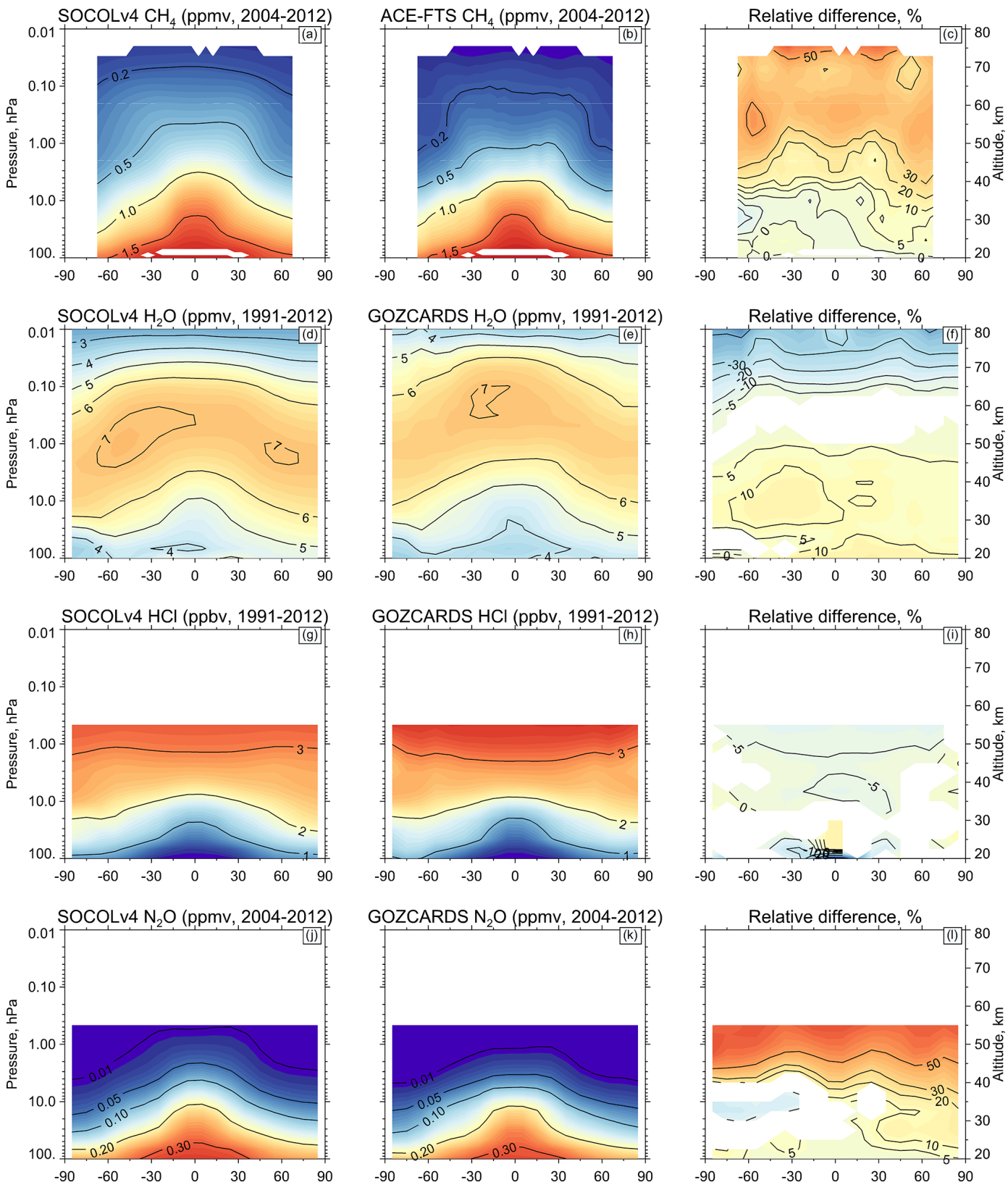

Figure 8. Annually averaged zonal mean distributions of $\mathrm{CH}_{4}, \mathrm{H}_{2} \mathrm{O}, \mathrm{HCl}$, and $\mathrm{N}_{2} \mathrm{O}$ (from top to bottom). First column: SOCOLv4 data. Second column: ACE-FTS and GOZCARDS observational data. Third column: relative difference between the model and observations in $\%$. An observational missing data mask is applied to the modeling results. Note that different species have different averaging periods. White areas are either the missing data or regions where the difference between model and observations is not statistically significant at the $95 \%$ confidence level.

2009). In the mesosphere, where odd nitrogen is mostly present in the form of nitric oxide (NO), the most important sources become the in situ $\mathrm{N}_{2}$ ionization by solar protons and middle energy electrons (MEEs) and the transport from the thermosphere, where it is produced by auroral electrons and $\mathrm{N}_{2}$ photolysis. Compared to ACE-FTS and MIPAS, which generally agree with each other, SOCOLv4 overestimates by $\sim 10 \%$ the maximum concentrations in the middle-upper stratosphere, the region where the odd nitrogen catalytic cycle of ozone destruction is the most effective. In the upper stratosphere and the mesosphere, the model also overestimates $\mathrm{NO}_{y}$ everywhere except polar mesospheric regions. The overestimation increases gradually with height, reaching $80 \%$ in the tropical mesosphere, where the absolute values, however, are rather small. As there is almost no $\mathrm{N}_{2} \mathrm{O}$ left at these altitudes, the overestimation 

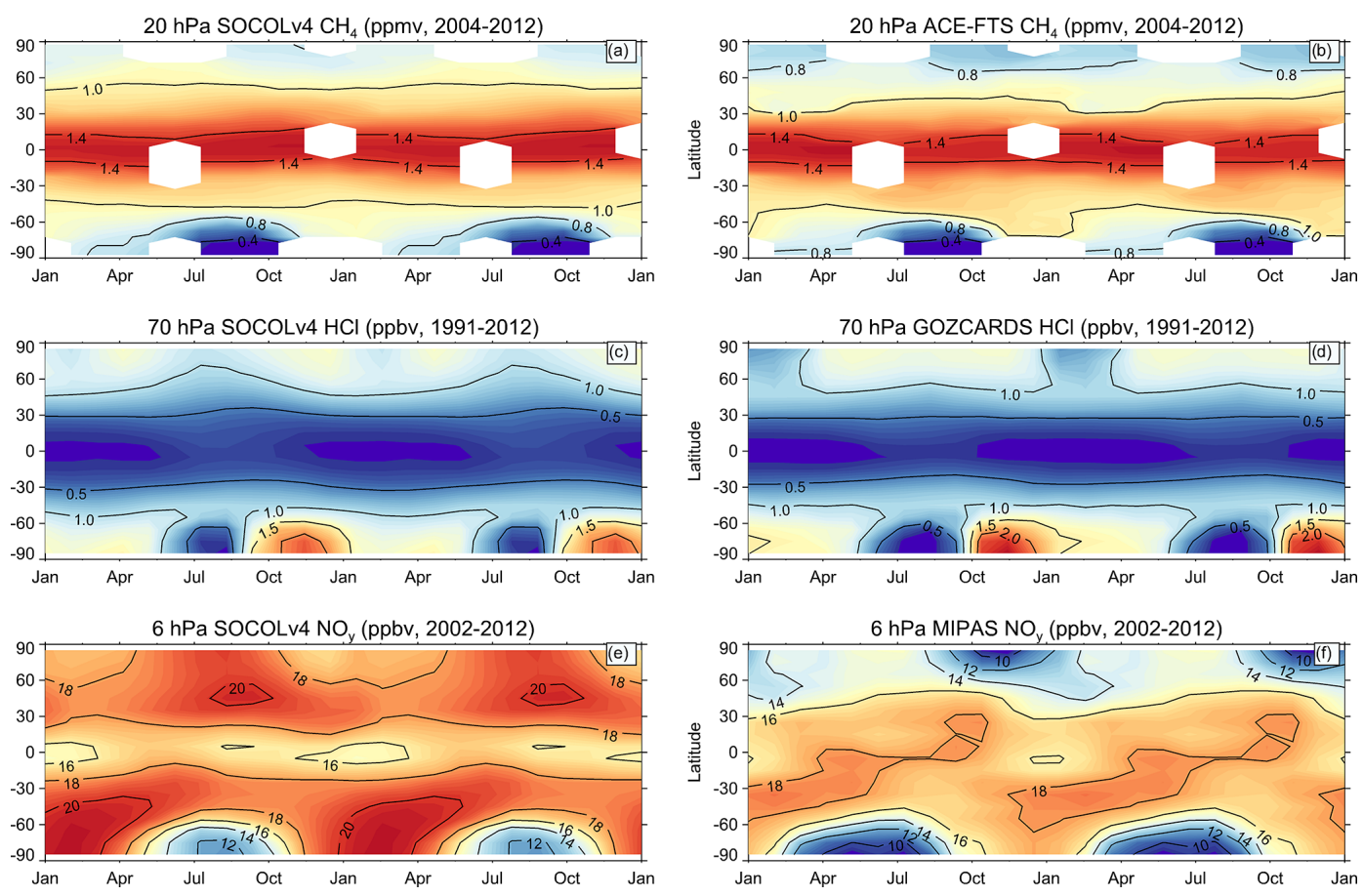

Figure 9. $\mathrm{CH}_{4}, \mathrm{HCl}$, and $\mathrm{NO}_{y}$ zonal mean seasonal cycles at 20, 70, and $6 \mathrm{hPa}$, respectively. First column: SOCOLv4 data. Second column: ACE-FTS, GOZCARDS, and MIPAS observational data. Two consecutive cycles are shown.

(a) GOZCARDS

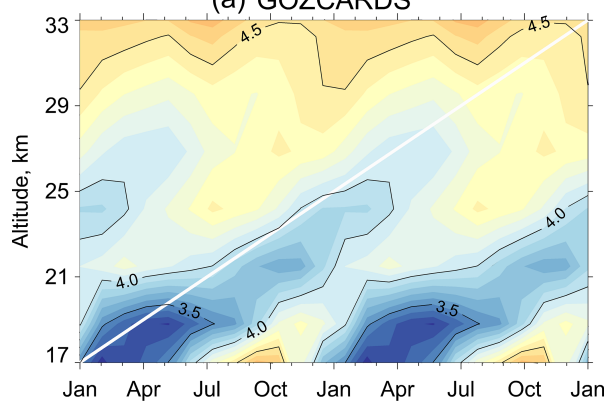

(b) SOCOLv4

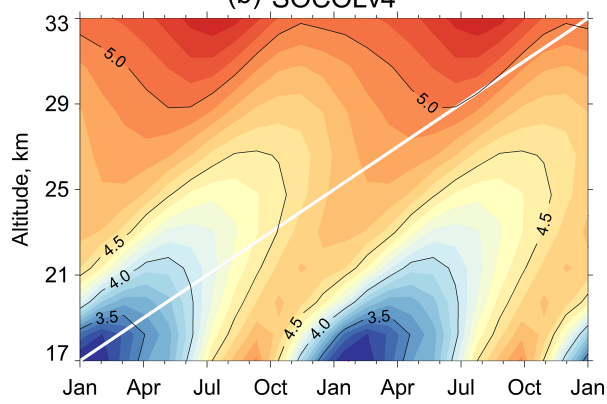

Figure 10. Annual cycle of water vapor mixing ratio (ppmv) averaged between $15^{\circ} \mathrm{N}$ and $15^{\circ} \mathrm{S}$ and over $1991-2012$ for the GOZCARDS satellite composite (a) and SOCOLv4 (b). Two consecutive cycles are shown. The white line in both panels indicates the approximate slope of the GOZCARDS tape recorder signal. likely comes from the underestimated sink through the NO photolysis. Despite the strong percentage deviation in the tropical mesosphere, the model underestimates $\mathrm{NO}_{y}$ in its polar regions, though the differences are almost insignificant due to a large interannual variability. The polar bias is most likely related to an underestimated contribution of either MEEs or the thermospheric NO downward flux. Mironova et al. (2019) compared CMIP6 MEE ionization effects to calculations based on polar balloon measurements and found that the related odd nitrogen signal can be up to $100 \%$ too low when CMIP6 forcing was used. High-latitude and midlatitude upper stratospheric $\mathrm{NO}_{y}$ concentrations are then affected by both the positive bias in the low latitudes and the negative bias in the polar high latitudes.

$\mathrm{NO}_{y}$ observational uncertainty is the largest in the lower stratosphere ( $\pm 30 \%$, SPARC, 2017), however both instruments suggest that the model has a pronounced low bias there. This can be explained by the insufficient production from $\mathrm{N}_{2} \mathrm{O}$ oxidation, which shows an underestimation in the middle and upper stratosphere (Fig. 7). This underestimation is very similar to that in methane, which suggests that both are probably related to the overestimation of the vertical transport. Another potential reason could be overestimated sinks to reservoir species; however, modeled $\mathrm{HNO}_{3}$ and $\mathrm{ClONO}_{2}$ (Fig. A2) agree reasonably well $( \pm 10 \%)$ with observations in the areas of their maximum concentrations in the lower stratospheric midlatitudes. The middle stratospheric overestimation of $\mathrm{HNO}_{3}$ is likely re- 

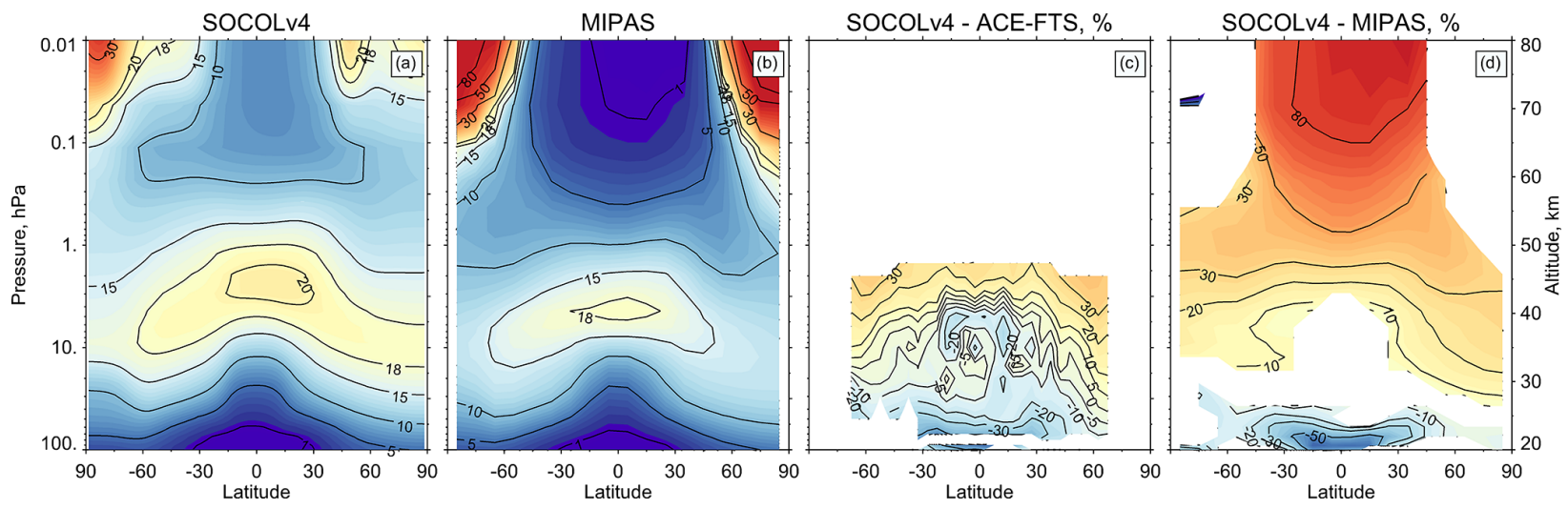

Figure 11. $\mathrm{NO}_{y}$ zonal mean annual mean climatology (ppbv) calculated by (a) the SOCOLv4 model and (b) provided by MIPAS. (c, d) Relative difference between the model and the ACE-FTS and MIPAS observations. White areas are either the missing data or regions where the difference between model and observations is not statistically significant at the $95 \%$ confidence level.

lated to the overestimated abundance of $\mathrm{H}_{2} \mathrm{O}$ and hence $\mathrm{HO}_{x}$ at these altitudes and the underestimated sink through photolysis (Sukhodolov et al., 2016). The tropical UTLS region shows large underestimation of both $\mathrm{NO}_{y}$ and $\mathrm{HNO}_{3}$, which suggests that either the free-tropospheric sink of odd nitrogen through $\mathrm{HNO}_{3}$ washout or the source through production by lightning activity is biased. Overall, $\mathrm{NO}_{y}$ representation in the model is defined by an underestimated sink in the upper stratosphere and the mesosphere, and the underestimated production in the lower stratosphere, which results in the slight vertical shift of the maximum $\mathrm{NO}_{y}$ concentrations upwards.

Modeled $\mathrm{NO}_{y}$ seasonal cycle at $6 \mathrm{hPa}$ is presented in Fig. 9e-f. The model shows generally higher values than MIPAS due to $\mathrm{NO}_{y}$ burden being biased high, as discussed before. However, the seasonality of the variations is reasonably well reproduced at this altitude. The high-latitude and midlatitude seasonality is controlled by the vertical motions, which either bring the $\mathrm{NO}_{y}$-low air from above during the wintertime or the $\mathrm{NO}_{y}$-high air from below in the summertime. This transport is modulated by horizontal mixing, which can cause some time shifts in the appearance of minima, like seen in the $\mathrm{NH}$ winter modeled results, where the contribution of the vertical transport is largely diminished by the mixing with midlatitudes. In the southern vortex, this is better reproduced by SOCOLv4 for the upper stratosphere; however, in the middle and lower stratosphere (not shown), there are traces of the modeled southern vortex being too isolated, which is consistent with the analysis of $\mathrm{CH}_{4}$ and $\mathrm{N}_{2} \mathrm{O}$. Boreal winter minimum in the tropics appears due to increased upwelling, and thus transport from below, which is well caught by the model.

\section{$\mathbf{O}_{3}$}

Figure 12 represents the ozone mixing ratio climatology calculated by the model versus two different ozone datasets.
Both observational datasets (BASIC and GOZCARDS) agree very well with each other. The difference plots demonstrate that SOCOLv4 has a very good representation of ozone in the tropics and subtropics throughout the stratosphere, except some overestimation in its lowermost part. The lower stratospheric overestimation spreads further to midlatitudes and reaches values of more than $20 \%$. This overestimation is a common feature in many CMIP6 models (Keeble et al., 2021 - see their Fig. 4). The lower stratosphere is a complex region with competing transport, mixing, and chemistry processes, variations of the tropopause, and exchange with the troposphere (Holton et al., 1995), which makes it difficult to identify exact factors responsible for these biases. From the chemistry side, there is no clear evidence from our analysis that can explain this overestimation. The low $\mathrm{NO}_{y}$ model bias (Fig. 11) would also contribute negatively to the ozone burden at these altitudes through reduced production by oxidation of carbon monoxide, methane, and higher hydrocarbons, similarly to the troposphere (Gauss et al., 2006; Grewe, 2009). Therefore, it is most likely that the high ozone bias is related to the photolysis problems in SOCOLv4. Sukhodolov et al. (2016) analyzed the stand-alone performance of the lookup-table photolysis scheme applied in SOCOL and found that the ozone photolysis in both channels is underestimated especially in the lower stratosphere. Although that study also showed the underestimated molecular oxygen photolysis at the same altitudes, which could partly compensate for the ozone photolysis underestimation, it appears that the latter still dominates. Comparison to the results of other codes in Sukhodolov et al. (2016) showed that the lower stratospheric problems in photolysis are probably related to the neglected Rayleigh scattering effect and temperature dependence of absorption cross sections and quantum yields. The applied photolysis corrections, as discussed in the MEZON module description, seem to improve ozone throughout the stratosphere; however, a more qualitative treatment of photolysis is already planned for the future. 

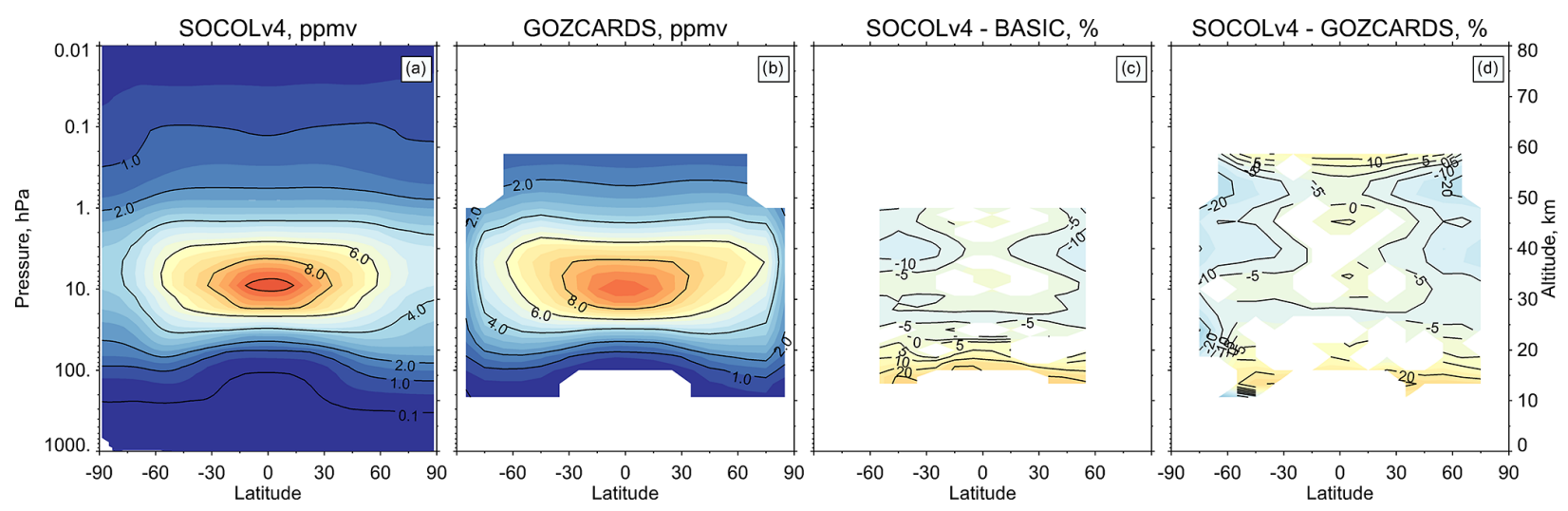

Figure 12. Ozone zonal mean annual mean climatology (1985-2012) calculated by the SOCOLv4 model (ppmv) (a) and provided by the GOZCARDS data (b). (c, d) Relative difference between the model and the observational composites BASIC and GOZCARDS. White areas are either the missing data or regions where the difference between model and observations is not statistically significant at the $95 \%$ confidence level.

Insufficient ozone photolysis also might affect $\mathrm{HO}_{x}$ formation via $\mathrm{O}\left({ }^{1} \mathrm{D}\right)+\mathrm{H}_{2} \mathrm{O}$ and related catalytic ozone destruction, thus intensifying the ozone high bias. Other factors that could contribute to the lower stratospheric overestimation in ozone are the $\sim 2 \mathrm{~K}$ underestimation in local temperatures (Fig. 6), which would slow down the ozone destroying chemistry, and overestimated tropospheric ozone. In addition, SOCOLv4 so far does not include iodine chemistry, while some recent studies suggested that it can be responsible for $\sim 30 \%$ of the halogen-induced ozone loss in the lowermost stratosphere (e.g., Koenig et al., 2020).

In the upper stratosphere at midlatitudes, SOCOLv4 underestimates ozone by up to $-20 \%$. This feature has been present in SOCOL models since the first version (Egorova et al., 2005) and is related to the transport issues, caused by the insufficient vertical resolution affecting the wave propagation and breaking in the stratosphere/mesosphere. Though SOCOLv4 now has 47 vertical levels compared to 39 in previous versions, all additional levels are located in the troposphere, while the number of levels in the middle atmosphere remains almost the same. As was discussed earlier, SOCOLv4 and its atmospheric base (ECHAM6) show stronger residual circulation that causes stronger vertical transport in the tropics and also stronger meridional and downward transport in the winter hemisphere. The increased BDC, however, also implies a stronger wave forcing for the polar vortex making it weaker and blurring the midlatitude transport barriers (Butchart, 2014). An associated increase of stirring, which dominates over the horizontal transport by the meridional circulation in these conditions (Plumb, 2007), would then lead to a decrease in the meridional gradient of tracers. As depicted in Fig. 6, the modeled polar vortex strength in both hemispheres is notably underestimated in the uppermost stratosphere and the lower mesosphere.

Figure 13 shows that the midlatitude ozone underestimation at $1 \mathrm{hPa}$ appears in the winter months and that it happens together with an underestimation in the polar-most latitudes due to the more intense downward transport from the mesosphere. These results are consistent with those seen from the analysis of methane. Part of the model biases here could be related to the $30 \% \mathrm{NO}_{y}$ overestimation (Fig. 11) that would intensify the ozone destruction. In the lower levels (10 and $70 \mathrm{hPa}$ ), the model shows a generally good agreement with GOZCARDS, with some deviations in timing and magnitude of extremes that can also be partly attributed to the deficiencies in transport. Thus, a too-deep ozone drop at $10 \mathrm{hPa}$ in the southern polar vortex is consistent with the too-low methane values under these conditions and can be explained by the insufficient mixing. Seasonality of the tropical values at all latitudes agrees very well with observations, showing a decrease of ozone in the lower stratosphere during boreal winter and a pronounced semi-annual oscillation in the middle and upper stratosphere.

Although the observations are very uncertain in the polar night regions, both the ozone mixing ratio (Fig. 13) and the total ozone measurements (Fig. 14) suggest that in SOCOLv4 the size and intensity of the Antarctic ozone hole is overestimated. This can be related to either a too-strong vortex isolation, as discussed before, or to problems in the polar heterogeneous chemistry. Since the low bias is also apparent in the higher levels, another potential reason could be the poleward dislocation of the southern polar night jet in the upper and middle stratosphere (Fig. 6), which would imply less upper stratospheric ozone production inside the vortex (McConnel and Jin, 2008) and thus less ozone available for the downward transport. The downward transport itself might also be biased high, as illustrated by small negative anomalies of $\mathrm{N}_{2} \mathrm{O}$ and $\mathrm{CH}_{4}$ in Fig. 8, which would negatively contribute to ozone by bringing too much chlorine from above.

A comparison of SOCOLv4 ozone to the prescribed CMIP6 ozone used by MPI-ESM (Fig. A3) is useful for understanding the differences in temperature and winds be- 
tween SOCOLv4 and MPI-ESM in Fig. A1. The comparison shows that SOCOLv4 has slightly more ozone in the tropical and subtropical upper stratosphere but less ozone in the wintertime high latitudes. SOCOLv4 also has higher ozone in the mesosphere (up to $70 \%$ ) and in the troposphere (up to $20 \%$ ). Upper and mid-stratospheric differences in ozone contribute to a slightly stronger meridional temperature gradient due to less heating in the high latitudes and more heating in the tropics. This makes the polar vortices, which are too weak in MPI-ESM, slightly stronger in SOCOLv4. It is the most pronounced for the $\mathrm{SH}$ polar vortex, which is weaker than in observations throughout the whole stratosphere in MPIESM (Fig. A3d), while in SOCOLv4 (Fig. 6f) the negative anomaly vanished in the middle stratosphere.

\subsubsection{Total ozone climatology}

Total ozone column (TOC) represents an aggregate of all features and model biases discussed above, as well as their compensating effects. Figures 14 and 15 show that SOCOLv4 has a very good representation of tropical and subtropical TOC compared to MSRv2 and SBUV data, which is consistent with the results of Figs. 12 and 13. The model accurately simulates both the seasonal cycle (Fig. 14) and the annual mean climatologies (Fig. 15). Mostly due to the corrected photolysis rates, SOCOLv4's TOC is about 20 DU lower in the tropics and subtropics than in the previous model version, which results in better agreement with observations. Compared to MSRv2 data, SOCOLv4 shows almost perfect annual mean TOC in the tropics with some regional biases on the order of \pm 10 DU (see also Fig. A4 for TOC anomalies). Midlatitudes are also generally well captured, with the most pronounced overestimation of up to $30 \mathrm{DU}$ being the spring seasons in the Northern Hemisphere. Note also the \pm 10 DU disagreement between SBUV and MSRv2 in the midlatitudes.

Major model bias appears in the polar latitudes under wintertime conditions. It has to be mentioned that the polar night observations are subject to substantial uncertainties. SBUV data give no information for the polar night conditions at all, while MSRv2 provides almost full spatial and temporal coverage by assimilating a large variety of data including the ground-based observations into a chemistry-transport model (Van der A et al., 2015a). This model, however, exploits a simplified scheme of stratospheric chemistry by Cariolle and Teyssèdre (2007) that tends to overestimate TOC under the ozone hole conditions by about 20 DU. However, taking this uncertainty into account while also using the direct satellite information by SBUV and GOZCARDS (Fig. 12) at the edge of the polar vortices, SOCOLv4 still shows some pronounced biases. Namely, the polar ozone depletion in the SH starts right after the vortex formation (Fig. 14a), while the observations and the current state of knowledge suggests that it starts later under the springtime conditions (Fig. 14c). This feature is fully inherited from the previous model version (Fig. 14b) and needs further detailed investigation. Likely reasons, as discussed earlier, could be related to the transport issues, the details of polar heterogeneous chemistry, or also the treatment of photolysis under high solar zenith angles. In the Northern Hemisphere, Figs. 6 and 7 suggest a clear underestimation of the NH vortex strength in the model, which can explain the difference with respect to observations. The observations suggest some local ozone decrease in the middle of the winter, which is then followed by a fast increase in the springtime caused by inflow from the midlatitudes. The vortex in the model is weaker, meaning that polar air masses are less isolated and can get enriched with ozone from midlatitudes throughout the wintertime, and therefore the modeled field shows a more gradual increase instead of an abrupt rise. This stronger mixing of polar vortex air is also responsible for the $\mathrm{NH}$ results in Fig. 15, where the model correctly reproduces the shape of the high ozone values but also shows some overestimation in the modeled annual mean total ozone.

\subsubsection{Ozone evolution}

The upper panel of Fig. 16 shows the evolution of the total ozone column (TOC). Near-global TOC was calculated for this comparison, because SBUV has no data over polar night regions, and the reliability of MSRv2 there is also low. SOCOLv3 and SOCOLv4 are presented as three separate ensemble members to illustrate the uncertainty due to the internal variability. SOCOLv3 data are taken from the RefC1 runs of CCMI-1, which assume prescribed historical sea surface temperatures and sea ice coverage. Using prescribed sea surface temperatures (SSTs) in v3 explains why the variability among ensemble members is smaller in v3 than in v4, where the ocean is now interactive, and the ENSO variability is stochastic rather than fixed (Fig. 4). It is clearly seen that SOCOLv3 has a large overestimation in TOC compared to other time series. As was discussed above, this is mostly related to the problems in the photolysis scheme that are now manually corrected. SOCOLv4 and MSRv2 agree well in terms of the mean values, while the mean TOC from SBUV is lower by about 5-7 DU with respect to MSRv2. Generally, the slight overestimation of global TOC is also seen in many CMIP6 models, and SOCOL is well within the spread across CMIP6 models (Keeble et al., 2021, see their Fig. 6a). The CMIP6 ozone composite, instead, shows slightly lower TOC than SOCOLv4 and MSRv2 in Fig. 16a.

For easier comparison of the TOC variability, we also show anomalies in Fig. 16b. The four decades shown are characterized by contributions from anthropogenic and natural forcings with varying importance during different periods. From 1980 to the mid-1990s, there is a strong hODSinduced ozone decline. This negative tendency is further enhanced by the two strong volcanic eruptions of El Chichón in 1982 and Pinatubo in 1991, which are then followed by several years of recovery. Since the mid-1990s, following a recovery after Pinatubo, ozone starts to increase further, in- 

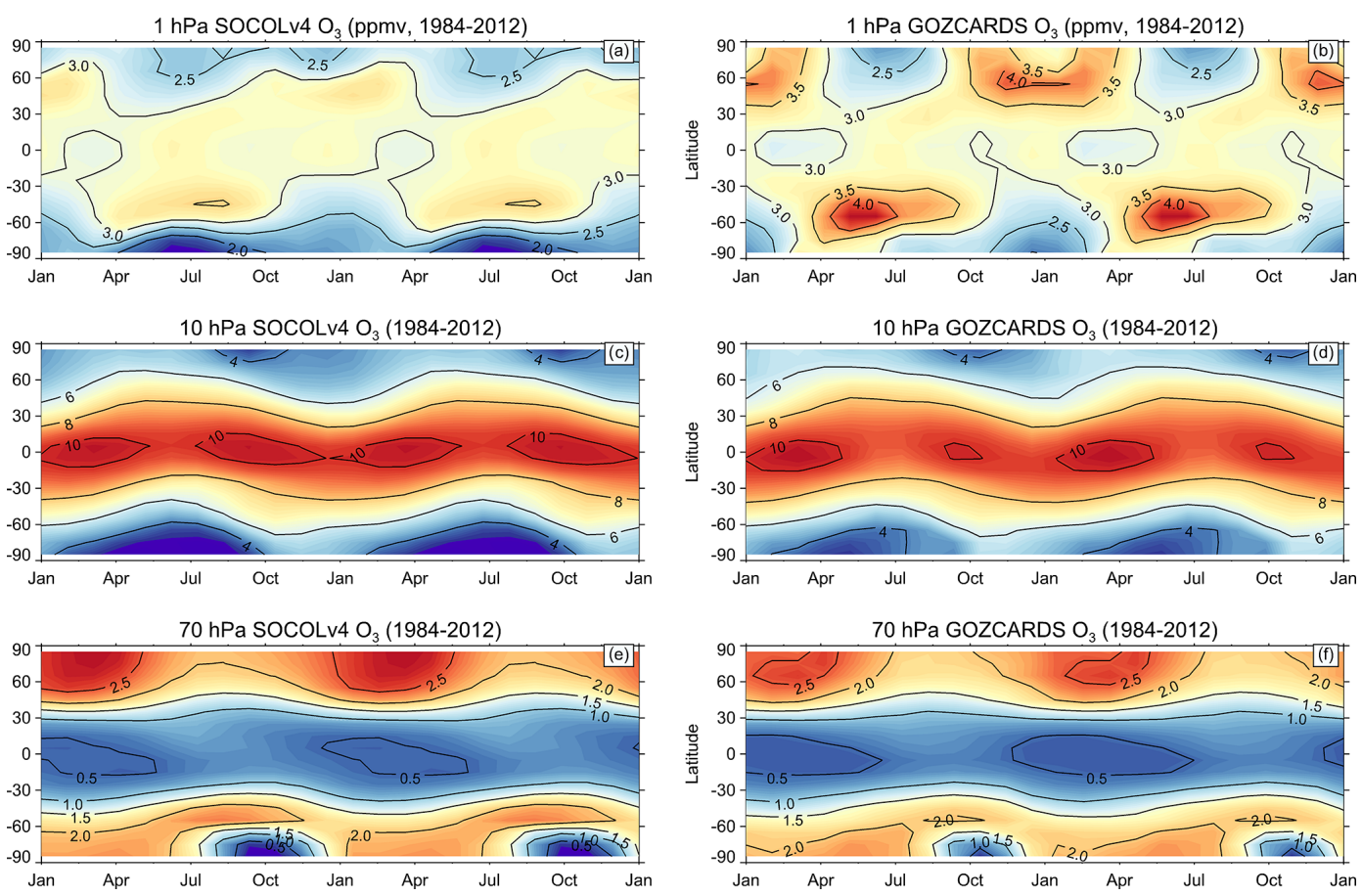

Figure 13. The 1, 10, and $70 \mathrm{hPa}$ ozone zonal mean seasonal cycles (ppmv). First column: SOCOLv4 data. Second column: GOZCARDS observational data. Two consecutive cycles are shown.
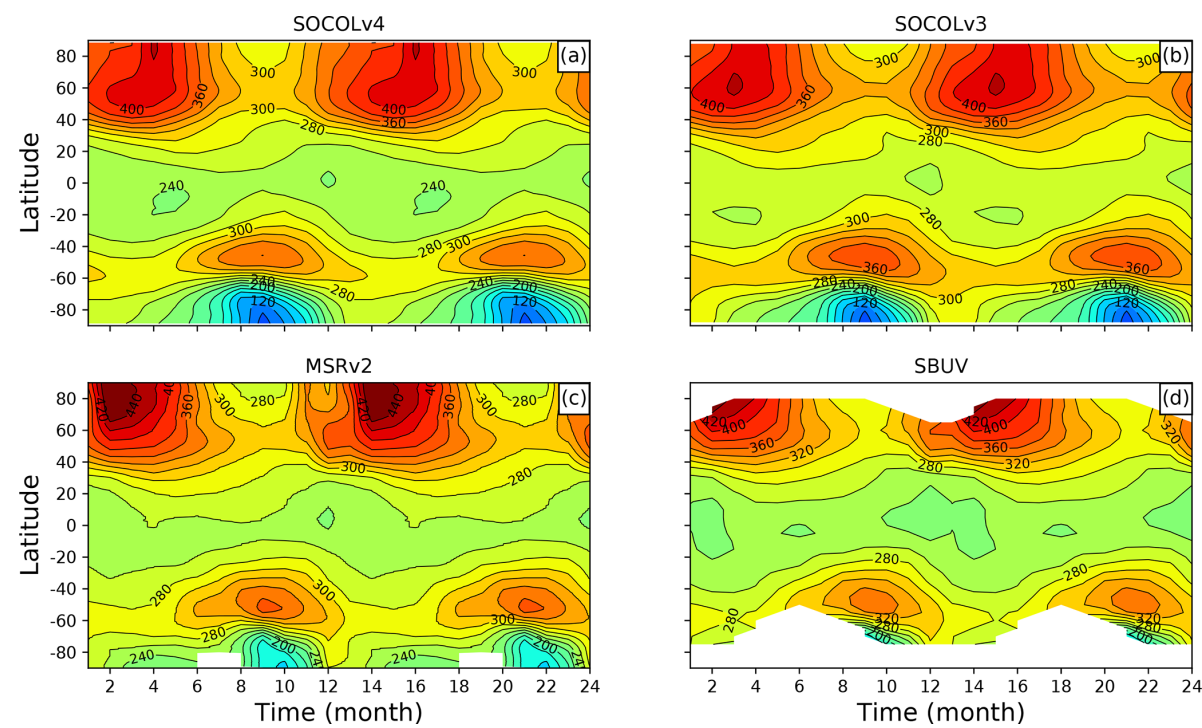

Figure 14. Seasonal cycle of total ozone simulated by SOCOLv4 (a) against SOCOLv3 (b), MSRv2 (c), and SBUV observations (d) averaged for the 1980-2014 period.

duced by the leveling-out of the hODS emissions as a consequence of the Montreal Protocol (Egorova et al., 2013; Chipperfield et al., 2015). Since the 2000s, there have been no major eruptions, and the ozone evolution is mostly determined by the decreasing halogen load and the global warming effects, though there are still many related uncertainties and other important factors in specific regions, especially in the lower stratosphere (Ball et al., 2018; Stone et al., 2018). Upper stratospheric ozone was shown to have the most pronounced recovery (Petropavlovskikh et al., 2019; Chipperfield et al., 2018) due to being the most sensitive to the chlorine catalytic cycle of ozone destruction. Furthermore, decreasing stratospheric temperatures also led to some deceleration of ozone destruction cycles. The contribution of 

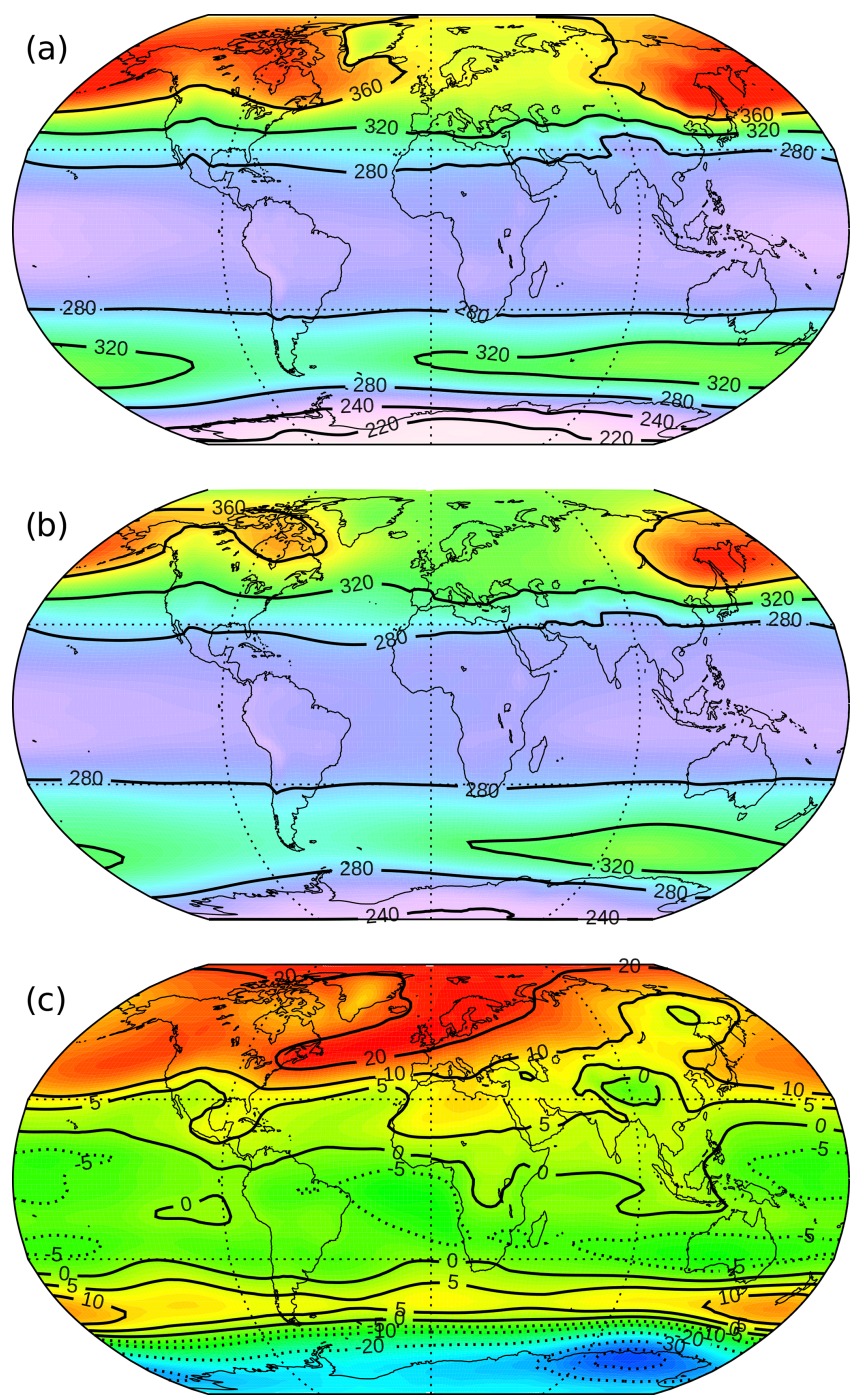

Figure 15. Global distribution of annual mean total ozone for 19802018 as (a) simulated by SOCOLv4 and (b) from the MSRv2 data record in DU. (c) Difference of panels (a)-(b) in DU with contour lines $-40,-30,-20,-10,-5,0,5,10,20,30 \mathrm{DU}$.

these positive changes to the total column is partly supplemented by an increase of the tropospheric column ozone at a rate of about $6 \%-7 \%$ per decade resulting from the continuous increase of the surface anthropogenic emissions of ozone precursors like $\mathrm{CH}_{4}, \mathrm{CO}, \mathrm{NO}_{x}$, and VOC (Ball et al., 2018). The recovery in the middle and lower stratosphere in the tropical and extratropical areas is still unclear and observations even suggest negative trends in the lowermost stratosphere, which are, however, barely significant due to a large dynamical variability of this region (Ball et al. 2018; 2019; Petropavlovskikh et al., 2019). There are indications that these negative trends are dynamically driven (Orbe et al, 2020) and can be related to acceleration of the BDC due to rising GHGs; however, models mostly fail to reproduce the observations in detail (Ball et al., 2020).
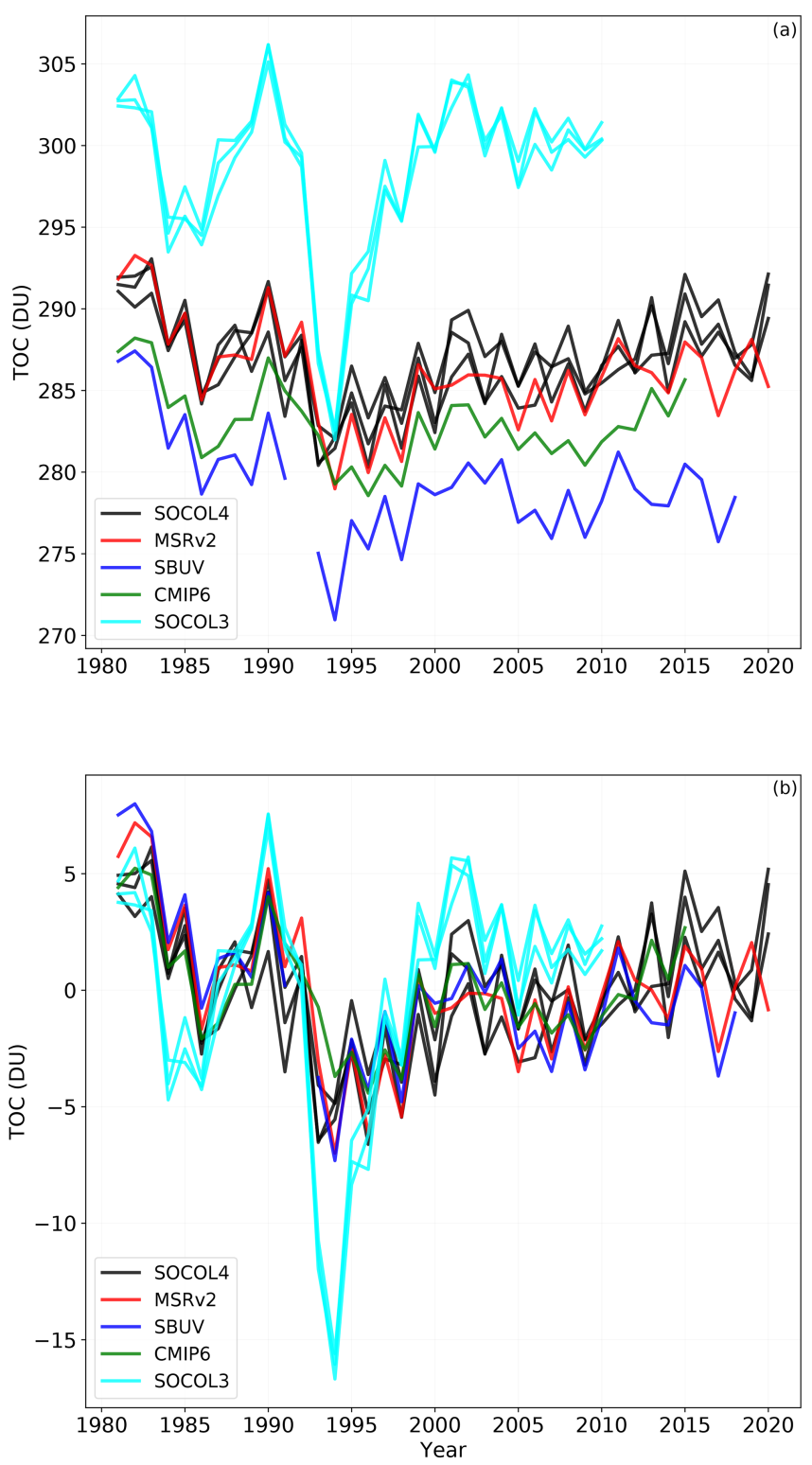

Figure 16. (a) Near-global $\left(55^{\circ} \mathrm{S}-55^{\circ} \mathrm{N}\right)$ mean ozone evolution simulated with SOCOLv4 (black), MSR2 (red), SBUV (dark blue), SOCOLv3 (light blue), and CMIP6 (green). (b) The same but anomalies with respect to the mean over the whole period.

In Fig. 16b, we show that SOCOLv3 had a reasonable TOC evolution under volcanically quiescent conditions, while the volcanic effects were strongly overestimated. Unlike SOCOLv4, which uses an interactive sulfate aerosol scheme, SOCOLv3 used prescribed fields recommended for CCMI that seem to be biased, probably because of the uncertain observations and also the assumptions made during the calculation of aerosol mass from extinction observations. The interactive aerosol scheme clearly improves the performance of SOCOLv4 in terms of volcanic effects on ozone. Sukhodolov et al. (2018) showed though that the observed 
hemispheric asymmetry of volcanic signals in ozone are still difficult to properly reproduce with a free-running model. Overall, the general behavior of the TOC evolution is very well captured by the new model both in terms of the mean values of the near-global field and the variability.

In Fig. 16, we looked into some drivers of the total column evolution. Depletion and further recovery of ozone in the middle stratosphere are well captured by the model (Fig. 17a) due to the good representation of changes in stratospheric chlorine (Fig. 17e) and the continuous cooling of the stratosphere (Fig. 17b). The lower stratospheric $(60 \mathrm{hPa})$ temperature and ozone observations show a much larger uncertainty but still somewhat pronounced negative trends that are also well captured by the model. A thorough analysis of lower stratospheric processes requires comprehensive statistical tools, and a set of sensitivity runs, which is already planned for future model applications.

\subsubsection{Stratospheric sulfur}

Figure 18 shows the total stratospheric sulfur load as well as the zonal mean stratospheric column of liquid $\mathrm{H}_{2} \mathrm{SO}_{4}$ for SOCOLv4 against CMIP6, MIPAS, and HIRS. The tropopause that was applied to calculate the stratospheric burden for the CMIP6 and MIPAS datasets was calculated from the ERAInterim temperature data using the WMO definition of the tropopause as the lowest level at which the temperature decreases less than $2 \mathrm{~K} \mathrm{~km}^{-1}$, while for SOCOLv4 the modeled tropopause is used. The peaks in aerosol originate from volcanic eruptions with the largest being the El Chichón (1982) and Pinatubo (1991) eruptions in the earlier time period and Kasatochi (2008), Sarychev (2009), Nabro (2011), and Calbuco (2015), as well as some others in the more recent past.

Generally, the aerosol evolution in the stratosphere is depicted quite well by the model in terms of the total aerosol amount, lifetime, and meridional transport. There are, however, a few differences that need to be addressed. Prior to and after the 1982 El Chichón eruption, there are some significant discrepancies between SOCOLv4 and CMIP6. In addition, the peak of stratospheric burden caused by this eruption (see Fig. 18a) is slightly shifted in time in comparison to the SOCOLv4 simulations. In Fig. 18c, the delayed peak of CMIP6 is seen mostly in the Northern Hemisphere and the tropical aerosol levels, where the eruption took place, are lower than in SOCOLv4. The El Chichón eruption occurred between the activities of the Stratospheric Aerosol and Gas Experiment (SAGE) and SAGE II. Data from this time are a composite of Stratospheric Aerosol Measurement II (SAM II) data in the extratropics, as well as several airborne lidar missions at low latitudes, which delivered data often many months apart, leading to very sparse data coverage. The gaps were then filled by means of interpolation (Thomason et al., 2018). It is, therefore, difficult to make a conclusive statement on the SOCOLv4 performance of this time due to large uncertainties in observations. The next larger event, Nevado
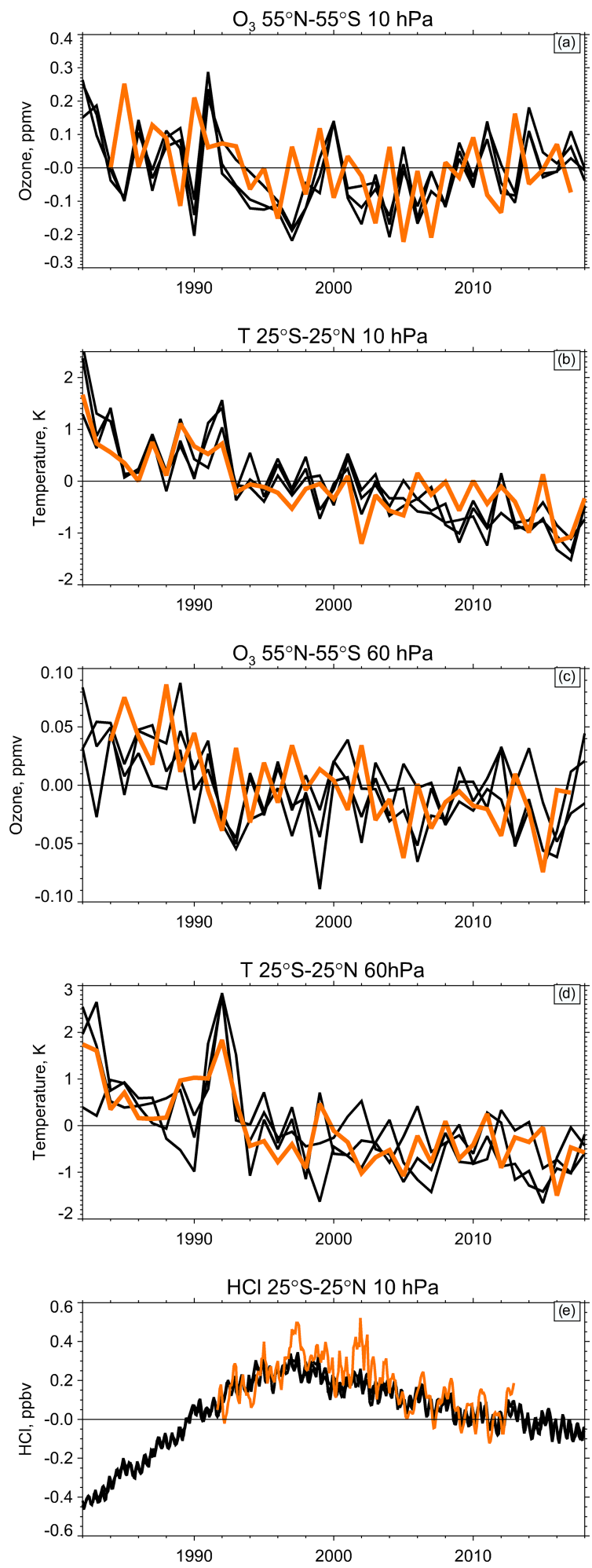

Figure 17. (a, c) Near-global $\left(55^{\circ} \mathrm{S}-55^{\circ} \mathrm{N}\right)$ annual mean ozone evolution at 60 and $10 \mathrm{hPa}$ compared to the BASIC composite. (b, d) Tropical annual mean evolution of temperature at 60 and $10 \mathrm{hPa}$ compared to ERA5. (e) Tropical monthly mean (smoothed with the 3-month running mean) evolution of $\mathrm{HCl}$ at $10 \mathrm{hPa}$ compared to the GOZCARDS composite. Black lines: three model ensemble members. Orange lines: observations. 

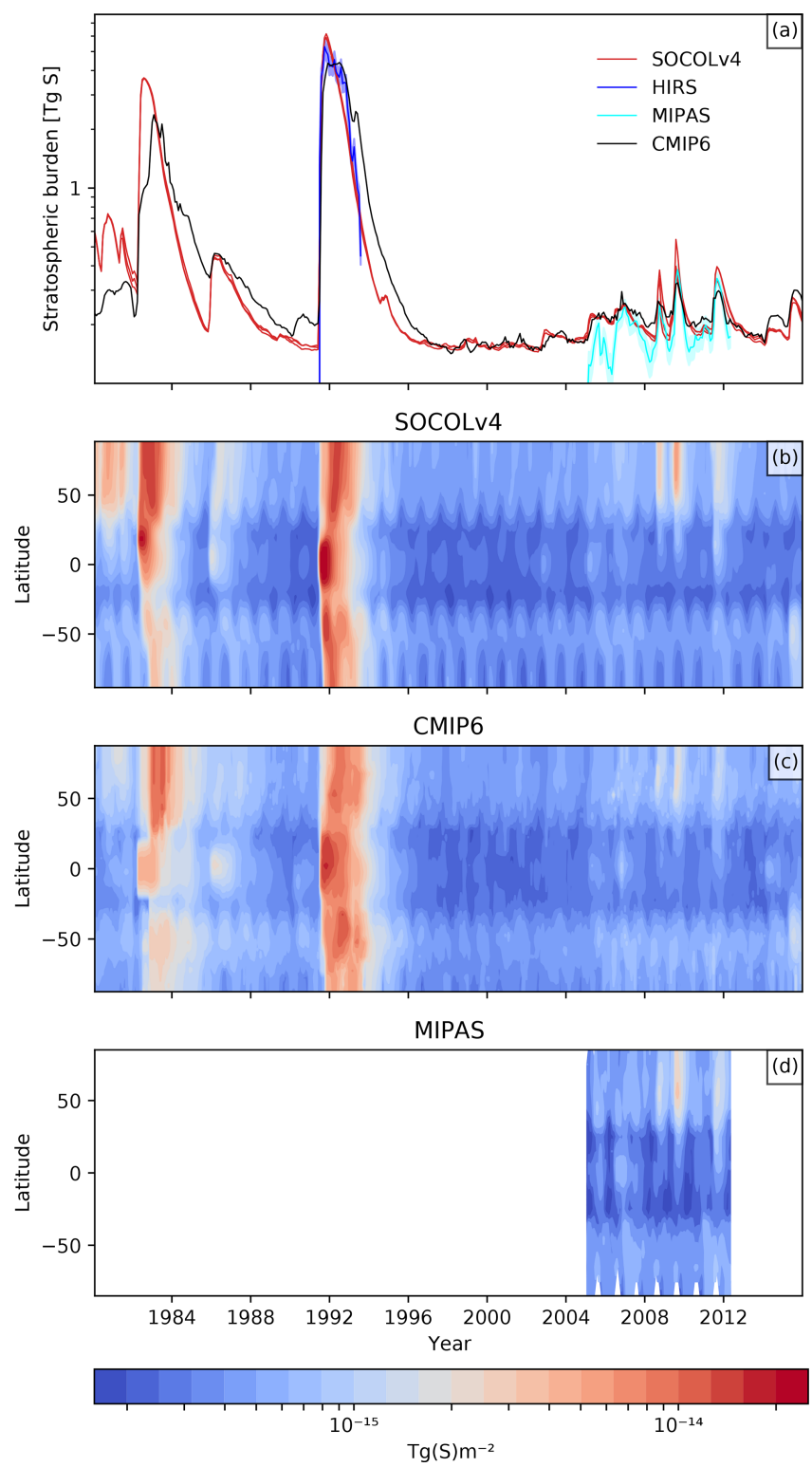

Figure 18. Global total stratospheric sulfur mass in sulfate aerosols (a) and its zonal mean values (b-d) simulated with SOCOLv4 against HIRS, CMIP6, and MIPAS. Data are plotted in a logarithmic scale so that both large and small eruptions can be distinguished.

del Ruiz in 1985, already occurred during the SAGE II era, which is deemed more reliable by Thomason et al. (2018).

The 1991 Mt. Pinatubo eruption has been discussed several times, since observations show a plateaued value for several months after the eruption instead of a more distinct peak as models like SOCOLv4 suggest (e.g., Dhomse et al., 2020). Something similar has not been observed since then. However, no other well-observed eruption was the size of the 1991 Mt. Pinatubo one. A source for measurement artifacts during this time is the increase in opacity of the atmosphere due to large amounts of aerosol resulting from the eruption. From the modeling side, a potential deficiency could be insufficient vertical resolution of the stratosphere leading to increased vertical diffusion and faster meridional transport of aerosols. Niemeier and Schmidt (2017) used a model with a similar dynamical core, ECHAM-HAM, with 39 and 90 vertical levels. They showed that the version with a higher vertical resolution maintains aerosols longer in the tropical reservoir, which increases their lifetime after low-latitude emission events. The post-plateau $e$-folding time looks very similar for CMIP6 and SOCOLv4, but in the CMIP6 data there is another small increase after the main Mt. Pinatubo plateau without there having been any other major eruptions. Again, this could be due to a change in the instruments used for the construction of this dataset.

The volcanically quiescent period in the late 1990s and early 2000s and the minor volcanic activity later, which is also better covered by observations, are well reproduced by the model. MIPAS observations are added here, as they are not included in the CMIP6 composite and thus represent an independent source of information. MIPAS and CMIP6 agree with each other quite well in terms of elevated values after eruptions, while the background level is slightly lower in MIPAS. Background levels in SOCOLv4 are located between CMIP6 and MIPAS and there is some spread over the ensemble members, which is caused by the variable tropopause in the model combined with vertically prescribed $\mathrm{SO}_{2}$ emission profiles. The model also captures the zonal mean distribution of elevated aerosol values, reproducing some equatorward transport after high-latitude eruptions of Kasatochi, Sarychev, and Calbuco, as well as dominant northward transport after the equatorial eruption of Nabro. It should be noted that our modeling results here are largely defined by the emission database that we used (Carn et al., 2016). Other volcanic emission databases report quite different estimates for each volcanic event, both in terms of emitted amount of $\mathrm{SO}_{2}$ and its vertical distribution (Timmreck et al., 2018).

Overall, we can conclude that SOCOLv4 nicely reproduces background aerosol levels and minor volcanic activity compared to observations, while potentially underestimating the aerosol lifetime after major eruptions of El Chichón, Nevado del Ruiz, and Pinatubo. The latter can be attributed to a number of factors. As mentioned above, the data from earlier periods are less reliable and had a lower temporal coverage (Thomason et al., 2018), which influences the forcing data used in the model, as well as the observational composites for its validation. Furthermore, the physical processes influencing aerosol concentrations after these larger eruptions differ from the smaller but better observed ones that happened more recently. Since more $\mathrm{SO}_{2}$ is injected into the stratosphere at once in a larger event, $\mathrm{OH}$ radicals are depleted more quickly, which can cause a delay in sulfate aerosol formation. Nevertheless, all $\mathrm{SO}_{2}$ is eventually (in 2-3 months' time) converted to sulfate aerosol and in higher concentrations the particles will collide and grow in size. These 
larger aerosols are subjected more to the force of gravity and more easily sediment to the troposphere (Timmreck et al., 2009), while the long-term decay of aerosols after smaller eruptions is more controlled by the BDC transport (Günther et al., 2018). Given that all major eruptions were tropical, a bias in vertical numerical diffusion due to insufficient vertical resolution could further intensify the sedimentation to the lower stratosphere and the troposphere and also reduce the confinement of aerosols in the tropical reservoir via increased leakage through the shallow branch of the BDC.

\section{Conclusions and outlook}

This paper presents the fourth generation of the coupled chemistry-climate model SOCOL. Unlike its predecessor chemistry-climate model SOCOLv3, SOCOLv4 includes both an interactive ocean and the sulfate aerosol module, which significantly broadens the range of potential model applications. The underlying general circulation model has also been updated from ECHAM5 to ECHAM6. Our validation of the new model showed that it performs very well in terms of the mean state of most variables and the largescale variability of the system. Namely, the warming trends in the troposphere, the cooling trends in the stratosphere, and variability of the stratospheric and the total column ozone agree very well with observations. In the stratosphere, SOCOLv4 shows very good results for the low- and midlatitude ozone and reasonably well reproduces climatologies of other trace gases. Compared to SOCOLv3, the new version of the model now performs significantly better both in terms of absolute values and variability of ozone, which is mostly due to corrections in the photolysis scheme and the inclusion of interactive stratospheric aerosol scheme.

However, as in the previous version, there are still some issues. Stratospheric polar night jets are weaker in the model throughout the whole stratosphere in the NH and in the upper SH stratosphere in comparison to the reanalysis data. Accordingly, the advective Brewer-Dobson circulation and horizontal diffusion are also biased and too strong. All this affects the transport and distribution of tracers, introducing biases in $\mathrm{CH}_{4}, \mathrm{~N}_{2} \mathrm{O}$, ozone, and related species. Photochemistry itself also suffers from the outdated photolysis lookuptable scheme, which needs to be replaced either by a lookup table that also considers temperature dependence or by an online radiative-transfer scheme. Furthermore, photolysis parameterizations of the shortwave UV need to be reviewed and updated, as we identified clear biases in the mesospheric budget of odd nitrogen, hydrogen, and oxygen. SOCOLv4 still underestimates polar winter and spring ozone in the $\mathrm{SH}$, which needs further detailed investigation. Performance of the sulfate aerosol scheme is very good for the smaller eruptions and background conditions, but the duration of volcanic peaks after major events is likely underestimated. An increase of the vertical resolution to 95 levels could be a po- tential source for major improvements, especially for stratospheric circulation and transport. However, it would at least double the computational needs, which might be too expensive for long-term experiments, given the number of tracers in the model. Marine emissions of species are currently prescribed in the model, but the interactive ocean and marine biogeochemistry modules now allow either to directly couple some emissions or to parameterize them as a function of other parameters. Inclusion of iodine chemistry is being currently tested and will also contribute to future updates.

Nevertheless, we showed that the model version documented here is already in a good condition to be used as a tool for studying interactions between the Earth system components. The presence of the interactive ocean and a successful representation of recent climate and ozone layer trends provide a strong case for this model to be applied for studies looking at future evolution and effects of greenhouse gases and ozone-destroying substances, as well as potential geoengineering measures through sulfur injections. SOCOLv4 will also be used in the upcoming model intercomparison project CCMI phase 2. 


\section{Appendix A}
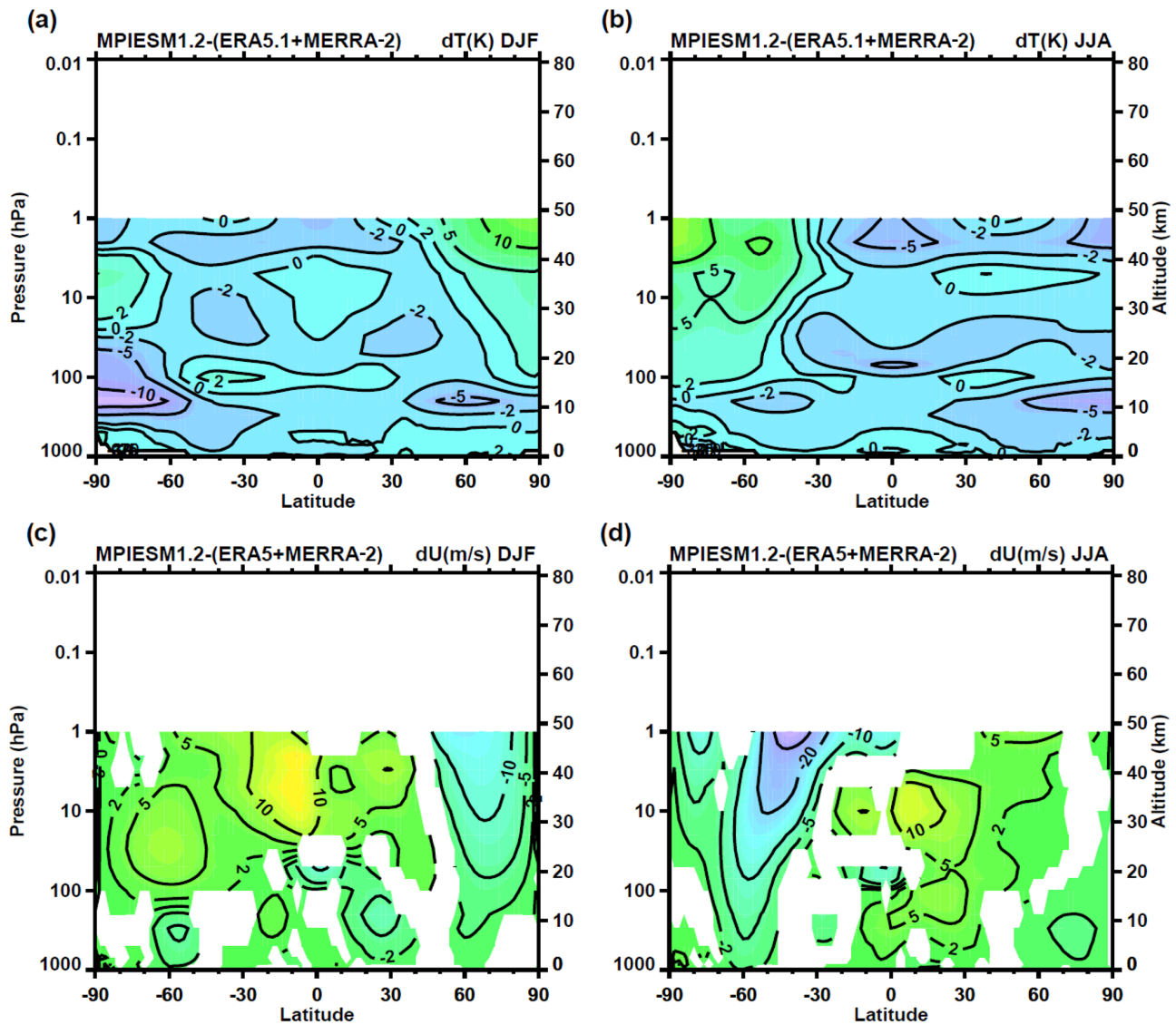

Figure A1. Zonal mean climatology differences between data simulated by MPI-ESM and the reanalysis data for temperature (a-b) and zonal wind (c-d). White areas denote regions where the difference between model and reanalysis data is not statistically significant at the $95 \%$ confidence level calculated with a Student's $t$ test. 

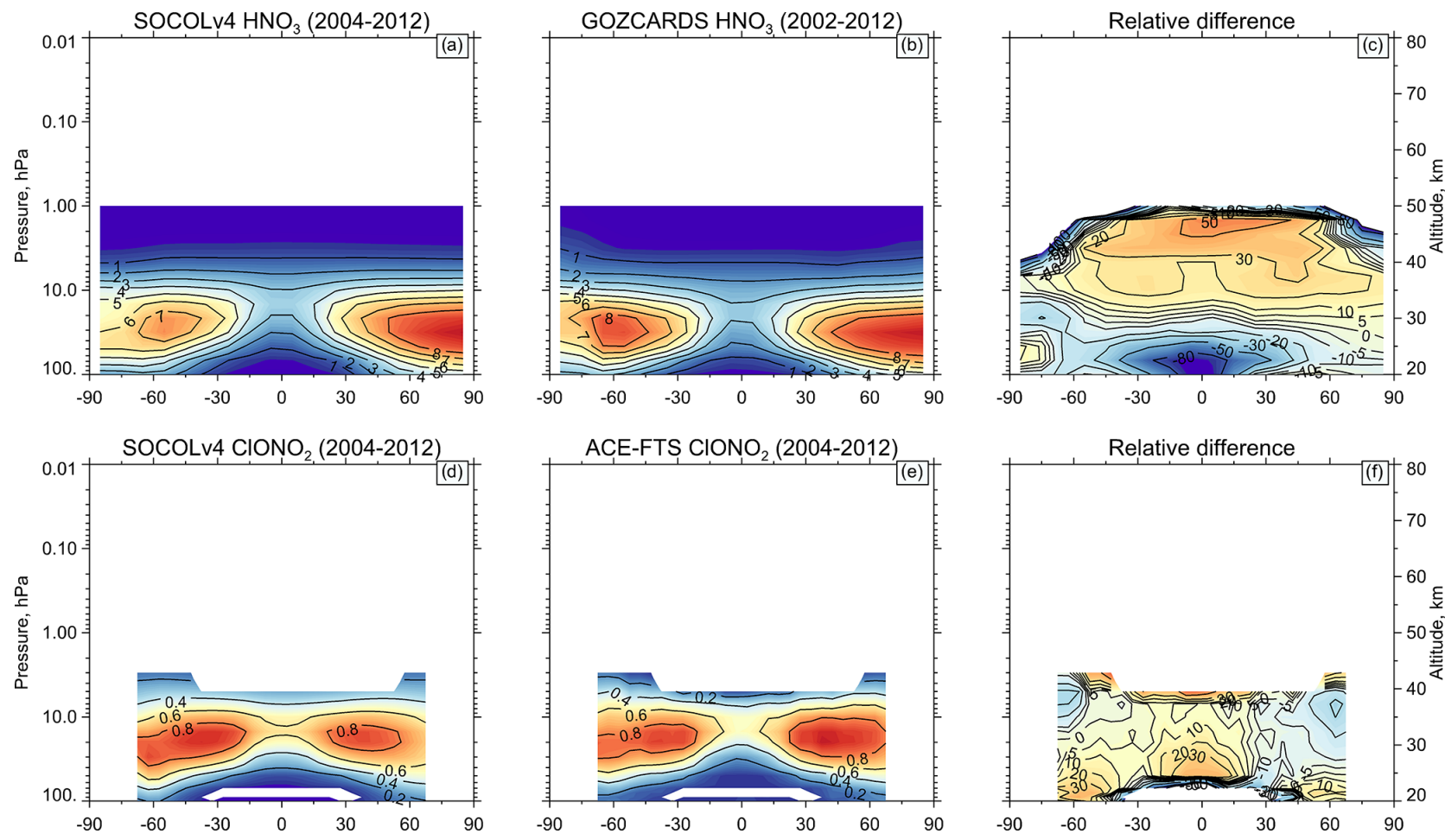

Figure A2. $\mathrm{HNO}_{3}$ and $\mathrm{ClONO}_{2}$ zonal mean annual mean climatologies (ppbv). (a, d) SOCOLv4 data. (b, e) ACE-FTS and GOZCARDS observational data. (c, f) Relative difference between the model and observations in \%. An observational missing data mask is applied to the model data. Note that different species have different averaged periods.
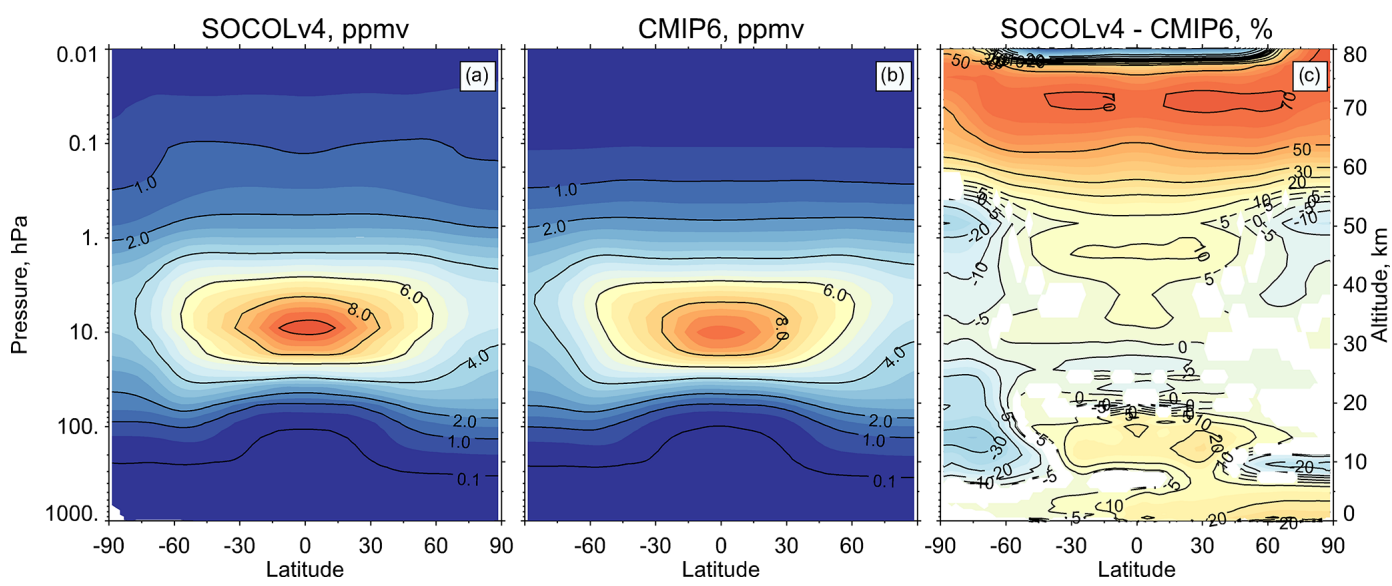

Figure A3. Ozone zonal and annual mean climatology (1985-2012) calculated by (a) the SOCOLv4 model (ppmv) and (b) provided by the CMIP6 modeling composite. The relative differences between SOCOLv4 and CMIP6 are shown in panel (c). White areas are either missing data or regions where the difference between model and observations is not statistically significant at the $95 \%$ confidence level. 

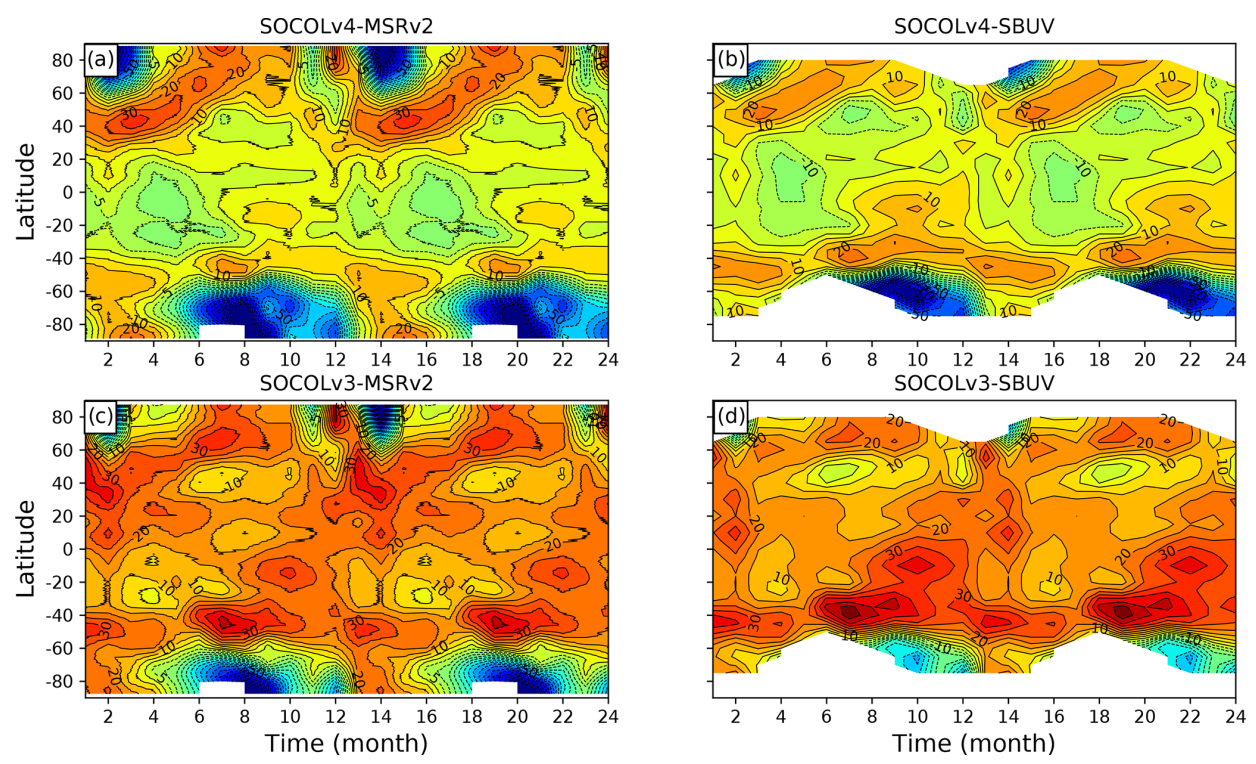

Figure A4. Mean seasonal cycle differences between the total ozone column simulated by SOCOLv4 and SOCOLv3 and estimated by MSRv2 reanalysis and SBUV observations. 
Code and data availability. The SOCOLv4.0 code can be downloaded from https://doi.org/10.5281/zenodo.4570622 (Sukhodolov et al., 2021), and the simulation data used in this study are available at https://doi.org/10.5281/zenodo.5148741 (Sukhodolov, 2021). In the event of problems, please contact the corresponding author. ERA5 data are available on the Copernicus Climate Change Service (C3S) Climate Data Store (https://doi.org/10.24381/cds.6860a573, Hersbach et al., 2019). MERRA-2 data are available at MDISC, managed by the NASA Goddard Earth Sciences (GES) Data and Information Services Center (DISC) (https://doi.org/10.5067/QBZ6MG944HW0, GMAO, 2015). The Berkeley Earth Surface temperature data are available at https://doi.org/10.5281/zenodo.3634712 (Rohde and Hausfather, 2019). GOZCARDS data can be found here: https://gozcards.jpl.nasa.gov/info.php (Froidevaux et al., 2015). The latest BASIC ozone composite data are available at https://doi.org/10.17632/2mgx2xzzpk.3 (Alsing and Ball, 2019). The ACE-FTS data can be found at http://www.ace.uwaterloo.ca/climatology/3.5/netcdf/ (Koo et al., 2017). The GloSSAC data v1.1 prepared for CMIP6 are available at ftp://iacftp.ethz.ch/pub_read/luo/CMIP6_SAD_radForcing_v4.0.0/ (Thomason et al., 2018). MSRv2 data can be downloaded from https://doi.org/10.21944/temis-ozone-msr2 (Van der A et al., 2015b). The SBUVv8.6 merged ozone dataset can be found at https: //acd-ext.gsfc.nasa.gov/Data_services/merged/instruments.html (McPeters et al., 2013). The CMIP6 ozone composite is accessible via the input4MIPs data server.

Author contributions. TS conducted the simulations, analyzed the data, and drafted most of the paper. TE, AKD, and CB drafted parts of the paper. TS, AS, AF, and ER led the model development work. All authors strongly participated in the model development, discussions about the results, and paper text corrections.

Competing interests. The authors declare that they have no conflict of interest.

Disclaimer. Publisher's note: Copernicus Publications remains neutral with regard to jurisdictional claims in published maps and institutional affiliations.

Acknowledgements. All calculations with the atmosphere-oceanaerosol-chemistry-climate model SOCOLv4.0 were supported by a grant from the Swiss National Supercomputing Centre (CSCS) under projects S-901 (ID 154), S-1029 (ID 249), and S-903. Part of the model development was performed on the ETH Zürich cluster EULER. We thank the Center for Climate Systems Modeling (C2SM) at ETH Zurich, the Max Planck Institute for Meteorology in Hamburg, Germany, and personally Sylvaine Ferrachat (ETH), Urs Beyerle (ETH), and Sebastian Rast (MPI) for technical support related to hosting and development of the model code. We also thank Bei-Ping Luo (ETH) for providing the Mie theory lookup table and Bernd Funke (CSIC) and Michael Höpfner (KIT) for providing the MIPAS data for $\mathrm{NO}_{y}$ and sulfate aerosol mass, respectively. The work of Eugene Rozanov and Timofei Sukhodolov on the satellite data was performed in the SPbSU "Ozone Layer and Upper Atmosphere Research" laboratory supported by the Ministry of Science and Higher Education of the Russian Federation.

Financial support. This research has been supported by the Swiss National Science Foundation (SNSF) (VEC (grant no. 200021_169241), POLE (grant no. 200020-182239), Ambizione (grant no. PZ00P2-180043)), ETH (grant no. ETH-17 19-2), and the Ministry of Science and Higher Education of the Russian Federation (grant no. 075-15-2021-583).

Review statement. This paper was edited by Samuel Remy and reviewed by two anonymous referees.

\section{References}

Alsing, J. and Ball, W.: BASIC Composite Ozone Time-Series Data, V3, Mendeley Data [data set], https://doi.org/10.17632/2mgx2xzzpk.3, 2019.

Andres, R. J. and Kasgnoc, A.D.: A time-averaged inventory of subaerial volcanic sulfur emissions, J. Geophys. Res., 103, 2525125261, https://doi.org/10.1029/98JD02091, 1998.

Arsenovic, P., Rozanov, E., Anet, J., Stenke, A., Schmutz, W., and Peter, T.: Implications of potential future grand solar minimum for ozone layer and climate, Atmos. Chem. Phys., 18, 34693483, https://doi.org/10.5194/acp-18-3469-2018, 2018.

Ayers, G. P., Gillett, R. W., and Gras, J. L.: On the vapor pressure of sulfuric acid, Geophys. Res. Lett., 7, 433-436, https://doi.org/10.1029/GL007i006p00433, 1980.

Bacmeister, J. T., Phillips, A. S., Neale, R. B., Simpson, I. R., DuVivier, A. K., Hodzic, A., and Randel, W. J.: The whole atmosphere community climate model version 6 (WACCM6), J. Geophys. Res.-Atmos., 124, 12380-12403, https://doi.org/10.1029/2019JD030943, 2019.

Baran, A. J. and Foot, J. S.: New application of the operational sounder HIRS in determining a climatology of sulphuric acid aerosol from the Pinatubo eruption, J. Geophys. Res.-Atmos., 99, 25673-25679, https://doi.org/10.1029/94JD02044, 1994.

Ball, W. T., Alsing, J., Mortlock, D. J., Staehelin, J., Haigh, J. D., Peter, T., Tummon, F., Stübi, R., Stenke, A., Anderson, J., Bourassa, A., Davis, S. M., Degenstein, D., Frith, S., Froidevaux, L., Roth, C., Sofieva, V., Wang, R., Wild, J., Yu, P., Ziemke, J. R., and Rozanov, E. V.: Evidence for a continuous decline in lower stratospheric ozone offsetting ozone layer recovery, Atmos. Chem. Phys., 18, 1379-1394, https://doi.org/10.5194/acp18-1379-2018, 2018.

Ball, W. T., Alsing, J., Staehelin, J., Davis, S. M., Froidevaux, L., and Peter, T.: Stratospheric ozone trends for 1985-2018: sensitivity to recent large variability, Atmos. Chem. Phys., 19, 1273112748, https://doi.org/10.5194/acp-19-12731-2019, 2019.

Ball, W. T., Chiodo, G., Abalos, M., Alsing, J., and Stenke, A.: Inconsistencies between chemistry-climate models and observed lower stratospheric ozone trends since 1998, Atmos. Chem. Phys., 20, 9737-9752, https://doi.org/10.5194/acp-209737-2020, 2020. 
Bernath, P. F, McElroy, C. T., Abrams, M. C., Boone, C. D.,, Butler, M., Camy-Peyret, C., Carleer, M., Clerbaux, C., Coheur, P.-F., Colin, R., DeCola, P., DeMazière, M., Drummond, J. R., Dufour, D., Evans, W. F. J., Fast, H., Fussen, D., Gilbert, K., Jennings, D. E., Llewellyn, E. J., Lowe, R. P., Mahieu, E., McConnell, J. C., McHugh, M., McLeod, S. D., Michaud, R., Midwinter, C., Nassar, R., Nichitiu, F., Nowlan, C., Rinsland, C. P., Rochon, Y. J., Rowlands, N., Semeniuk, K., Simon, P., Skelton, R., Sloan, J. J., Soucy, M.-A., Strong, K., Tremblay, P., Turnbull, D. Walker, K. A., Walkty, I., Wardle, D. A., Wehrle, V., Zander, R., and Zou, J.: Atmospheric Chemistry Experiment (ACE): Mission overview, Geophys. Res. Lett., 32, L15S01, https://doi.org/10.1029/2005GL022386, 2005.

Biermann, U. M., Luo, B. P., and Peter, T.: Absorption spectra and optical constants of binary and ternary solutions of $\mathrm{H} 2 \mathrm{SO} 4, \mathrm{HNO}_{3}$, and $\mathrm{H} 2 \mathrm{O}$ in the mid infrared at atmospheric temperatures, J. Phys. Chem. A, 104, 783- 793, https://doi.org/10.1021/jp992349i, 2000.

Bock, L., Lauer, A., Schlund, M.,Barreiro, M., Bellouin, N., Jones, C., Meehl, G. A., Predoi, V., Roberts, M. J., and Eyring, V.: Quantifying progress across different CMIP phases with the ESMValTool, J. Geophys. Res.-Atmos., 125, e2019JD032321, https://doi.org/10.1029/2019JD032321, 2020.

Brinkop, S. and Roeckner, E.: Sensitivity of a general circulation model to parameterizations of cloud-turbulence interactions in the atmospheric boundary layer, Tellus A, 47, 197-220, https://doi.org/10.1034/j.1600-0870.1995.t01-1-00004.x, 1995.

Brovkin, V. Boysen, L. Raddatz, T. Gayler, V. Loew, A., and Claussen, M.: Evaluation of vegetation cover and land-surface albedo in MPI-ESM CMIP5 simulations, J. Adv. Model. Earth Syst., 5, 48- 57, https://doi.org/10.1029/2012MS000169, 2013.

Brönnimann, S., Jacques-Coper, M., Rozanov, E., Fischer, A.M., Morgenstern, O., Zeng, G., Akiyoshi, H., and Yamashita, Y.: Tropical circulation and precipitation response to ozone depletion and recovery, Environ. Res. Lett., 6, 064011, https://doi.org/10.1088/1748-9326/aa7416, 2017.

Bulgin, C. E., Merchant, C. J., and Ferreira, D.: Tendencies, variability and persistence of sea surface temperature anomalies, Sci. Rep., 10, 7986, https://doi.org/10.1038/s41598-020-647859, 2020.

Burkholder, J. B., Sander, S. P., Abbatt, J., Barker, J. R., Huie, R. E., Kolb, C. E., Kurylo, M. J., Orkin, V. L., Wilmouth, D. M., and Wine, P. H.: Chemical kinetics and photochemical data for use in atmospheric studies, Evaluation No. 18, JPL Publication 15-10, Jet Propul. Lab., Pasadena, California, available at: https: //jpldataeval.jpl.nasa.gov (last access: 2 September 2021), 2015.

Butchart, N.: The Brewer-Dobson circulation, Rev. Geophys.,52, 157-184, https://doi.org/10.1002/2013RG000448, 2014.

Engel, A., Rigby, M, Burkholder, J. B., Fernandez, R. P., Froidevaux, L., Hall, B. D., Hossaini, R., Saito, T., Vollmer, M. K., and Yao, B.: Update on Ozone-Depleting Substances (ODSs) and other gases of interest to the Montreal Protocol, Chapter 1 in Scientific Assessment of Ozone Depletion: 2018, Global Ozone Research and Monitoring, Project-Report No. 58, World Meteorological Organization, Geneva, Switzerland, 2018.

Cariolle, D. and Teyssèdre, H.: A revised linear ozone photochemistry parameterization for use in transport and general circulation models: multi-annual simulations, Atmos. Chem. Phys., 7, 2183 2196, https://doi.org/10.5194/acp-7-2183-2007, 2007.
Carn, S., Clarisse, L., and Prata, A.: Multi-decadal satellite measurements of global volcanic degassing, J. Volcanol. Geotherm. Res., 311, 99-134, https://doi.org/10.1016/j.jvolgeores.2016.01.002, 2016.

Carslaw, K. S., Luo, B. P., and Peter, T.: An analytic-expression for the composition of aqueous $\mathrm{HNO}_{3}-\mathrm{H}_{2} \mathrm{SO}_{4}$ stratospheric aerosols including gas-phase removal of $\mathrm{HNO}_{3}$, Geophys. Res. Lett., 22, 1877-1880, 1995.

Checa-Garcia, R.: CMIP6 Ozone forcing dataset: supporting information, Zenodo, https://doi.org/10.5281/zenodo.1135127, 2018.

Chiodo, G., Polvani, L. M., Marsh, D. R., Ball, W., Muthers, S., Stenke, A., Rozanov, E., and Tsigaridis, K.: The ozone response to quadrupled $\mathrm{CO}_{2}$ concentrations, J. Climate, 31, 3893-3907, https://doi.org/10.1175/JCLI-D-17-0492.1, 2018.

Chipperfield, M. P., Dhomse, S. S., Feng, W., McKenzie, R. L., Velders, G. J. M., and Pyle, J. A.: Quantifying the ozone and ultraviolet benefits already achieved by the Montreal Protocol, Nat Commun., 6, 7233, https://doi.org/10.1038/ncomms8233, 2015.

Chipperfield, M., Bekki, S., Dhomse, S., Harris, N. R. P., Hassler, B., Hossaini, R., Steinbrecht, W., Thiéblemont, R., and Weber M.: Detecting recovery of the stratospheric ozone layer, Nature, 549, 211-218, https://doi.org/10.1038/nature23681, 2017.

Chipperfield, M. P., Dhomse, S., Hossaini, R., Feng, W., Santee, M. L., Weber, M., Burrows, J. P., Wild, J. D., Loyola, D., and Coldewey-Egbers, M.: On the cause of recent variations in lower stratospheric ozone, Geophys. Res. Lett., 45, 5718-5726, https://doi.org/10.1029/2018GL078071, 2018.

Cowtan, K., Hausfather, Z., Hawkins, E., Jacobs, P., Mann, M. E., Miller, S. K., Steinman, B. A., Stolpe, M. B., and Way, R. G.: Robust comparison of climate models with observations using blended land air and ocean sea surface temperatures, Geophys. Res. Lett., 42, 6526-6534, https://doi.org/10.1002/2015GL064888, 2015.

Craig, A., Valcke, S., and Coquart, L.: Development and performance of a new version of the OASIS coupler, OASIS3-MCT_3.0, Geosci. Model Dev., 10, 3297-3308, https://doi.org/10.5194/gmd-10-3297-2017, 2017.

Dentener, F., Kinne, S., Bond, T., Boucher, O., Cofala, J., Generoso, S., Ginoux, P., Gong, S., Hoelzemann, J. J., Ito, A., Marelli, L., Penner, J. E., Putaud, J.-P., Textor, C., Schulz, M., van der Werf, G. R., and Wilson, J.: Emissions of primary aerosol and precursor gases in the years 2000 and 1750 prescribed data-sets for AeroCom, Atmos. Chem. Phys., 6, 43214344, https://doi.org/10.5194/acp-6-4321-2006, 2006.

Dhomse, S. S., Mann, G. W., Antuña Marrero, J. C., Shallcross, S. E., Chipperfield, M. P., Carslaw, K. S., Marshall, L., Abraham, N. L., and Johnson, C. E.: Evaluating the simulated radiative forcings, aerosol properties, and stratospheric warmings from the 1963 Mt Agung, 1982 El Chichón, and 1991 Mt Pinatubo volcanic aerosol clouds, Atmos. Chem. Phys., 20, 13627-13654, https://doi.org/10.5194/acp-20-13627-2020, 2020.

Dietmüller, S., Eichinger, R., Garny, H., Birner, T., Boenisch, H., Pitari, G., Mancini, E., Visioni, D., Stenke, A., Revell, L., Rozanov, E., Plummer, D. A., Scinocca, J., Jöckel, P., Oman, L., Deushi, M., Kiyotaka, S., Kinnison, D. E., Garcia, R., Morgenstern, O., Zeng, G., Stone, K. A., and Schofield, R.: Quantifying the effect of mixing on the mean age of air in CCMVal2 and CCMI-1 models, Atmos. Chem. Phys., 18, 6699-6720, https://doi.org/10.5194/acp-18-6699-2018, 2018. 
Ding, Q., Schweiger, A., L'Heureux, M., Steig, E. J., Battisti, D. S., Johnson, N. C., Blanchard-Wrigglesworth, E., Po-Chedley, S., Zhang, Q., Harnos, K., Bushuk, M., Markle, B., and Baxter, I.: Fingerprints of internal drivers of Arctic sea ice loss in observations and model simulations, Nature Geosci., 12, 28-33, https://doi.org/10.1038/s41561-018-0256-8, 2019.

Domeisen, D. I., Garfinkel, C. I., and Butler, A. H.: The teleconnection of El Niño Southern Oscillation to the stratosphere, Rev. Geophys., 57, 5-47, https://doi.org/10.1029/2018RG000596, 2019.

Egorova, T., Rozanov, E., Zubov, V., and Karol, I.: Model for investigating ozone trends (MEZON), Izvestiya, Atmos. Ocean. Phys., 39, 277-292, 2003.

Egorova, T., Rozanov, E., Zubov, V., Manzini, E., Schmutz, W., and Peter, T.: Chemistry-climate model SOCOL: a validation of the present-day climatology, Atmos. Chem. Phys., 5, 1557-1576, https://doi.org/10.5194/acp-5-1557-2005, 2005.

Egorova, T., Rozanov, E., Gröbner, J., Hauser, M., and Schmutz, W.: Montreal Protocol Benefits simulated with CCM SOCOL, Atmos. Chem. Phys., 13, 3811-3823, https://doi.org/10.5194/acp13-3811-2013, 2013.

Ehhalt, D., Prather, M., Dentener, F., Derwent, R., Dlugokencky, E., Holland, E., Isaksen, I., Katima, J., Kirchhoff, V., Matson, P., Midgley, P., and Wang, M.: Atmospheric chemistry and greenhouse gases, in: Climate Change 2001: the Scientific Basis, Contribution of Working Group I to the Third Assessment Report of the Intergovernmental Panel on Climate Change, edited by: Houghton, J. T., Ding, Y., Griggs, D. J., Noguer, M., van der Linden, P. J., Dai, X., Maskell, K., and Johnson, C. A., Cambridge University Press, Cambridge, UK, New York, 239-288, 2001.

Evans, M. J. and Jacob, D. J.: Impact of new laboratory studies of $\mathrm{N}_{2} \mathrm{O}_{5}$ hydrolysis on global model budgets of tropospheric nitrogen oxides, ozone, and OH, Geophys. Res. Lett., 32, L09813, https://doi.org/10.1029/2005GL022469, 2005.

Farman, J., Gardiner, B., and Shanklin, J.: Large losses of total ozone in Antarctica reveal seasonal $\mathrm{ClO}_{x} / \mathrm{NO}_{x}$ interaction, Nature, 315, 207-210, https://doi.org/10.1038/315207a0, 1985.

Feinberg A. I., Coulon A., Stenke A., Schwietzke S., and Peter T.: Isotopic source signatures: Impact of regional variability on the $\delta 13 \mathrm{CH} 4$ trend and spatial distribution, Atmos. Environ., 174, 99111, https://doi.org/10.1016/j.atmosenv.2017.11.037, 2018.

Feinberg, A., Sukhodolov, T., Luo, B.-P., Rozanov, E., Winkel, L. H. E., Peter, T., and Stenke, A.: Improved tropospheric and stratospheric sulfur cycle in the aerosol-chemistry-climate model SOCOL-AERv2, Geosci. Model Dev., 12, 3863-3887, https://doi.org/10.5194/gmd-12-3863-2019, 2019.

Feinberg, A., Maliki, M., Stenke, A., Sudret, B., Peter, T., and Winkel, L. H. E.: Mapping the drivers of uncertainty in atmospheric selenium deposition with global sensitivity analysis, Atmos. Chem. Phys., 20, 1363-1390, https://doi.org/10.5194/acp20-1363-2020, 2020.

Fiedler, S., Stevens, B., and Mauritsen, T.: On the sensitivity of anthropogenic aerosol forcing to model-internal variability and parameterizing a Twomey effect, J. Adv. Model. Earth Sy., 9, 13251341, https://https://doi.org/10.1002/2017MS000932, 2017.

Fleming, E. L., Newman, P. A., Liang, Q., and Daniel, J. S.: The impact of continuing CFC-11 emissions on stratospheric ozone, J. Geophys. Res.-Atmos., 125, e2019JD031849, https://doi.org/10.1029/2019JD031849, 2020.
Froidevaux, L., Anderson, J., Wang, H.-J., Fuller, R. A., Schwartz, M. J., Santee, M. L., Livesey, N. J., Pumphrey, H. C., Bernath, P. F., Russell III, J. M., and McCormick, M. P.: Global OZone Chemistry And Related trace gas Data records for the Stratosphere (GOZCARDS): methodology and sample results with a focus on $\mathrm{HCl}, \mathrm{H}_{2} \mathrm{O}$, and $\mathrm{O}_{3}$, Atmos. Chem. Phys., 15, 1047110507, https://doi.org/10.5194/acp-15-10471-2015, 2015 (data available at: https://gozcards.jpl.nasa.gov/info.php, last access: 2 September 2021).

Fuchs, N. A.: The mechanics of aerosols, Q. J. Roy. Meteor. Soc., 91, 249-249, https://doi.org/10.1002/qj.49709138822, 1964.

Funke, B., López-Puertas, M., Holt, L., Randall, C. E., Stiller, G. P., and von Clarmann, T.: Hemispheric distributions and interannual variability of $\mathrm{NO}_{y}$ produced by energetic particle precipitation in 2002-2012, J. Geophys. Res.-Atmos., 119, 13565-13582, https://doi.org/10.1002/2014JD022423, 2014.

Funke, B., López-Puertas, M., Stiller, G. P., Versick, S., and von Clarmann, T.: A semi-empirical model for mesospheric and stratospheric $\mathrm{NO}_{y}$ produced by energetic particle precipitation, Atmos. Chem. Phys., 16, 8667-8693, https://doi.org/10.5194/acp-16-8667-2016, 2016.

Gauss, M., Isaksen, I. S. A., Lee, D. S., and Søvde, O. A.: Impact of aircraft $\mathrm{NO}_{x}$ emissions on the atmosphere - tradeoffs to reduce the impact, Atmos. Chem. Phys., 6, 1529-1548, https://doi.org/10.5194/acp-6-1529-2006, 2006.

Gelaro, R., McCarty, W., Suárez, M. J., Todling, R., Molod, A., Takacs, L., Randles, C. A., Darmenov, A., Bosilovich, M. G., Reichle, R., Wargan, K., Coy, L., Cullather, R., Draper, C., Akella, S., Buchard, V., Conaty, A., da Silva, A. M., Gu, W., Kim, G.K., Koster, R., Lucchesi, R., Merkova, D., Nielsen, J. E., Partyka, G., Pawson, S., Putman, W., Rienecker, M., Schubert, S. D., Sienkiewicz, M., and Zhao, B.: The Modern-Era Retrospective Analysis for Research and Applications, Version 2 (MERRA-2), J. Climate, 30, 5419-5454, https://doi.org/10.1175/JCLI-D-160758.1, 2017.

Gerber, E. P., Butler, A., Calvo, N., Charlton-Perez, A., Giorgetta, M., Manzini, E., Perlwitz, J., Polvani, L. M., Sassi, F., Scaife, A. A., Shaw, T. A., Son, S.-W., and Watanabe, Sh.: Assessing and understanding the impact of stratospheric dynamics and variability on the earth system, B. Am. Meteorol. Soc., 93, 845-859, https://doi.org/10.1175/BAMS-D-11-00145.1, 2012.

Gettelman, A., Mills, M. J., Kinnison, D. E., Garcia, R. R., Smith, A. K., Marsh, D. R., Tilmes, S., Vitt, F., Bardeen, C. G., McInerny, J., Liu, H.-L., Solomon, S. C., Polvani, L. M., Emmons, L. K., Lamarque, J.-F., Richter, J. H., Glanville, A. S., and Giorgetta, M. A.: Der Einfluss der quasi-zweijährigen Oszillation: Modellrechnungen mit ECHAM4, Max-Planck-Institut für Meteorologie, Hamburg, Examensarbeit Nr. 40, MPI-Report 218, 1996.

Giorgetta, M. A., Jungclaus, J., Reick, C. H., Legutke, S., Bader, J., Böttinger, M., Brovkin, V., Crueger, T., Esch, M., Fieg, K., Glushak, K., Gayler, V., Haak, H., Hollweg, H.-D., Ilyina, T., Kinne, S., Kornblueh, L., Matei, D., Mauritsen, T., Mikolajewicz, U. M. W., Notz, D., Pithan, F., Raddatz, T., Rast, S., Redler, R., Roeckner, E., Schmidt, H., Schnur, R., Segschneider, J., Six, Katharina, D., Stockhause, M., Timmreck, C., Wegner, J., Widmann, H., Wieners, K.-H., Claussen, M., Marotzke, J., and Stevens, B.: Climate and carbon cycle changes demo 1850 to 2100 in MPI-ESM simulations for the Coupled Model Intercom- 
parison Project phase 5, J. Adv. Model. Earth Sy., 5, 572-597, https://doi.org/10.1002/jame.20038, 2013.

Global Modeling and Assimilation Office (GMAO): MERRA2 inst3_3d_asm_Np: 3d,3-Hourly,Instantaneous,PressureLevel,Assimilation,Assimilated Meteorological Fields V5.12.4, Greenbelt, MD, USA, Goddard Earth Sciences Data and Information Services Center (GES DISC) [data set], https://doi.org/10.5067/QBZ6MG944HW0, 2015.

Goll, D. S., Winkler, A. J., Raddatz, T., Dong, N., Prentice, I. C., Ciais, P., and Brovkin, V.: Carbon-nitrogen interactions in idealized simulations with JSBACH (version 3.10), Geosci. Model Dev., 10, 2009-2030, https://doi.org/10.5194/gmd-102009-2017, 2017.

Grewe, V.: Impact of lightning on air chemistry and climate, in: Lightning: Principles, Instruments and Applications (Review of Modern Lightning Research), edited by: Betz, H. D., Schumann, U., and Laroche, P., Springer Netherlands, 537-549, https://doi.org/10.1007/978-1-4020-9079-0, 2009.

Guenther, A., Karl, T., Harley, P., Wiedinmyer, C., Palmer, P. I., and Geron, C.: Estimates of global terrestrial isoprene emissions using MEGAN (Model of Emissions of Gases and Aerosols from Nature), Atmos. Chem. Phys., 6, 3181-3210, https://doi.org/10.5194/acp-6-3181-2006, 2006.

Günther, A., Höpfner, M., Sinnhuber, B.-M., Griessbach, S., Deshler, T., von Clarmann, T., and Stiller, G.: MIPAS observations of volcanic sulfate aerosol and sulfur dioxide in the stratosphere, Atmos. Chem. Phys., 18, 1217-1239, https://doi.org/10.5194/acp-18-1217-2018, 2018.

Guo, Y., Yu, Y., Lin, P., Liu, H., He, B., Bao, O., Zhao, S., and Wang, X.: Overview of the CMIP6 Historical Experiment Datasets with the Climate System Model CAS FGOALS-f3-L, Adv. Atmos. Sci., 37, 1057-1066, https://doi.org/10.1007/s00376-020-20044, 2020.

Haase, S. and Matthes, K.: The importance of interactive chemistry for stratosphere-troposphere coupling, Atmos. Chem. Phys., 19, 3417-3432, https://doi.org/10.5194/acp-19-3417-2019, 2019.

Hagemann, S. and Stacke, T.: Impact of the soil hydrology scheme on simulated soil moisture memory, Clim. Dynam., 44, 17311750, https://doi.org/10.1007/s00382-014-2221-6, 2015.

Hansen, J., Ruedy, R., Sato, M., and Reynolds, R.: Global surface air temperature in 1995: Return to pre-Pinatubo level, Geophys. Res. Lett., 23, 1665-1668, https://doi.org/10.1029/96GL01040, 1996.

Hanson, D. R. and Ravishankara, A. R.: Reactive Uptake of $\mathrm{ClONO}_{2}$ onto Sulfuric Acid Due to Reaction with $\mathrm{HCl}$ and $\mathrm{H}_{2} \mathrm{O}$, J. Phys. Chem., 98, 5728-5735, https://doi.org/10.1021/j100073a026, 1994.

Hersbach, H., Bell, B., Berrisford, P., Biavati, G., Horányi, A., Muñoz Sabater, J., Nicolas, J., Peubey, C., Radu, R., Rozum, I., Schepers, D., Simmons, A., Soci, C., Dee, D., and Thépaut, J.N.: ERA5 monthly averaged data on pressure levels from 1979 to present, Copernicus Climate Change Service (C3S) Climate Data Store (CDS) [data set], https://doi.org/10.24381/cds.6860a573, 2019.

Hersbach, H., Bell, B., Berrisford, P., Hirahara, S., Horányi, A., Muñoz-Sabater, J., Nicolas, J., Peubey, C., Radu, R., Schepers, D., Simmons, A., Soci, C., Abdalla, S., Abellan, X., Balsamo, G. Bechtold, P., Biavati, G., Bidlot, J., Bonavita, M., De Chiara, G., Dahlgren, P., Dee, D., Diamantakis, M., Dragani, R.,
Flemming, J., Forbes, R. Fuentes, M., Geer, A., Haimberger, L., Healy, S., Hogan, R. J., Hólm, E., Janisková, M., Keeley, S., Laloyaux, P., Lopez, Ph., Lupu, C., Radnoti, G., de Rosnay, P., Rozum, I. Vamborg, F., Villaume, S., and Thépaut, J.-N.: The ERA5 global reanalysis, Q. J. Roy. Meteor. Soc., 146, 19992029, https://doi.org/10.1002/qj.3803, 2020.

Hibler, W. D.: A Dynamic Thermodynamic Sea Ice Model, J. Phys. Oceanogr., 9, 815-846, https://doi.org/10.1175/15200485(1979)009, 1979.

Hines, C. O.: Doppler-spread parameterization of gravity-wave momentum deposition in the middle atmosphere, 1, Basic formulation, J. Atmos. Solar Terr. Phy., 59, 371-386, https://doi.org/10.1016/S1364-6826(96)00079-X, 1997a.

Hines, C. O.: Doppler-spread parameterization of gravity-wave momentum deposition in the middle atmosphere, 2, Broad and quasi monochromatic spectra, and implementation, J. Atmos. Solar Terr. Phy., 59, 387-400, https://doi.org/10.1016/S13646826(96)00080-6, 1997b.

Hoesly, R. M., Smith, S. J., Feng, L., Klimont, Z., JanssensMaenhout, G., Pitkanen, T., Seibert, J. J., Vu, L., Andres, R. J., Bolt, R. M., Bond, T. C., Dawidowski, L., Kholod, N., Kurokawa, J.-I., Li, M., Liu, L., Lu, Z., Moura, M. C. P., O'Rourke, P. R., and Zhang, Q.: Historical (1750-2014) anthropogenic emissions of reactive gases and aerosols from the Community Emissions Data System (CEDS), Geosci. Model Dev., 11, 369-408, https://doi.org/10.5194/gmd-11-369-2018, 2018.

Holton, J. R., Haynes, P. H., McIntyre, M. I., Douglass, A. R., Rood, R. B., and Pfister, L.: Stratosphere-Troposphere Exchange, Rev. Geophys., 33, p. 405, 1995.

Hurtt, G. C., Chini, L. P., Frolking, S., Betts, R. A., Feddema, J., Fischer, G., Fisk, J. P., Hibbard, K., Houghton, R. A., Janetos, A., Jones, C. D., Kindermann, G., Kinoshita, T., Klein Goldewijk, K., Riahi, K., Shevliakova, E., Smith, S., Stehfest, E., Thomson, A., Thornton, P., van Vuuren, D. P., and Wang, Y. P.: Harmonization of land-use scenarios for the period 1500-2100: 600 years of global gridded annual land-use transitions, wood harvest, and resulting secondary lands, Clim. Change, 109, 117 161, https://doi.org/10.1007/s10584-011-0153-2, 2011.

Iacono, M. J., Delamere, J. S., Mlawer, E. J., Shephard, M. W., Clough, S. A., and Collins, W. D.: Radiative forcing by long-lived greenhouse gases: Calculations with the AER radiative transfer models, J. Geophys. Res., 113, D13103, https://doi.org/10.1029/2008JD009944, 2008.

Ilyina, T., Wolf-Gladrow, D., Munhoven, G., and Heinze, C.: Assessing the potential of calcium-based artificial ocean alkalinization to mitigate rising atmospheric $\mathrm{CO}_{2}$ and ocean acidification, Geophys. Res. Lett., 40, 5909-5914, https://doi.org/10.1002/2013GL057981, 2013.

Jacob, D. J.: Chemistry of $\mathrm{OH}$ in remote clouds and its role in the production of formic acid and peroxymonosulfate, J. Geophys. Res., 91, 9807-9826, https://doi.org/10.1029/JD091iD09p09807, 1986.

Jacobson, M. Z. and Seinfeld, J. H.: Evolution of nanoparticle size and mixing state near the point of emission, Atmos. Environ. 38, 1839-1850, https://doi.org/10.1016/j.atmosenv.2004.01.014, 2004.

Jöckel, P., von Kuhlmann, R., Lawrence, M. G., Steil, B., Brenninkmeijer, C. A. M., Crutzen, P. J., Rasch, P. J., and Eaton, B.: On a fundamental problem in implementing flux-form advection 
schemes for tracer transport in 3-dimensional general circulation and chemistry transport models, Q. J. Roy. Meteor. Soc., 127, 1035-1052, https://doi.org/10.1002/qj.49712757318, 2001.

Jungclaus, J. H., Keenlyside, N., Botzet, M., Haak, H., Luo, J.-J., Latif, M., Marotzke, J., Mikolajewicz, U., and Roeckner, E.: Ocean circulation and tropical variability in the coupled model ECHAM5/MPI-OM, J. Climate, 19, 3952-3972, https://doi.org/10.1175/JCLI3827.1, 2006.

Jungclaus, J. H., Fischer, N., Haak, H., Lohmann, K., Marotzke, J., Matei, D., Mikolajewicz, U., Notz, D., and von Storch, J. S.: Characteristics of the ocean simulations in MPIOM, the ocean component of the MPI-Earth system model, J. Adv. Model. Earth Sy., 5, 422-446, https://doi.org/10.1002/jame.20023, 2013.

Karagodin-Doyennel, A., Rozanov, E., Kuchar, A., Ball, W., Arsenovic, P., Remsberg, E., Jöckel, P., Kunze, M., Plummer, D. A., Stenke, A., Marsh, D., Kinnison, D., and Peter, T.: The response of mesospheric $\mathrm{H}_{2} \mathrm{O}$ and $\mathrm{CO}$ to solar irradiance variability in models and observations, Atmos. Chem. Phys., 21, 201216, https://doi.org/10.5194/acp-21-201-2021, 2021.

Kasten, F.: Falling speed of aerosol particles, J. Appl. Meteorol. Clim., 7, 944-947, https://doi.org/10.1175/1520-0450(1968)007, 1968.

Keeble, J., Hassler, B., Banerjee, A., Checa-Garcia, R., Chiodo, G., Davis, S., Eyring, V., Griffiths, P. T., Morgenstern, O., Nowack, P., Zeng, G., Zhang, J., Bodeker, G., Burrows, S., CameronSmith, P., Cugnet, D., Danek, C., Deushi, M., Horowitz, L. W., Kubin, A., Li, L., Lohmann, G., Michou, M., Mills, M. J., Nabat, P., Olivié, D., Park, S., Seland, Ø., Stoll, J., Wieners, K.-H., and $\mathrm{Wu}, \mathrm{T}$.: Evaluating stratospheric ozone and water vapour changes in CMIP6 models from 1850 to 2100, Atmos. Chem. Phys., 21, 5015-5061, https://doi.org/10.5194/acp-21-5015-2021, 2021.

Kerkweg, A., Buchholz, J., Ganzeveld, L., Pozzer, A., Tost, H., and Jöckel, P.: Technical Note: An implementation of the dry removal processes DRY DEPosition and SEDImentation in the Modular Earth Submodel System (MESSy), Atmos. Chem. Phys., 6, 4617-4632, https://doi.org/10.5194/acp-6-4617-2006, 2006.

Kidston, J., Scaife, A., Hardiman, S., Mitchel, D. M., Butchart, N., Baldwin, M. P., and Gray, L. J.: Stratospheric influence on tropospheric jet streams, storm tracks and surface weather, Nat. Geosci., 8, 433-440, https://doi.org/10.1038/ngeo2424, 2015.

Kinne, S., O’Donnel, D., Stier, P., Kloster, S., Zhang, K., Schmidt, H., Rast, S., Giorgetta, M., Eck, T. F., and Stevens, B.: MAC-v1: A new global aerosol climatology for climate studies, J. Adv. Model. Earth Sy., 5, 704-740, https://doi.org/10.1002/jame.20035, 2013.

Koenig, Th. K., Baidara, S., Campuzano-Josta, P., Cuevasc, C. A., Dixa, B., Fernandez, R. P., Guoa, H., Halle, S. R., Kinnisone, D., Naulta, B. A., Ullmanne, K., Jimeneza, L. L., SaizLopezc, A., and Volkamera, R.: Quantitative detection of iodine in the stratosphere, P. Natl. Acad. Sci. USA, 117, 1860-1866, https://doi.org/10.1073/pnas.1916828117, 2020.

Koepke P., Hess, M., Schult, I., and Shettle, E. P.: Global aerosol dataset, Report N 243, Max-Plank-Institut für Meteorologie, Hamburg, 44 pp., 1997.

Koo, J.-H., Walker, K. A., Jones, A., Sheese, P. E., Boone, C. D., Bernath, P. F., and Manney, G. L.: Global climatology based on the ACE-FTS version 3.5 data set: Addition of mesospheric levels and carbon-containing species in the UTLS, J. Quant. Spectros. Ra., 12, 52-62, https://doi.org/10.1016/j.jqsrt.2016.07.003, 2017 (data available at: http://www.ace.uwaterloo.ca/climatology/3.5/netcdf/, last access: 6 September 2021).

Kulmala, M. and Laaksonen, A.: Binary nucleation of watersulfuric acid system: Comparison of classical theories with different $\mathrm{H}_{2} \mathrm{SO}_{4}$ saturation vapor pressures, J. Chem. Phys., 93, 696-701, https://doi.org/10.1063/1.459519, 1990.

Lana, A., Bell, T. G., Simó, R., Vallina, S. M., Ballabrera-Poy, J., Kettle, A. J., Dachs, J., Bopp, L., Saltzman, E. S., Stefels, J., Johnson, J. E., and Liss, P. S.: An updated climatology of surface dimethlysulfide concentrations and emission fluxes in the global ocean, Global Biogeochem. Cy., 25, GB1004, https://doi.org/10.1029/2010GB003850, 2011.

Lin, S. J. and Rood, R. B.: Multidimensional flux-form semiLagrangian transport schemes, Mon. Weather Rev., 124, 20462070, https://doi.org/10.1175/1520-0493(1996)124, 1996.

Long, C. S., Fujiwara, M., Davis, S., Mitchell, D. M., and Wright, C. J.: Climatology and interannual variability of dynamic variables in multiple reanalyses evaluated by the SPARC Reanalysis Intercomparison Project (S-RIP), Atmos. Chem. Phys., 17, 1459314629, https://doi.org/10.5194/acp-17-14593-2017, 2017.

Lott, F.: Alleviation of stationary biases in a GCM through a mountain drag parameterization scheme and a simple representation of mountain lift forces, Mon. Weather Rev., 127, 788-801, https://doi.org/10.1175/1520-0493(1999)127, 1999.

Manabe S. and Bryan, K.: Climate calculations with a combined ocean-atmosphere model, J. Atmos. Sci., 26, 786-789, https://doi.org/10.1175/1520-0469(1969)026, 1969.

Manney, G. L., Livesey, N. J., Santee, M. L., Froidevaux, L., Lambert, A., Lawrence, Z. D., Millán, L. F., Neu, J. L., Read, W. G., Schwartz, M. J., and Fuller, R. A.: Recordlow Arctic stratospheric ozone in 2020: MLS observations of chemical processes and comparisons with previous extreme winters, Geophys. Res. Lett., 47, e2020GL089063, https://doi.org/10.1029/2020GL089063, 2020.

Manzini, E., Giorgetta, M. A., Esch, M., Kornblueh, L., and Roeckner, E.: The influence of the sea surface temperatures on the northern winter stratosphere: Ensemble Simulations with the MAECHAM5 model, J. Climate, 19, 3863-3881, https://doi.org/10.1175/JCLI3826.1, 2006.

Marsh, D. R., Janches, D., Feng, W., and Plane, J. M. C.: A global model of meteoric sodium, J. Geophys. Res.-Atmos., 118, 11442-11452, https://doi.org/10.1002/jgrd.50870, 2013.

Matthes, K., Funke, B., Andersson, M. E., Barnard, L., Beer, J., Charbonneau, P., Clilverd, M. A., Dudok de Wit, T., Haberreiter, M., Hendry, A., Jackman, C. H., Kretzschmar, M., Kruschke, T., Kunze, M., Langematz, U., Marsh, D. R., Maycock, A. C., Misios, S., Rodger, C. J., Scaife, A. A., Seppälä, A., Shangguan, M., Sinnhuber, M., Tourpali, K., Usoskin, I., van de Kamp, M., Verronen, P. T., and Versick, S.: Solar forcing for CMIP6 (v3.2), Geosci. Model Dev., 10, 2247-2302, https://doi.org/10.5194/gmd-10-2247-2017, 2017.

Matthes, K., Biastoch, A., Wahl, S., Harlaß, J., Martin, T., Brücher, T., Drews, A., Ehlert, D., Getzlaff, K., Krüger, F., Rath, W., Scheinert, M., Schwarzkopf, F. U., Bayr, T., Schmidt, H., and Park, W.: The Flexible Ocean and Climate Infrastructure version 1 (FOCI1): mean state and variability, Geosci. Model Dev., 13, 2533-2568, https://doi.org/10.5194/gmd-13-2533-2020, 2020. 
Mauritsen, T., Bader, J., Becker, T., Behrens, J., Bittner, M., Brokopf, R., Brovkin, V., Claussen, M., Crueger, T., Esch, M., Fast, I., Fiedler, S., Fläschner, D., Gayler, V., Giorgetta, M., Goll, D. S., Haak, H., Hagemann, S., Hedemann, C., Hohenegger, C., Ilyina, T., Jahns, Th., Jimenéz-de-la-Cuesta, D., Jungclaus, J., Kleinen, Th., Kloster, S., Kracher, D., Kinne, S., Kleberg, D., Lasslop, G., Kornblueh, L., Marotzke, J., Matei, D., Meraner, K., Mikolajewicz, U., Modali, K., Möbis, B., Müller, W. A., Nabel, J. E. M. S., Nam, C. C. W., Notz, D., Nyawira, S.-S., Paulsen, H., Peters, K., Pincus, R., Pohlmann, H., Pongratz, J., Popp, M., Raddatz, Th. J., Rast, S., Redler, R., Reick, Ch. H., Rohrschneider, T., Schemann, V., Schmidt, H., Schnur, R., Schulzweida, U., Six, K. D., Stein, L., Stemmler, I., Stevens, B., von Storch, J.S., Tian, F., Voigt, A., Vrese, Ph., Wieners, K.-H., Wilkenskjeld, S., Winkler, A., and Roeckner, E.: Developments in the MPIM Earth System Model version 1.2 (MPI-ESM1.2) and its response to increasing $\mathrm{CO}_{2}$, J. Adv. Model. Earth Sy., 11, 9981038, https://doi.org/10.1029/2018MS001400, 2019.

McConnell, J. C. and Jin, J. J.: Stratospheric ozone chemistry, Atmos.-Ocean, 46, 69-92, https://doi.org/10.3137/ao.460104, 2008.

McPeters, R. D., Bhartia, P. K., Haffner, D., Labow, G. J., and Flynn, L.: The version 8.6 SBUV ozone data record: An overview, J. Geophys. Res.-Atmos., 118, 8032-8039, https://doi.org/10.1002/jgrd.50597, 2013 (data available at: https://acd-ext.gsfc.nasa.gov/Data_services/merged/ instruments.html, last access: 2 September 2021).

Meinshausen, N., Hauser, A., Mooij, J. M., Peters, J., Versteeg, Ph., and Bühlmann, P.: Methods for causal inference from gene perturbation experiments and validation, P. Natl. Acad. Sci. USA, 27, 7361-7368, https://doi.org/10.1073/pnas.1510493113, 2016.

Meinshausen, M., Vogel, E., Nauels, A., Lorbacher, K., Meinshausen, N., Etheridge, D. M., Fraser, P. J., Montzka, S. A., Rayner, P. J., Trudinger, C. M., Krummel, P. B., Beyerle, U., Canadell, J. G., Daniel, J. S., Enting, I. G., Law, R. M., Lunder, C. R., O’Doherty, S., Prinn, R. G., Reimann, S., Rubino, M., Velders, G. J. M., Vollmer, M. K., Wang, R. H. J., and Weiss, R.: Historical greenhouse gas concentrations for climate modelling (CMIP6), Geosci. Model Dev., 10, 2057-2116, https://doi.org/10.5194/gmd-10-2057-2017, 2017.

Miller, M. J., Palmer, T. N., and Swinbank, R.: Parametrization and influence of subgridscale orography in general circulation and numerical weather prediction models, Meteorol. Atmos. Phys., 40, 84-109, https://doi.org/10.1007/BF01027469, 1989.

Mironova, I. A., Aplin, K. L., Arnold, F., Bazilevskaya, G. A., Harrison, R. G., Giles, R., Krivolutsky, A. A., Nicoll, K. A., Rozanov, E. V., Turunen, E., and Usoskin, I. G.: Energetic Particle Influence on the Earth's Atmosphere, Space Sci. Rev., 194, 1-96, https://doi.org/10.1007/s11214-015-0185-4, 2015.

Mote, P. W., Dunkerton, T. J., McIntyre, M. E., Ray, E. A., Haynes, P. H., and Russell, J. M.: Vertical velocity, vertical diffusion, and dilution by midlatitude air in the tropical lower stratosphere, J. Geophys. Res., 103, 8651-8666, https://doi.org/10.1029/98JD00203, 1998.

Möbis, B. and Stevens, B.: Factors controlling the position of the Intertropical Convergence Zone on an aquaplanet, J. Adv. Model. Earth Sy., 4, M00A04, https://https://doi.org/10.1029/2012MS000199, 2012.
Müller, W. A., Jungclaus, J. H., Mauritsen, T., Baehr, J., Bittner, M., Budich, R., Bunzel, F., Esch, M., Ghosh, R., Haak, H., Ilyina, T., Kleine, T., Kornblueh, L., Li, H., Modali, K., Notz, D., Pohlmann, H., Roeckner, E., Stemmler, I., Tian, F., and Marotzke, J.: A higher-resolution version of the Max Planck Institute Earth System Model (MPIESM1.2-HR), J. Adv. Model. Earth Sy., 10, 1383-1413, https://doi.org/10.1029/2017MS001217, 2018.

Muthers, S., Anet, J. G., Stenke, A., Raible, C. C., Rozanov, E., Brönnimann, S., Peter, T., Arfeuille, F. X., Shapiro, A. I., Beer, J., Steinhilber, F., Brugnara, Y., and Schmutz, W.: The coupled atmosphere-chemistry-ocean model SOCOL-MPIOM, Geosci. Model Dev., 7, 2157-2179, https://doi.org/10.5194/gmd-7-21572014, 2014.

Nakajima, H., Wohltmann, I., Wegner, T., Takeda, M., Pitts, M. C., Poole, L. R., Lehmann, R., Santee, M. L., and Rex, M.: Polar stratospheric cloud evolution and chlorine activation measured by CALIPSO and MLS, and modeled by ATLAS, Atmos. Chem. Phys., 16, 3311-3325, https://doi.org/10.5194/acp16-3311-2016, 2016.

Niemeier, U. and Schmidt, H.: Changing transport processes in the stratosphere by radiative heating of sulfate aerosols, Atmos. Chem. Phys., 17, 14871-14886, https://doi.org/10.5194/acp-1714871-2017, 2017.

Nightingale, P. D., Malin, G., Law, C. S., Watson, A. J., Liss, P. S., Liddicoat, M. I., Boutin, J., and Upstill-Goddard, R. C.: In situ evaluation of air-sea gas exchange parameterizations using novel conservative and volatile tracers, Global Biogeochem. Cy., 1, 373- 387, https://https://doi.org/10.1029/1999GB900091, 2000.

Nordeng, T. E.: Extended versions of the convective parameterization scheme at ECMWF and their impact on the mean and transient activity of the model in the tropics, ECMWF Research Department Tech. Memo., 41 pp., 1994

Nowack, P. J., Abraham, N. L., Maycock, A. C., Braesicke, P., Gregory, J. M., Joshi, M. M., Osprey, A., and Pyle, J. A.: A large ozone-circulation feedback and its implications for global warming assessments, Nat. Clim. Chang., 5, 41-45, https://doi.org/10.1038/nclimate2451, 2015.

Oehrlein, J., Chiodo, G., and Polvani, L. M.: The effect of interactive ozone chemistry on weak and strong stratospheric polar vortex events, Atmos. Chem. Phys., 20, 10531-10544, https://doi.org/10.5194/acp-20-10531-2020, 2020.

Orbe, C., Wargan, K., Pawson, S., and Oman, L. D.: Mechanisms linked to recent ozone decreases in the Northern Hemisphere lower stratosphere, J. Geophys. Res.-Atmos., 125, e2019JD031631, https://doi.org/10.1029/2019JD031631, 2020.

Ozolin, Y.: Modelling of diurnal variations of gas species in the atmosphere and diurnal averaging in photochemical models, Izv. Akad. Nauk. Phys. Atmos. Ocean., 28, 135-143, 1992.

Palmer, T. N., Shutts, G. J., and Swinbank, R.: Alleviation of a systematic westerly bias in general circulation and numerical weather prediction models through an orographic gravity wave drag parametrization, Q. J. Roy. Meteor. Soc., 112, 1001-1039, https://doi.org/10.1002/qj.49711247406, 1986.

Paulsen, J., Sekelja, M., Oldenburg, A. R., Barateau, A., Briand, N., Delbarre, E., Shah, A., Sørensen, A. L., Vigouroux, C., Buendia, B., and Collas, Ph.: Chrom3D: three-dimensional genome modeling from $\mathrm{Hi}-\mathrm{C}$ and nuclear lamin-genome con- 
tacts, Genome Biol., 18, 1-15, https://doi.org/10.1186/s13059016-1146-2, 2017.

Pedersen, C. A., Roeckner, E., Lüthje, M., and Winther, J.-G.: A new sea ice albedo scheme including melt ponds for ECHAM5 general circulation model, J. Geophys. Res., 114, D08101, https://https://doi.org/10.1029/2008JD010440, 2009.

Petropavlovskikh, I., Godin-Beekmann, S., Hubert, D., Damadeo, R., Hassler, B., and Sofieva, V.: SPARC/IO3C/GAW report on Long-term Ozone Trends and Uncertainties in the Stratosphere, SPARC/IO3C/GAW, SPARC Report No. 9, WCRP-17/2018, GAW Report No. 241, https://doi.org/10.17874/f899e57a20b, 2019.

Pincus, R. and Stevens, B.: Paths to accuracy for radiation parameterizations in atmospheric models, J. Adv. Model. Earth Sy., 5, 225-233, https://doi.org/10.1002/jame.20027, 2013.

Plumb, R. A.: Stratospheric transport, J. Meteorol. Soc. Jpn., 80, 793-809, https://doi.org/10.2151/jmsj.80.793, 2002.

Plumb, R. A.: Tracer interrelationships in the stratosphere, Rev. Geophys., 45, RG4005, https://doi.org/10.1029/2005RG000179, 2007.

Polvani, L. M., Wang, L., Abalos, M., Butchart, N., Chipperfield, M. P., Dameris, M., Deushi, M., Dhomse, S. S., Jöckel, P., Kinnison, D., Michou, M., Morgenstern, O., Oman, L. D., Plummer, D. A., and Stone, K. A.: Large impacts, past and future, of ozonedepleting substances on Brewer-Dobson circulation trends: A multimodel assessment, J. Geoph. Res.-Atmos., 124, 6669-6680, https://doi.org/10.1029/2018JD029516, 2019.

Pöschl, U., von Kuhlmann, R., Poisson, N., and Crutzen, P. J.: Development and Intercomparison of Condensed Isoprene Oxidation Mechanisms for Global Atmospheric Modeling, J. Atmos. Chem., 37, 29-52, https://doi.org/10.1023/A:1006391009798, 2000.

Previdi, M. and Polvani, L. M.: Climate system response to stratospheric ozone depletion and recovery, Q. J. Roy. Meteor. Soc., 140, 2401-2419, https://doi.org/10.1002/qj.2330, 2014.

Price, C. and Rind, D.: A simple lightning parameterization for calculating global lightning distributions, J. Geophys. Res., 97, 9919-9933, https://doi.org/10.1029/92JD00719, 1992.

Pruppacher, H. R. and Klett, J. D.: Microphysics of Clouds and Precipitation, 2nd edn., Kluwer Academic, Dordrecht, 954 pp., 1997.

Revell, L. E., Tummon, F., Stenke, A., Sukhodolov, T., Coulon, A., Rozanov, E., Garny, H., Grewe, V., and Peter, T.: Drivers of the tropospheric ozone budget throughout the 21 st century under the medium-high climate scenario RCP 6.0, Atmos. Chem. Phys., 15, 5887-5902, https://doi.org/10.5194/acp15-5887-2015, 2015.

Revell, L. E., Stenke, A., Rozanov, E., Ball, W., Lossow, S., and Peter, T.: The role of methane in projections of 21 st century stratospheric water vapour, Atmos. Chem. Phys., 16, 13067-13080, https://doi.org/10.5194/acp-16-13067-2016, 2016.

Revell, L. E., Stenke, A., Tummon, F., Feinberg, A., Rozanov, E., Peter, T., Abraham, N. L., Akiyoshi, H., Archibald, A. T., Butchart, N., Deushi, M., Jöckel, P., Kinnison, D., Michou, M., Morgenstern, O., O'Connor, F. M., Oman, L. D., Pitari, G., Plummer, D. A., Schofield, R., Stone, K., Tilmes, S., Visioni, D., Yamashita, Y., and Zeng, G.: Tropospheric ozone in CCMI models and Gaussian process emulation to understand biases in the SOCOLv3 chemistry-climate model, Atmos. Chem.
Phys., 18, 16155-16172, https://doi.org/10.5194/acp-18-161552018, 2018.

Rohde, R. and Hausfather, Z.: Berkeley Earth Combined Land and Ocean Temperature Field, Jan 1850-Nov 2019, Zenodo [data set], https://doi.org/10.5281/zenodo.3634712, 2019.

Rieder, H., Chiodo, G., Fritzer, J., Wienerroither, C., and Polvani, L.: Is interactive ozone chemistry important to represent polar cap stratospheric temperature variability in Earth-System Models?, Environ. Res. Lett., 14, 044026, https://doi.org/10.1088/1748-9326/ab07ff, 2019.

Rozanov, E. V., Zubov, V. A., Schlesinger, M. E., Yang, F., and Andronova, N. G.: The UIUC three-dimensional stratospheric chemical transport model: Description and evaluation of the simulated source gases and ozone, J. Geophys. Res., 104, 1175511781, https://https://doi.org/10.1029/1999JD900138, 1999.

Rozanov, E. V., Schlesinger, M. E., and Zubov, V. A.: The University of Illinois, Urbana-Champaign three-dimensional stratosphere-troposphere general circulation model with interactive ozone photochemistry: Fifteen-year control run climatology, J. Geophys. Res., 106, 27233-27254, https://doi.org/10.1029/2000JD000058, 2001.

Rozanov, E., Calisto, M., Egorova, T., Peter, T., and Schmutz, W.: Influence of the Precipitating Energetic Particles on Atmospheric Chemistry and Climate, Surv. Geophys., 33, 483-501, https://doi.org/10.1007/s10712-012-9192-0, 2012.

Schmidt, T., Alexander, P., and de la Torre, A.: Stratospheric gravity wave momentum flux from radio occultations, J. Geophys. Res.-Atmos., 121, 4443-4467, https://doi.org/10.1002/2015JD024135, 2013.

Schmidt, H., Brasseur, G. P., Charron, M., Manzini, E., Giorgetta, M. A., Diehl, T., Fomichev, V. I., Kinnison, D., Marsh, D., and Walters, S.: The HAMMONIA Chemistry Climate Model: Sensitivity of the Mesopause Region to the 11-Year Solar Cycle and $\mathrm{CO}_{2}$ Doubling, J. Clim., 19, 3903-3931, https://doi.org/10.1175/JCLI3829.1, 2006.

Schraner, M., Rozanov, E., Schnadt Poberaj, C., Kenzelmann, P., Fischer, A. M., Zubov, V., Luo, B. P., Hoyle, C. R., Egorova, T., Fueglistaler, S., Brönnimann, S., Schmutz, W., and Peter, T.: Technical Note: Chemistry-climate model SOCOL: version 2.0 with improved transport and chemistry/microphysics schemes, Atmos. Chem. Phys., 8, 5957-5974, https://doi.org/10.5194/acp8-5957-2008, 2008.

Semtner, A. J.: A model for the thermodynamic growth of sea ice in numerical investigations of climate, J. Phys. Oceanogr., 6, 379389, 1976.

Sheng, J.-X., Weisenstein, D. K., Luo, B.-P., Rozanov, E., Stenke, A., Anet, J., Bingemer, H., and Peter, T.: Global atmospheric sulfur budget under volcanically quiescent conditions: Aerosol-chemistry-climate model predictions and validation, J. Geophys. Res.-Atmos., 120, 256-276, https://doi.org/10.1002/2014JD021985, 2015.

Simmons, A. J., Soci, C., Nicolas, J., Bell, B., Berrisford, P., Dragani, R., Flemming, J., Haimberger, L., Healey, S. B., Hersbach, H., Horányi, A., Inness, A., Muñoz-Sabater, J., Radu, R.. and Schepers, D.: Global stratospheric temperature bias and other stratospheric aspects of ERA5 and ERA5.1, Technical Memorandum 859, ECMWF, Reading, UK, https://doi.org/10.21957/rcxqfmg0, 2020. 
SPARC: The SPARC Data Initiative: Assessment of stratospheric trace gas and aerosol climatologies from satellite limb sounders, edited by: Hegglin, M. I. and Tegtmeier, S., SPARC Report No. 8, WCRP-5/2017, available at: https://www.sparc-climate. org/publications/sparc-reports/sparc-report-no-8/ (last access: 2 September 2021), 2017.

Stenke, A., Schraner, M., Rozanov, E., Egorova, T., Luo, B., and Peter, T.: The SOCOL version 3.0 chemistry-climate model: description, evaluation, and implications from an advanced transport algorithm, Geosci. Model Dev., 6, 1407-1427, https://doi.org/10.5194/gmd-6-1407-2013, 2013.

Stevens, B., Giorgetta, M., Esch, M., Mauritsen, T., Crueger, T., Rast, S., Salzmann, M., Schmidt, H., Bader, J., Block, K., Brokopf, R., Fast, I., Kinne, S., Kornblueh, L., Lohmann, U., Pincus, R., Reichler, Th., and Roeckner, E.: Atmospheric component of the MPI-M Earth System Model: ECHAM6, J. Adv. Model. Earth Sy., 5, 1942-2466, https://doi.org/10.1002/jame.20015, 2013.

Stevens, B., Fiedler, S., Kinne, S., Peters, K., Rast, S., Müsse, J., Smith, S. J., and Mauritsen, T.: MACv2-SP: a parameterization of anthropogenic aerosol optical properties and an associated Twomey effect for use in CMIP6, Geosci. Model Dev., 10, 433452, https://doi.org/10.5194/gmd-10-433-2017, 2017.

Strahan, S. E.: Middle Atmosphere - Transport Circulation, in: Encyclopedia of Atmospheric Sciences, 2nd edn., edited by: North, G. R., Pyle, J., and Zhang, F., Academic Press, 41-49, https://doi.org/10.1016/B978-0-12-382225-3.00231-0, 2015.

Stone, K. A., Solomon, S., and Kinnison, D. E.: On the identification of ozone recovery, Geophys. Res. Lett., 45, 5158-5165, https://doi.org/10.1029/2018GL077955, 2018.

Stott, P. A. and Harwood, R. S.: An implicit time-stepping scheme for chemical species in a global atmospheric circulation model, Ann. Geophys., 11, 377-388, 1993.

Sukhodolov, T.: SOCOlv4.0 simulation results for 1980-2018, Zenodo [data set], https://doi.org/10.5281/zenodo.5148741, 2021.

Sukhodolov, T., Rozanov, E., Shapiro, A. I., Anet, J., Cagnazzo, C., Peter, T., and Schmutz, W.: Evaluation of the ECHAM family radiation codes performance in the representation of the solar signal, Geosci. Model Dev., 7, 2859-2866, https://doi.org/10.5194/gmd-7-2859-2014, 2014.

Sukhodolov, T., Rozanov, E., Ball, W. T., Bais, A., Tourpali, K., Shapiro, A. I., Telford, P., Smyshlyaev, S., Fomin, B., Sander, R., Bossay, B., Bekki, S., Marchand, M., Chipperfield, M. P., Dhomse, S., Haigh, J. D., Peter, Th., and Schmutz, W.: Evaluation of simulated photolysis rates and their response to solar irradiance variability, J. Geophys. Res.-Atmos., 121, 6066-6084, https://doi.org/10.1002/2015JD024277, 2016.

Sukhodolov, T., Sheng, J.-X., Feinberg, A., Luo, B.-P., Peter, T., Revell, L., Stenke, A., Weisenstein, D. K., and Rozanov, E.: Stratospheric aerosol evolution after Pinatubo simulated with a coupled size-resolved aerosol-chemistry-climate model, SOCOL-AERv1.0, Geosci. Model Dev., 11, 2633-2647, https://doi.org/10.5194/gmd-11-2633-2018, 2018.

Sukhodolov, T., et al.: Atmosphere-Ocean-Aerosol-ChemistryClimate Model SOCOLv4.0 code (Version 1.0), Zenodo [code], https://doi.org/10.5281/zenodo.4570622, 2021.

Sundqvist, H., Berge, E., and Kristjánsson, J. E.: Condensation and cloud parameterization studies with a mesoscale numerical weather prediction model, Mon.
Weather Rev., 117, 1641-1657, https://doi.org/10.1175/15200493(1989)117<1641:CACPSW>2.0.CO;2, 1989.

Tabazadeh, A., Toon, O. B., Clegg, S. L., and Hamill, P.: A new parameterization of $\mathrm{H}_{2} \mathrm{SO}_{4} / \mathrm{H}_{2} \mathrm{O}$ aerosol composition: Atmospheric implications, Geophys. Res. Lett., 24, 1931-1934, https://doi.org/10.1029/97GL01879, 1997.

Tian, F., von Storch, J.-S., and Hertwig, E.: Impact of SST diurnal cycle on ENSO asymmetry, Clim. Dynam., 52, 2399-2411, https://doi.org/10.1007/s00382-018-4271-7, 2019.

Tiedtke, M.: A Comprehensive Mass Flux Scheme for $\mathrm{Cu}-$ mulus Parameterization in Large Scale Models, Mon. Weather Rev., 117, 1779-1800, https://doi.org/10.1175/15200493(1989)117<1779:ACMFSF>2.0.CO;2, 1989.

Tilmes, S., Garcia, R. R., Kinnison, D. E., Gettelman, A., and Rasch, P. J.: Impact of geoengineered aerosols on the troposphere and stratosphere, J. Geophys. Res., 114, D12305, https://doi.org/10.1029/2008JD011420, 2009.

Timmreck, C., Lorenz, S. J., Crowley, T. J., Kinne, S., Raddatz, T. J., Thomas, M. A., and Jungclaus, J. H.: Limited temperature response to the very large AD 1258 volcanic eruption, Geophys. Res. Lett., 36, L21708, https://doi.org/10.1029/2009GL040083, 2009.

Timmreck, C., Mann, G. W., Aquila, V., Hommel, R., Lee, L. A., Schmidt, A., Brühl, C., Carn, S., Chin, M., Dhomse, S. S., Diehl, T., English, J. M., Mills, M. J., Neely, R., Sheng, J., Toohey, M., and Weisenstein, D.: The Interactive Stratospheric Aerosol Model Intercomparison Project (ISA-MIP): motivation and experimental design, Geosci. Model Dev., 11, 2581-2608, https://doi.org/10.5194/gmd-11-2581-2018, 2018.

Thomason, L. W., Ernest, N., Millán, L., Rieger, L., Bourassa, A., Vernier, J.-P., Manney, G., Luo, B., Arfeuille, F., and Peter, T.: A global space-based stratospheric aerosol climatology: 1979-2016, Earth Syst. Sci. Data, 10, 469-492, https://doi.org/10.5194/essd-10-469-2018, 2018 (data availalbe at: ftp://iacftp.ethz.ch/pub_read/luo/CMIP6_SAD_radForcing_ v4.0.0/, last access: 2 September 2021).

Tost, H., Jöckel, P., and Lelieveld, J.: Influence of different convection parameterisations in a GCM, Atmos. Chem. Phys., 6, 54755493, https://doi.org/10.5194/acp-6-5475-2006, 2006.

Tost, H., Jöckel, P., and Lelieveld, J.: Lightning and convection parameterisations - uncertainties in global modelling, Atmos. Chem. Phys., 7, 4553-4568, https://doi.org/10.5194/acp-7-45532007, 2007.

Twomey, S.: The influence of pollution on the short wave albedo of clouds, J. Atmos. Sci., 34, 1149-1152, https://doi.org/10.1175/1520-0469(1977)034, 1977.

van der A, R. J., Allaart, M. A. F., and Eskes, H. J.: Extended and refined multi sensor reanalysis of total ozone for the period 1970-2012, Atmos. Meas. Tech., 8, 3021-3035, https://doi.org/10.5194/amt-8-3021-2015, 2015a.

Van der A, R. J., Allaart, M. A. F., and Eskes, H. J.: Multi-Sensor Reanalysis (MSR) of total ozone, version 2, Royal Netherlands Meteorological Institute (KNMI) [data set], https://doi.org/10.21944/temis-ozone-msr2, 2015b.

Vattioni, S., Weisenstein, D., Keith, D., Feinberg, A., Peter, T., and Stenke, A.: Exploring accumulation-mode $\mathrm{H}_{2} \mathrm{SO}_{4}$ versus $\mathrm{SO}_{2}$ stratospheric sulfate geoengineering in a sectional aerosolchemistry-climate model, Atmos. Chem. Phys., 19, 4877-4897, https://doi.org/10.5194/acp-19-4877-2019, 2019. 
Vehkamäki, H., Kulmala, M., Napari, I., Lehtinen, K. E. J., Timmreck, C., Noppel, M., and Laaksonen, A.: An improved parameterization for sulfuric acid-water nucleation rates for tropospheric and stratospheric conditions, J. Geophys. Res., 107, 4622, https://doi.org/10.1029/2002JD002184, 2002.

Velders, G. J. M., Andersen, S. O., Daniel, J. S., Fahey, D. W., and McFarland, M.: The importance of the Montreal Protocol in protecting climate, P. Natl. Acad. Sci. USA, 104, 4814-4819, https://doi.org/10.1073/pnas.0610328104, 2007.

Voigt, C., Schlager, H., Ziereis, H., Kärcher, B., Luo, B. P., Schiller, C., Krämer, M., Popp, P. J., Irie, H., and Kondo, Y.: Nitric acid in cirrus clouds, Geophys. Res. Lett., 33, L05803, https://doi.org/10.1029/2005GL025159, 2006.

Weisenstein, D. K., Yue, G. K., Ko, M. K. W., Sze, N.-D., Rodriguez, J. M., and Scott, C. J.: A two-dimensional model of sulfur species and aerosols, J. Geophys. Res., 102, 13019-13035, https://doi.org/10.1029/97JD00901, 1997.
Wesely, M. L.: Parameterization of surface resistances to gaseous dry deposition in regional-scale numerical models, Atmos. Environ., 23, 1293-1304, https://doi.org/10.1016/00046981(89)90153-4, 1989.

Witze A.: Rare ozone hole opens over Arctic - it's big, Nature, 580, 18-19, https://doi.org/10.1038/d41586-020-00904-w, 2020.

Walcek, C. J.: Minor flux adjustment near mixing ratio extremes for simplified yet highly accurate monotonic calculation of tracer advection, J. Geophys. Res., 105, 9335-9348, https://doi.org/10.1029/1999JD901142, 2000.

Wolff, J.-O., Maier-Reimer, E., and Legutke, S.: The Hamburg Ocean Primitive Equation Model. World Data Center for Climate (WDCC) at DKRZ, https://doi.org/10.2312/WDCC/DKRZ_Report_No13, 1997. 